

\section{Public JOURNAL OF Transportation}

Volume 4, No. 1, 2001

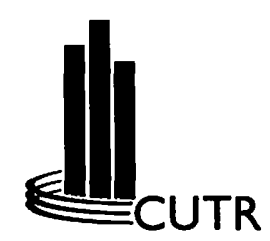

(C) 2001 Center for Urban Transportation Research

National Center for Transit Research Center for Urban Transportation Research

College of Engineering - University of South Florida 4202 E. Fowler Avenue, CUT 100, Tampa, FL 33620-5375

(813) $974-3120$ - Fax (813) 974-5168

E-mail: pball@cutr.eng.usf.edu

Web Site: http://www.cutr.eng.usf.edu 


\section{Public \\ JOURNAL OF \\ Transportation}

Volume 4, No. 1, 2001

\section{Contents}

Bus Transit Operations Control: Review and an Experiment

Involving Tri-Met's Automated Bus Dispatching System

James G. Strathman, Thomas J. Kimpel, Kenneth J. Dueker,

Richard L. Gerhart, Kenneth Turner; David Griffin, and Steve Callas

Transit Quality as an Integrated Traffic Management Strategy:

Measuring Perceived Service

Matthew G. Karlaftis, John Golias, and Efstratios Papadimitriou

The Modernization of Routes and New Railway Lines:

Different Viewpoints and Instruments for Commercial Objective

Andrés López-Pita and Francesc Robusté

A Rural Transit Vehicle Management System

and Condition Predictor Model

Michael D. Anderson and Adam B. Sandlin

Decision Structuring and Robustness Analysis

in Selecting Urban Transit Alternatives

Isam A. Kaysi and Mohamed-Asem U. Abdul-Malak

Our troubled planet can no longer afford the luxury of pursuits confined to an ivory tower: Scholarship has to prove its worth, not on its own terms, but by service to the nation and the world.

-Oscar Handlin 


\title{
Bus Transit Operations Control: Review and an Experiment Involving Tri-Met's Automated Bus Dispatching System
}

James G. Strathman, Thomas J. Kimpel, and Kenneth J. Dueker

Center for Urban Studies, Portland State University

Richard L. Gerhart, Kenneth Turner, David Griffin, and Steve Callas Tri-Met, Portland, Oregon

\begin{abstract}
$\overline{\text { Abstract }}$
Tri-Met has implemented an automated bus dispatching system (BDS) employing satellite-based automatic vehicle location (AVL) technology. The BDS is capable of facilitating real-time operations control actions to improve service regularity. This article focuses on a service regularity problem that often occurs during peak periods when regular service is augmented by extra-board trips ("trippers"). In this case, "bus bunching" results when regular service trips experience departure delays while trippers depart on schedule. With the aid of BDS information, field supervisors stationed at a key location on Portland's (Oregon) bus mall used holding, short turning, and reassignment actions to maintain headways on six selected routes. Analysis of their efforts reveals an improvement in service regularity as well as a leveling of passenger loads.
\end{abstract}

\section{Introduction}

An operations plan contains information on the provision of transit service, including intended service levels, vehicle availability, and driver schedules. Agency resources would be utilized efficiently if the operations plan could 
be executed without disruptions in service. When service disruptions occur, the aim of operations control is to optimize system performance given the current state of the system (Wilson et al. 1992). This typically involves actions intended to either return service to schedule or restore headways separating vehicles. Disruptions in service impose costs on transit providers in the form of reduced productivity and on passengers in the form of increased in-vehicle travel time, longer waiting time at stops, and greater uncertainty.

This article has two overall purposes. First, it provides a review of operations control principles and practices reported in the literature. Second, it reports the results of an operations control experiment whose objective was to maintain headways, or the time separation between buses on a route. The experiment was developed to explore a possible application of the automated BDS recently implemented by Tri-Met, the transit provider for the Portland metropolitan region. The main components of Tri-Met's BDS are:

- AVL based on Global Positioning System (GPS) technology, supplemented by dead-reckoning sensors;

- voice and data communication within a preexisting mobile radio system;

- onboard computer and a control head displaying schedule adherence to operators, detection and reporting of schedule and route deviations to dispatchers, and two-way, preprogrammed messaging between operators and dispatchers;

- automatic passenger counter (APC) technology; and

- computer-aided dispatch (CAD) center.

The BDS recovers very detailed operating information in real time, and thus enables the use of a variety of control actions that would potentially yield substantial improvements in service reliability. The growing deployment of BDS technology in the transit industry is timely, given that worsening traffic congestion in most urban areas has made schedule adherence increasingly difficult.

\section{Operations Control Research}

To understand how operations control can be effective in reducing variability in system performance, it is first necessary to discuss the causes of unreliable 
service. Woodhull (1987) classifies the causes of unreliable service according to whether they are internal (endogenous) or external (exogenous) to the system. Exogenous causes include such factors as traffic congestion and incidents, traffic signalization, and interference with on-street parking. Endogenous causes include such factors as driver behavior, improper scheduling, route configuration, variable passenger demand, and interbus effects. Turnquist and Blume (1980) make a distinction between service planning and real-time control strategies. Service planning strategies can address problems of a persistent nature through route restructuring and schedule modification. This is in contrast to realtime control strategies, which focus on immediate responses to sporadic service problems. Abkowitz (1978) suggests that there are three basic categories of methods to improve transit service reliability: priority, control, and operational. Priority methods involve the special treatment of transit vehicles apart from general vehicular traffic. Examples of this type of strategy are exclusive bus lanes and traffic signal prioritization. Operational methods take place over a longer period of time and include such strategies as schedule modification, route restructuring, and driver training. Control methods take place in real time and include vehicle holding, short turning, stop skipping, and speed modification.

It is important to distinguish between low- and high-frequency service when discussing operations control strategies. For routes characterized by long headways, schedule adherence is the most important operations objective. Passengers will attempt to time their arrivals with that of the bus based on a given probability of missing the departure (Turnquist 1978; Bowman and Turnquist 1981). In these circumstances, average wait times are less than onehalf of the scheduled headway. Schedule adherence is also an important objective at timed transfer locations. Alternatively, for routes that operate at headways of 10 minutes or less, headway maintenance is the most important operations objective. This is because passengers do not find it advantageous to time their arrivals with that of the schedule, and are thus assumed to arrive at stops randomly. The aggregate wait time of passengers is minimized when buses are evenly spaced on routes operating at high frequencies.

\section{First-Generation Operations Control Research}

Early research on operations control involved the design and evaluation of vehicle holding strategies. Most of the studies relied on either analytical or 
simulation techniques in the absence of data on actual transit operations. A common thread in many of these early studies is that the models were based on rather restrictive assumptions.

Osuna and Newell (1972) developed a model to determine the amount of time needed to hold a bus in order to improve service regularity. A hypothetical route was analyzed consisting of one stop and either one or two vehicles. The objective of the model was to minimize the average wait time of passengers. The authors concluded that control should be implemented following service deterioration rather than in anticipation of a potential problem, and that control should be applied sparingly to prevent service deterioration beyond a tolerable limit.

Barnett and Kleitman (1973) developed a model building on the research of Osuna and Newell. Their analysis involved a hypothetical bus route with one vehicle and several stops. Vehicle holding was allowed at one of two possible control points. The study sought to devise a holding strategy that would minimize the average wait times of passengers. The authors concluded that holding was most effective when trips returned unusually early, and that the location of the control point proved crucial.

Barnett (1974) later developed a more detailed model that analyzed a hypothetical multistop route with one control point. The objective of the model was to determine the optimal interval at which vehicles should be dispatched from a control point. The problem attempted to minimize aggregate passenger wait time relative to holding costs imposed on passengers already on board the vehicle. The optimal strategy was dependent on the mean and variance of the headway distribution, the ratio of passengers on board the bus at the control point to those waiting downstream, and the correlation between successive vehicle arrival times at the control point.

Bly and Jackson (1974) designed a simulation model that looked at the effects of holding buses at a control point until a threshold headway was reached. Under a threshold-based holding strategy, an early bus is held until the preceding headway reaches a prescribed value. The results of the study showed that holding resulted in reduced passenger wait times at the expense of longer running times.

Koffman (1978) developed a simulation model analyzing four different control strategies (holding, stop skipping, priority signalization, and reducing dis- 
patching uncertainty) for a simplified bus route. The model is noteworthy because it took into account traffic signalization, different boarding and alighting rates, acceleration/deceleration delay, and variable passenger demand. Similar to the finding by Bly and Jackson, Koffman concluded that holding produced very small improvements in wait times at the expense of longer passenger travel times.

Turnquist and Blume (1980) developed a set of equations seeking to determine upper and lower bounds on the expected benefits of threshold-based holding. They showed that the optimal control point along a route is located where relatively few passengers are on board the vehicle and many are waiting at subsequent stops. The authors point out that control should be implemented as early along the route as possible because headway variability tends to increase with running time. An important result of the study was that the authors discovered cases where headway control was unlikely to produce benefits and could actually prove detrimental to transit operations.

The general contribution of the first generation of operations control studies can be summarized as follows:

- Holding imposes costs on passengers already on board vehicles in the form of increased travel time.

- Holding imposes costs on transit providers in the form of increased running time.

- The selection of an appropriate control point is crucial for minimizing aggregate wait times.

- Headway control is most effective when passenger loads at the control point are light and demand immediately following the control point is heavy.

- Holding is most effective at reducing wait times at stops immediately following the control point.

- Headway variability begins to increase again following control.

- Holding may prove detrimental to transit operations in some situations.

\section{Second-Generation Operations Control Research}

The primary distinction between first- and second-generation operations control studies is that the latter are empirically validated with data on actual 
transit operations. Turnquist and Bowman (1980) developed a model using data from a bus route in Evanston, Illinois, to address schedule-based holding. Under schedule-based holding, early vehicles are held to their scheduled departure time. The authors found that schedule-based holding was an appropriate control strategy for routes characterized by large headways. A study by Abkowitz and Engelstein (1984) analyzed headway-based holding strategies in detail. The study employed a simulation using data from Cincinnati, Ohio, with the results later validated with data from Los Angeles, California. An algorithm was developed to identify the locations where the greatest reductions in passenger wait times would occur for specific threshold headways. The authors found that the optimal control point is sensitive to the ratio of passengers on board the bus to those waiting downstream, and that the main benefits of control are realized by passengers immediately downstream from the control point. A later study by Abkowitz, Eiger, and Engelstein (1986) found that headway variation does not increase linearly along a route, but instead increases sharply at low values of running time variation, then tapers off once bunching occurs.

Both schedule- and headway-based holdings were analyzed by Turnquist (1982) in a report focusing on strategies to improve transit service reliability. The study was based on a simulation later validated with data from Evanston, Illinois, and Cincinnati, Ohio. The author analyzed two types of headway control strategies: single headway and prefol. The single-headway strategy requires information about the current headway only and consists of holding a vehicle until the scheduled headway is reached. The prefol strategy consists of holding a vehicle until the preceding headway is as close as possible to the following headway. The prefol strategy requires more information than the single-headway strategy in that prediction of the arrival time of the following vehicle is necessary. Turnquist found that the single-headway strategy does not perform as well as the prefol strategy when vehicle arrivals are largely independent from one another. As headways become more correlated, the effectiveness of the single-headway strategy begins to approach that of the prefol strategy.

According to Turnquist (1982), the headway control strategy that would maximize wait-time savings would require that all headways be known in advance. Both the single-headway and prefol strategies are near-optimal solutions in that they neglect to consider the effects of holding on other vehicles 
serving the route. Turnquist found that the various holding strategies are sensitive to three characteristics of the control point:

1) the current level of unreliability,

2) the amount of correlation between successive headways, and

3) knowledge of the percentage of passengers on board the bus at the control point relative to those downstream.

A study analyzing the benefits of operations control was undertaken for the MBTA Green Line in Boston, Massachusetts, by Wilson et al. (1992). Their study considered four types of control actions: holding, short turning, expressing, and deadheading. The major operational problem on the Green Line consisted of headway variation. Field supervisors implemented control actions based on direct observation, communication, and intuition. The authors found that some control actions actually increased aggregate passenger wait times, while others were not implemented when justified. The reason for such a wide variation in the effectiveness of operations control was attributed to the lack of timely information available to field supervisors (Wilson et al. 1992). One of the more interesting aspects of the research was that the authors developed a set of location- and condition-specific decision rules for control actions.

The study by Wilson et al. (1992) addressed several types of control actions that have not been extensively addressed in the literature. For example, stop skipping is a strategy that involves skipping one or more stops as a vehicle moves along a segment. Stop skipping serves to reduce running time on the vehicle of interest while shortening its headway. In essence, this represents a transformation from regular to limited service in real time. The benefits of stop skipping are reduced running time on the vehicle of interest, shorter travel times for passengers already on board the vehicle, and lower wait times for downstream passengers. These benefits are at the expense of increased wait time for persons at stops that have been passed by and passengers who are forced to alight early and take the next vehicle. The ideal scenario for stop skipping is to have a long preceding headway, a short following headway, and high passenger demand beyond the segment where skipping is implemented (e.g., on the vehicle's subsequent trip). Only two studies have analyzed stop 
skipping in detail, with one viewing it as a reasonable control action and the other recommending that it be avoided completely because of adverse effects on certain passengers (Wilson et al. 1992; Lin et al. 1995). A less disruptive variant of stop skipping that avoids forcing passengers to alight early is to limit stops to dropoffs of onboard passengers.

Short turning involves turning a vehicle around before it reaches the route terminus, with the goal of reducing headway variance in the opposite direction by filling in a large gap in service. The ideal scenario for short turning is to select a bus with a light passenger load, low preceding headway, low following headway, and high headway further up the route (i.e., the large gap). Similar to stop skipping, short turning adversely affects passengers on board the vehicle who are forced to alight and transfer to the subsequent bus. Short turning primarily benefits passengers traveling in the opposite direction because of reduced headway variation. Deadheading is similar to expressing except that no passengers remain on board the vehicle. The ideal scenario is to deadhead a vehicle where there is a long preceding headway and a short following headway. One of the drawbacks to deadheading is that all passengers are forced to alight at the control point, including some passengers who would have benefited from an expressed trip. The practices of stop skipping, deadheading, and short turning are not viewed as desirable control actions by many transit agencies because they force passengers to transfer to other vehicles, and they also degrade service for persons who are passed up.

Abkowitz and Lepofsky (1988) analyzed headway-based reliability control on two bus routes in Boston, Massachusetts. Control was exercised on both routes during the A.M. period in the inbound direction and on one route during the P.M. period in the outbound direction. Of the three experiments, only one was found to significantly reduce headway variance and run-time variability. This proved to be a radial through route that intersected downtown. The study was hampered by manual data collection problems and the failure of field supervisors to adhere to holding instructions consistently. For the two experiments where control proved to be ineffective, it was discovered that field supervisors were only holding a portion of the buses when action was justified (Abkowitz and Lepofsky 1988). This again highlights the fact that human factors can reduce the effectiveness of headway control strategies if they are not 
implemented properly. Although the results of this study were mixed, it sets the stage for evaluating context-specific control experiments based on the use of actual operations data.

Signal priority is a mechanism for reducing delays to transit vehicles at signalized intersections. A number of researchers have found that signalized intersections are an important contributor to unreliable service (Welding 1957; Abkowitz and Engelstein 1983). Signal priority typically involves changing the phase of a signal to green or extending the duration of the green phase when a bus approaches an intersection. While it is not the intent of this article to discuss signal control strategies in detail, it is important to recognize that this strategy is finding favor within the transit community. In contrast to holding, which always causes delay to some passengers and also results in increased running time, signal prioritization reduces running times and decreases delay for all passengers (Khasnabis et al. 1999). However, signal prioritization also imposes additional costs on general motor vehicle traffic, and it may also adversely affect operations on intersecting bus routes. An optimal signal timing control system would incorporate real-time information on transit operations and general traffic conditions, and would be able to respond to changing operating conditions while minimizing disruptions to traffic flow (Lin et al. 1995).

The relevance of the second-generation studies of operations control can be summarized as follows:

- Holding is likely to be more effective at earlier points along a route.

- Human factors play an important role in the success or failure of operations control practices.

- Decision rules should be developed to assist field supervisors in making choices as to whether to implement control.

- Control actions should be analyzed using data from actual transit operations.

- Short turning, stop skipping, and deadheading are second-best solutions because passengers are forced to transfer to other vehicles.

- Signal prioritization does not impose adverse costs on passengers or transit operators, but does impose costs on general motor vehicle traffic and may impose costs on intersecting bus routes. 


\section{The Next Generation of Operations Control Research}

Two areas that need further study are the evaluation of passenger waiting time and the incorporation of vehicle seating capacity in operations control models. Previous studies have assumed that the utility function for wait time is linear, implying, for example, that the disutility of one five-minute delay is equivalent to five one-minute delays. Additionally, in-vehicle and out-of-vehicle times have often been treated equally in evaluating the benefits of control. Research has shown that travelers value time spent waiting at stops much higher than time spent in motion (Kemp 1973; Lago and Mayworm 1981; Mohring et al. 1987). Incorporating different weights for wait and in-vehicle times will likely influence the identification of the optimal control point location.

Another important aspect of headway-based reliability control concerns seating availability. Abkowitz and Tozzi (1987) found this to be an important omission in previous studies because limited seating availability results in passups whereby passengers are forced to wait for a subsequent bus. The main issue is that passenger benefits may be incorrectly determined, resulting in incorrect control actions being applied. The MBTA study by Wilson et al. (1992) is the only known analysis to take seating capacity constraints into account.

APC technology has not been fully exploited for operations control. This is because APC systems in North America do not produce reliable passenger counts in real time (Levinson 1991). APC data are typically subject to a considerable amount of postprocessing before they are considered reliable for service planning and scheduling. The ability to generate accurate passenger load information in real time would provide decision-makers with one of the key parameters needed for estimating the potential benefits of control. To develop estimates of the number of passengers waiting at downstream locations, archived APC and operations data can be used to construct boarding and alighting profiles at specific stops for specific trips.

Pilot projects are under way in Chicago and Paris for AVL systems that generate real-time information on vehicle headways. A display connected to an onboard computer shows drivers the amount of headway delay from the preceding bus. This system allows drivers to make small changes in driving behavior to keep bunches from forming or becoming progressively worse. This is an example of a preemptive strategy; it does not wait for system instability to set in before control decisions have to be made. This idea is consistent with 
Welding (1957), who argues for the need to identify the onset of irregularity and the need to restore service to normal as soon as possible, and also with Turnquist (1982), who argues that one of the purposes of operations control is to keep bunches from forming in the first place.

Schedule adherence, rather than headway regularity, is the dominant operational objective on high-frequency transit routes. This is somewhat perplexing given that average wait times would be minimized if headway regularity were maintained. Both Welding (1957) and Hundenski (1997) note that, in principle, schedules are largely irrelevant for routes that operate at high frequencies. At San Francisco MUNI, schedules on certain routes were disregarded in favor of a policy of headway maintenance. This approach was originally supported by both operators and patrons, but was later discarded because subsequent checks revealed that headways were not being maintained and that bunching still posed a problem. Hundenski (1997) claims that these two problems stem from MUNI's high level of missed service rather than flaws in the basic concept. This idea will likely surface again in the future as advancements in real-time technologies make headway maintenance more feasible. One of the main arguments against headway maintenance policies is that timed transfers must be met. While it is probable that schedule adherence, as opposed to headway maintenance, would minimize wait time for passengers at timed transfer points, this has never been empirically tested on routes operating at high frequencies. For uncoordinated transfers, it is likely that the average wait time of transferring passengers would be reduced if buses were evenly spaced. Additional research is needed to determine which policy would be more appropriate for minimizing passenger wait times at transfer locations under different service frequencies.

The immediate future of operations control practices can be summarized as follows:

- Incorporating distinct values of wait and in-vehicle times will produce more realistic evaluations of the costs and benefits of operations control actions.

- Vehicle capacity constraints need to be included in models to fully capture passenger wait-time costs.

- Real-time APC technology will provide valuable information to decision-makers on the number of onboard passengers likely to be adversely affected by holding. 
- Archived APC and operations data can be used to construct boarding and alighting profiles at various locations to estimate the number of persons likely to be waiting at downstream locations.

- Providing drivers with real-time headway information will allow for a passive form of headway maintenance. Real-time vehicle headway information will also prove useful to decision-makers in deciding whether control is justified.

- For high-frequency routes, it may prove beneficial to disregard schedule adherence policies in favor of headway maintenance.

- Additional research should be undertaken to determine whether schedule adherence or headway maintenance results in less wait time for passengers at transfer points on high-frequency routes.

\section{Operations Control at Tri-Met}

Following the recent implementation of its BDS, operators at Tri-Met are now aware of schedule deviations from the "minutes-late" display on their vehicle control head. When possible, drivers modify vehicle speeds to better adhere to schedule. Another form of control that is emerging in the wake of the new system is the practice by some field supervisors of requesting recent BDS data to identify schedule deviation patterns, or "trouble spots." Finally, although dispatchers have not taken on regular responsibility for operations control, the preprogrammed messaging feature of the new system has been heavily utilized. Both operators and dispatchers have become better informed about operating problems in real time, and this has most likely improved both dispatching and operating performances. Collectively, these changes following the implementation of the BDS have contributed to improvements in on-time performance and reductions in passenger travel time and bus running time (Strathman et al. 2000).

\section{Headway Control: An Experiment}

Despite the initial improvements in reliability, delay problems continue to threaten Tri-Met's service quality. These problems are most pronounced for outbound trips in the afternoon peak period, when service frequencies are increased by the addition of extra service buses (known as "trippers"). Aside from the normal challenges of maintaining service in a high-frequency, heavy- 
traffic environment, the coordination of trippers with regular service buses is complicated by traffic problems that trippers encounter in traveling to their staging points, which are compounded by the disruptions that regular service buses experience on their prior inbound trips. In combination, these problems frequently result in bus bunching on outbound trips, which negates effective utilization of the added capacity.

There are several possible solutions to the bus-bunching problem. The first would be to rewrite schedules to expand layover times for regular service buses and to add staging time for trippers, which would make schedule maintenance more feasible. No control action would be required with this approach. But unless delay problems are recurrent, these adjustments will shift resources from revenue to nonrevenue service and will not be cost effective. Schedule writers tend to be responsive to passenger and operator complaints about delays, and thus, in the absence of active operations control, schedule adjustments can be considered a default solution.

Alternatively, headways can be maintained by holding buses at the departure point. This would not bring service back to schedule, but in short-headway situations passengers tend to arrive at stops randomly and the main objective should be to keep service evenly distributed to respond to that passenger flow. Thus, holding buses to maintain headways is the focus of the experiment described below.

There are two additional features that guided the design of the holding experiment. First, Tri-Met coordinates its downtown service along directional, access-limited transit malls. Thus, a number of routes share the same departure point and traverse the malls. A single, dedicated field supervisor is capable of controlling departures for multiple routes. Second, with the BDS, a dispatcher can identify delays on inbound trips and communicate this information to the field supervisor. Communicating these delays allows the supervisor to employ Turnquist's (1982) prefol strategy, or holding given buses to the midpoint of the time separating their leader and follower. As a final consideration, given the expectation by the dispatcher that a tripper or regular service bus will be delayed by more than the scheduled headway, the supervisor can be alerted to send the other in its place. Consideration of this "switching" action had to be factored into the design of the experiment because some consecutive trips terminate at different locations (e.g., due to short-lining or routing permutations). 
A list of the routes and scheduled trips involved in the headway experiment is given in Table 1. Nineteen regular service blocks and 11 trippers (identified in bold type) were selected for study. One consideration in the selection of the trippers was that they are deadheaded (i.e., not in revenue service) to the route origin and could thus be more easily staged at the downtown departure location.

One dispatcher and one field supervisor were responsible for making and implementing the control actions. These individuals remained in radio contact. In instances where it was determined that the bus following the tripper was running less than one headway late, the supervisor instructed the tripper operator to maintain a headway that was half the combined headway linking the lead and trailing bus. For example, if this difference was 20 minutes and the tripper's scheduled headway was 8 minutes, the supervisor would instruct the tripper operator to try to maintain a 2-minute delay on his or her vehicle control head.

Load checkers were also stationed at the maximum load points to recover passenger counts. This was done because the subject buses were not all APC equipped, and there was some concern about the accuracy of the passenger counts recorded by the equipment. The reliance on manual load checking did affect the time frame of the study. Given that the BDS recovers actual headway and other operating data automatically, the baseline against which the effects of the control experiment can be compared already exists. With loads being counted manually, however, the baseline period was defined by the amount of time the load checkers were deployed prior to the implementation of the control strategy. This period covered 10 weekdays, extending from October 18 to 29,1999 . This was followed by a "treatment" period that covered 18 weekdays, extending from November 1 to 24, 1999.

\section{Statistical Analysis}

From a statistical standpoint, improvements in headway maintenance are represented by reductions in headway variance. A reduction in load variation would also be expected to correspond to a reduction in headway variability. As can be seen in Table 1, the scheduled headways of the trips involved in the experiment vary both within and between routes. It is, thus, necessary to standardize the headway measure to establish a consistent basis for comparison. This is done by forming the ratio of observed to scheduled headway, as follows: 


\begin{tabular}{|c|c|c|}
\hline \multicolumn{3}{|c|}{$\begin{array}{c}\text { Table } 1 \\
\text { Routes and Scheduled Trips SElected for } \\
\text { Headway Control }\end{array}$} \\
\hline Route-Block No. & $\begin{array}{c}\text { Scheduled } \\
\text { Departure Time }\end{array}$ & $\begin{array}{l}\text { Scheduled } \\
\text { Headway } \\
\text { (minutes) }\end{array}$ \\
\hline \multicolumn{3}{|l|}{12 Sandy Blvd. } \\
\hline 1276 & $4: 07$ & - \\
\hline 1288 & $4: 10$ & $3: 00$ \\
\hline 1285 & $4: 20$ & $10: 00$ \\
\hline 1275 & $4: 22$ & - \\
\hline 1286 & $4: 30$ & $8: 00$ \\
\hline 1277 & $4: 37$ & $7: 00$ \\
\hline 1283 & $4: 40$ & $3: 00$ \\
\hline 1294 & $4: 50$ & $10: 00$ \\
\hline \multicolumn{3}{|l|}{14 Hawthorne } \\
\hline 1409 & $4: 57$ & - \\
\hline 1417 & $5: 02$ & $5: 00$ \\
\hline 1418 & $5: 03$ & 1:00 \\
\hline 1407 & 5:08 & $5: 00$ \\
\hline \multicolumn{3}{|l|}{96 Tualatin 15} \\
\hline 9677 & $3: 50$ & - \\
\hline 9673 & $4: 00$ & $10: 00$ \\
\hline 9679 & $4: 08$ & $8: 00$ \\
\hline 9669 & $4: 30$ & - \\
\hline 9675 & $4: 35$ & $5: 00$ \\
\hline 9676 & $4: 45$ & $10: 00$ \\
\hline 9668 & $4: 55$ & - \\
\hline 9680 & $5: 00$ & $5: 00$ \\
\hline 9671 & $5: 05$ & $5: 00$ \\
\hline \multicolumn{3}{|l|}{4 Division } \\
\hline 438 & $4: 43$ & - \\
\hline 459 & $4: 50$ & $7: 00$ \\
\hline 436 & $4: 57$ & $7: 00$ \\
\hline \multicolumn{3}{|l|}{9 Powell } \\
\hline 935 & $5: 01$ & - \\
\hline 952 & 5:07 & $6: 00$ \\
\hline 946 & $5: 15$ & $8: 00$ \\
\hline \multicolumn{3}{|l|}{10 Harold } \\
\hline 1035 & $4: 55$ & - \\
\hline 1046 & $5: 02$ & $7: 00$ \\
\hline 1045 & $5: 10$ & $8: 00$ \\
\hline
\end{tabular}

Note: "Trippers" are identified in bold type. 


\section{Headway Ratio $=[($ Observed Headway/Scheduled Headway $) * 100]$}

A similar ratio could be constructed for passenger loads, but it is not needed because bus seating capacity does not vary.

Wonnacott and Wonnacott (1972, pp. 180-182) explain the test for determining the significance of a change in variance using a $\mathrm{C}^{2}$ statistic, which is a modified chi-square. Critical values from the distribution of this statistic are used to construct confidence intervals around the baseline and treatment sample variances to determine whether they can be significantly distinguished from each other. For example, the 95 percent confidence interval at 120 degrees of freedom is defined as:

$$
\operatorname{Pr}\left(\mathrm{s}^{2} / 1.27<\sigma^{2}<\mathrm{s}^{2} / .763\right)=95 \%,
$$

where:

$\mathrm{s}^{2}$ is the sample variance, and $\sigma^{2}$ is the underlying population variance.

The BDS recovers headway data over the entire route. Thus, it is possible to assess the consequences of headway control actions at the point where the actions are taken and at subsequent points on the route. This implies significance tests for three locational configurations:

1) at the control point, in which the test would determine whether service regularity improved at the location where the control actions occurred;

2) progressively, at time points extending from the control point, in which case one could determine how far an initial improvement (assuming that such an improvement occurred) was sustained along the route; and

3) over all time points, whereby one could determine whether an overall improvement in service regularity was discernable.

\section{Results}

A summary of the control actions taken is provided in Table 2. Six actions were taken on regular service buses: 3 holds, 1 swap, and 2 short turns. For trippers, there were 16 actions taken: 7 holds and 9 swaps. There were no opportunities for short-turning tripper buses, given that they were deadheaded to the departure point. Control actions were taken on 12 of the 18 days during 
which the experiment was conducted and were imposed relatively more frequently for trippers $(9.6 \%$ of recorded trips) than for regular service buses (3.2\% of recorded trips). Overall, the decisions by the dispatcher and field supervisor to implement controls can be characterized as conservative. This is not undesirable, given the finding by Wilson et al. (1992) of instances where control decisions were actually found to be counterproductive.

The impact of the control actions on headway ratio variances is reported in Table 3 for all time points on the affected routes as well as for the control point at which the actions were taken. Compared to their baseline values, headway ratio variances declined 3.8 percent overall and 15.8 percent at the control point. Two items related to this outcome are noteworthy:

1) The improvement in headway regularity was substantially greater at the location of the control action.

2) Headway regularity generally tends to be better in the initial stages of trips.

The change in headway variance was evaluated with the $\mathrm{C}^{2}$ statistic. Neither of the reductions reported in Table 3 were found to be statistically significant at the .05 level.

\section{Table 2}

\section{Control Actions Taken}

\begin{tabular}{l|c|c} 
Action & $\begin{array}{c}\text { Regular Service } \\
\text { Buses }\end{array}$ & Tripper Buses \\
\hline Holds & 3 & 7 \\
\hline Swaps & 1 & 9 \\
\hline Short turns & 2 & 0 \\
\hline Total & 6 & 16
\end{tabular}




\section{Table 3}

Baseline and Control Period Headway Ratio Variances

\begin{tabular}{l|c|c|l} 
Reference Point(s) & Baseline & Control Period & Change \\
\hline All time points & $\begin{array}{c}0.559 \\
(1,037)\end{array}$ & $\begin{array}{c}0.538 \\
1,756)\end{array}$ & $-3.8 \%$ \\
\hline Control point & $\begin{array}{c}0.234 \\
(209)\end{array}$ & $\begin{array}{c}.197 \\
(356)\end{array}$ & $-15.8 \%$ \\
& & &
\end{tabular}

Note: Sample sizes are reported in parentheses.

The pattern of headway ratio variances for the baseline and control periods was also evaluated over the sequence of time points comprising the routes studied. These patterns are shown in Figure 1. Overall, the figure shows a pattern of increasing variance over the routes' time points in both the baseline and control periods, which is consistent with what has been observed in earlier studies (e.g., Abkowitz and Tozzi 1987). Also, the figure indicates that the effect of the control actions (taken at Time point 1 ) in reducing headway ratio variation is concentrated over the first three time points. The differences in headway ratio variance were tested by the time point using the $\mathrm{C}^{2}$ statistic, and none was found to be significant at the .05 level.

Passenger loads were also evaluated to determine if their variation declined in correspondence with the improvement in headway regularity. Analysis of passenger loads was complicated by a number of missed assignments by load checkers. Fortunately, an effort was made to assign buses equipped with APCs to the study routes during the control period, which provides a second source of passenger load data. However, it may not be appropriate to simply combine the load counts of APCs and manual checkers, given possible differences in the way the two methods measure the same phenomenon. Wonnacott and Wonnacott (1970) provide a means of testing for the relative effects of measurement error in such cases. They suggest a regression of each variable on the other. If measurement error is present in either variable, it will have the effect of biasing its parameter estimate downward when it is specified as the independent variable. 


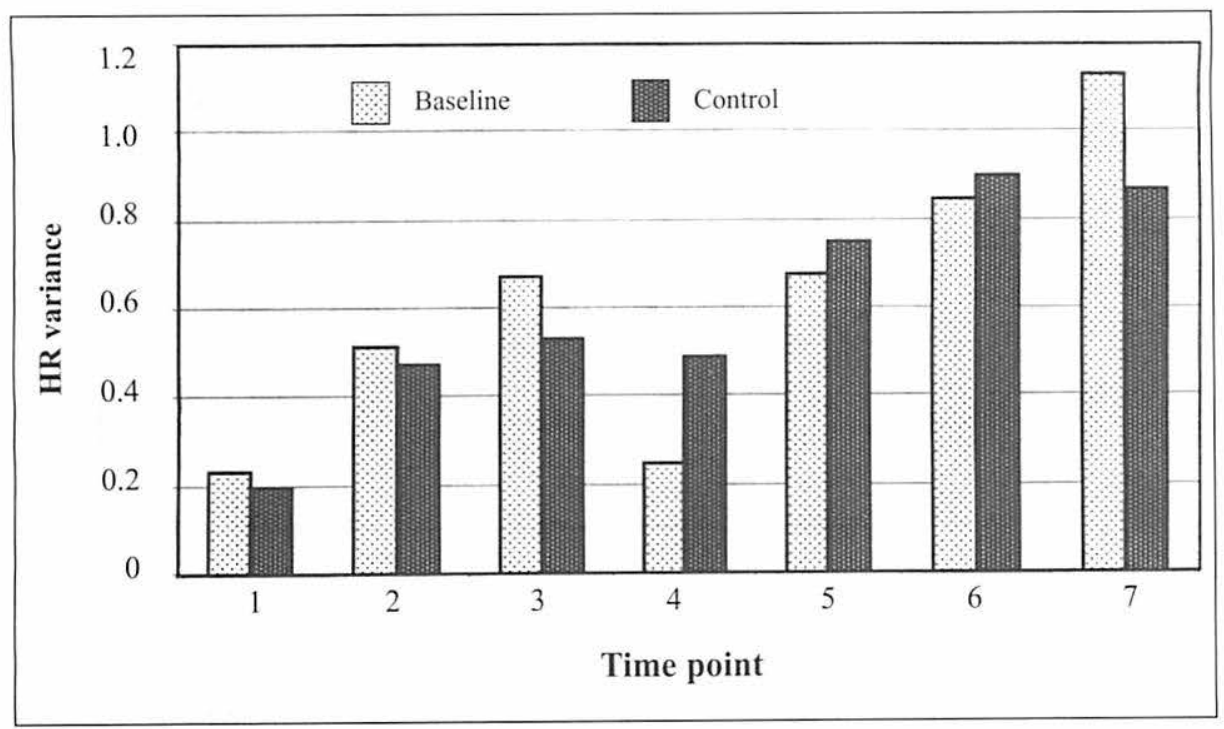

Figure 1. Baseline and control period headway ratio variances by time point

These regressions were performed for the sample of 212 baseline and control period trips for which passenger loads were recorded by both APCs and load checkers. The results of these regressions are reported in Table 4. In the manual-count regression, the APC passenger count serves as the independent variable. A 95 percent confidence interval is constructed around its parameter estimate of 0.932 , and the result ranges from 0.85 to 1.01 . We conclude that this parameter estimate is not significantly different from 1 and that manual counts can be estimated APC counts. Alternatively, in the APC count regression, manual counts serve as the independent variable, with an associated parameter estimate of 0.779 . The 95 percent confidence interval around this estimate ranges from 0.71 to 0.84 . Thus, the parameter estimate is both significantly less than 1 and it also falls below the range for the APC parameter estimate. Two conclusions can be drawn from these results:

1) Passenger load counts from the two sources should not be combined.

2) The manual count data are subject to a relatively greater level of measurement error than the APC count data. 


\begin{tabular}{|c|c|c|}
\hline \multicolumn{3}{|c|}{$\begin{array}{l}\text { Table } 4 \\
\text { Baseline and Control Period Headway Ratio Variances }\end{array}$} \\
\hline & \multicolumn{2}{|c|}{ Dependent Variable } \\
\hline & Manual Count & APC Count \\
\hline Intercept & $\begin{array}{l}4.44 \\
(1.1)\end{array}$ & $\begin{array}{l}3.35 \\
(1.0)\end{array}$ \\
\hline APC count & $\begin{array}{l}.932 \\
(.04)\end{array}$ & - \\
\hline Manual count & - & $\begin{array}{r}.779 \\
(.03)\end{array}$ \\
\hline$\overline{\mathbf{R}^{2}}$ & .73 & .73 \\
\hline$\overline{\text { SEE }}$ & 7.75 & 7.09 \\
\hline $\mathrm{n}$ & 212 & 212 \\
\hline
\end{tabular}

As a result, the following passenger load analysis draws solely on APC data.

From the perspective of transit operations, improving headway maintenance should lead to more balanced passenger loads. This issue is examined for both load variation and average load levels in Table 5. In the baseline period, the average load of regular service buses is 7.1 passengers greater than the average load for trippers, a difference that is significant at the .025 level, based on the student's t-test statistic. During the control period, however, the average load of regular service buses declines by almost 4 passengers, while average tripper loads increase by nearly 1 passenger. As a result, the difference in mean loads shrinks to 2.7 passengers during the control period and is no longer significant. This outcome is consistent with an improvement in the spacing between regular service and tripper buses. 
Turning to load variance, the composite effect of the various control actions contributed to a convergence of passenger load variability of regular service and tripper buses. The control actions, particularly holding, likely contributed to the increase in load variance for tripper buses, which was more than offset by the reduction in passenger load variance among regular service buses. Overall, the improvements in service regularity contributed to a 16 percent reduction in passenger load variance. Although the differences in variances between tripper and

Table 5

Baseline and Control Period Passenger Loads and Variances (sample sizes in parentheses)

\begin{tabular}{l|c|c|c}
\hline & Mean Passenger Loads & Control Period & Change \\
\hline \multirow{3}{*}{ Regular service buses } & 29.0 & 25.4 & $-12.4 \%$ \\
& $(42)$ & $(101)$ & \\
\hline \multirow{3}{*}{ Tripper buses } & 21.9 & 22.7 & $3.7 \%$ \\
& $(39)$ & $(79)$ & \\
\hline \multirow{2}{*}{ Overall } & 25.6 & 24.2 & $-5.5 \%$ \\
& $(81)$ & $(180)$ & \\
\hline
\end{tabular}

Passenger Load Variance

\begin{tabular}{l|c|c|c}
\hline & Baseline & Control Period & Change \\
\hline Regular service buses & 239.3 & 165.9 & $-30.7 \%$ \\
\hline Tripper buses & 135.4 & 167.0 & $23.3 \%$ \\
\hline Overall & 199.5 & 167.3 & $-16.1 \%$ \\
\hline
\end{tabular}


regular service buses and changes between the baseline and control period are substantial, $\mathrm{C}^{2}$ tests indicate that none are statistically significant. This reflects the effects of the relatively small sample size of APC trips.

In summary, the statistical analysis of headways and passenger loads provides mixed evidence of the effects of the control experiment. Headway variation declined, but not significantly, while there was a significant convergence (leveling) of passenger loads. Given that the latter outcome relates to a principal motivation for engaging in operations control, we can conclude that the actions taken produced the desired effect. The analysis also indicates that small improvements in service regularity can potentially generate more substantial improvements in passenger load maintenance.

\section{Conclusions}

Most of the research and field experience to date on operations control has focused on headway-based holding. This reflects the fact that service regularity problems on high-frequency routes affect more passengers, and that corrective actions will have a larger effect on reducing aggregate wait times. Headway control is most effective on high-frequency routes when passenger loads at the control point are light and demand immediately following the control point is heavy. The same holds true for schedule-based holding. As a general rule, control should be implemented as early as possible along the route because delay variation tends to increase as buses proceed further downstream. The main drawback to holding is that it imposes costs on passengers already on board buses.

A large body of useful information presently exists that can be used to design models capable of directing when and where to implement control actions and what the expected savings in wait time would be. The current trend is to implement and evaluate control actions using actual operations data. Assuming that effective control points can be found, decision rules can be developed to aid in decision making. Advances in communications and transportation technologies, such as real-time APC and AVL systems capable of displaying headway deviations, will serve to increase prediction accuracy in the future.

The organization of operations control in the new BDS environment is evolving and somewhat uncertain. In the initial stage of BDS implementation, it was thought that the role of dispatchers might grow to include some opera- 
tions control responsibility. There is not much evidence that this has happened. Dispatchers report that they are paying attention to schedule adherence and bus spacing, but operations control has traditionally been managed in the field. Thus, greater improvements in operations control may occur from extending vehicle location and monitoring technology into the field, thereby improving the quality of information available to supervisors. The experiment reported in this article represents an intermediate step where supervisors are still reliant on dispatchers for real-time information.

Finally, discussions among the participants of the control study reported here also indicate the need and opportunity for automating real-time operations control actions. It was felt that a simple decision support system could effectively deal with vehicle holding decisions. The dispatcher in the control experiment noted that there was insufficient time to deal with some of the problems that developed, and that an automated decision support system would have been able to recognize and resolve such problems more effectively.

\section{References}

Abkowitz, M. D. 1978. Transit service reliability. Cambridge, MA: U.S. DOT Transportation Systems Center and Multisystems, Inc. (NTIS No. UMTA/MA06-0049-78-1).

Abkowitz, M. D., A. Eiger, and I. Engelstein. 1986. Optimal headway variation on transit routes. Journal of Advanced Transportation 20(1): 47-65.

Abkowitz, M. D., and I. Engelstein. 1983. Factors affecting running time on transit routes. Transportation Research 17A(2): 107-113.

Abkowitz, M. D., and I. Engelstein. 1984. Methods for maintaining transit service regularity. Transportation Research Record 961: 1-8.

Abkowitz, M. D., and M. Lepofsky. 1988. Implementing headway-based reliability controls on transit routes. Journal of Transportation Engineering 116(1): 49-63.

Abkowitz, M. D., and J. Tozzi. 1987. Research contributions to managing transit service reliability. Journal of Advanced Transportation 21: 47-65. 
Barnett, A. I. 1974. On controlling randomness in transit operations. Transportation Science 8(2): 101-116.

Barnett, A. I., and D. J. Kleitman. 1973. Optimal scheduling for some simple transportation systems. Transportation Science 7: 85-99.

Bly, P. H., and R. L. Jackson. 1974. Evaluation of bus control strategies by simulation. TRRL Laboratory Report No. 637.

Bowman, L. A., and M. A. Turnquist. 1981. Service frequency, schedule reliability and passenger wait times at transit stops. Transportation Research 15A: 465-471.

Hundenski, R. J. 1997. A matter of time: Cultural values and the "problem" of schedules. Paper presented at the 76th Annual Meeting of the Transportation Research Board, Washington, DC.

Kemp, M. A. 1973. Some evidence of transit demand elasticities. Transportation 2(1): $25-51$.

Khasnabis, S., R. K. Rudraraju, and M. F. Baig. 1999. Economic evaluation of signal preemption projects. Journal of Transportation Engineering 125(2): 160-167.

Koffman, D. 1978. A simulation study of alternative real-time bus headway control strategies. Transportation Research Record 663: 41-46.

Lago, A. M., and P. D. Mayworm. 1981. Transit service elasticities. Journal of Transport Economics and Policy 15(2): 99-119.

Levinson, H. S. 1991. Supervision strategies for improved reliability of bus routes. NCTRP Synthesis of Transit Practice 15. Washington, DC: Transportation Research Board.

Lin, G., P. Liang, P. Schonfeld, and R. Larson. 1995. Adaptive control of transit operations. College Park: University of Maryland. (NTIS No. MD-26-7002).

Mohring, H., J. Schroeter, and P. Wiboonchutikula. 1987. The values of waiting time, travel time, and a seat on the bus. Rand Journal of Economics 18(1): 40-56.

Osuna, E. E., and G. F. Newell. 1972. Control strategies for an idealized public transportation system. Transportation Science 6: 52-72. 
Strathman, J. G., K. J. Dueker, T. Kimpel, R. L. Gerhart, K. Turner, P. Taylor, S. Callas, and D. Griffin. 2000. Service reliability impacts of computer-aided dispatching and automatic vehicle location technology: A Tri-Met case study. Transportation Quarterly 54: 85-102.

Turnquist, M. A. 1978. A model for investigating the effects of service frequency and reliability on bus passenger waiting times. Transportation Research Record 663: 70-73.

Turnquist, M. A. 1982. Strategies for improving bus transit service reliability. Evanston, IL: Northwestern University. (NTIS Report No. DOT/RSPA/DPB-5081-27). U.S. DOT, Research and Special Programs Administration.

Turnquist, M. A., and S. W. Blume. 1980. Evaluating potential effectiveness of headway control strategies for transit systems. Transportation Research Record 746: 25-29.

Turnquist, M. A., and L. A. Bowman. 1980. The effects of network structure on reliability of transit service. Transportation Research 14B: 79-86.

Welding, P. I. 1957. The instability of close interval service. Operational Research Quarterly 8: 133-148.

Wilson, N., R. A. Macchi, R. E. Fellows, and A. A. Deckoff. 1992. Improving service on the MBTA Green Line through better operations control. Transportation Research Record 1361: 10-15.

Wonnacott, T. H., and R. J. Wonnacott. 1970. Econometrics. New York: John Wiley and Sons, Inc.

Wonnacott, T. H., and R. J. Wonnacott. 1972. Introductory statistics for business and economics. New York: John Wiley and Sons, Inc.

Woodhull, J. 1987. Issues in on-time performance of bus systems. Unpublished paper.

Los Angeles, CA: Southern California Rapid Transit District.

\section{About the Authors}

JAMEs STrathman (strathmanj@pdx.edu) is the director of the Center for Urban Studies and a professor of urban studies and planning at Portland State University. His research focuses on transit operations and planning and travel behavior. 
ThOMAS J. KimPel (kimpelt@pdx.edu) is a Ph.D. candidate in urban studies and planning at Portland State University. His interests are in transit operations, performance, and demand analysis.

KenNeth J. Dueker (duekerk@pdx.edu) is the director of the Transportation Studies Center and a professor of urban studies and planning at Portland State University. Over the past 35 years his research has dealt with transportation and land-use issues. He has served as the chair of the Transportation Research Board subcommittee on Geographic Information Systems in Transportation (GIS-T), and was recently recognized as an emeritus member of the Spatial Data and Information Sciences Committee of TRB.

RICHARD L. GERHART (gerhatr@tri-met.org.), P.E., the director of operations planning and analysis at Tri-Met, is currently working on Intelligent Transportation Systems (ITS) applications for improving transit operations productivity. He holds a master of science in transportation engineering from Ohio State University and a bachelor of science in civil engineering from Lehigh University, Bethlehem, Pennsylvania.

KEN TURNER (turnerk@tri-met.org) is senior manager of operations project development at Tri-Met, where he is responsible for the planning and development of ITS projects. His current focus is on developing Advanced Traveler Information Systems to benefit transit riders, and the integration of transit operations with regional ITS projects.

DAVID GRIFFIN (griffind@tri-met.org) has been contracting with Tri-Met as a data analyst since 1998. He holds a bachelor of science in engineering and has worked in community college education and in upper-stage telemetry for Boeing Aerospace.

STEve Callas (callasc@tri-met.org) is the coordinator of service and performance analysis at Tri-Met, in Portland, Oregon, where he is responsible for the agency's performance statistics. He has a masters in urban and regional planning from the University of Iowa. Mr. Callas has worked in the transportation planning field for more than 10 years. 


\section{Transit Quality as an Integrated Traffic Management Strategy: Measuring Perceived Service}

Matthew G. Karlaftis, John Golias, and Efstratios Papadimitriou

\section{Abstract}

Declining ridership, shrinking market share, and increasing operating costs have led many transit systems to adopt quality management strategies. These strategies help transit systems improve and evolve continuously by focusing on the customer (passengers) first. An integral step in adopting quality systems is measuring customer satisfaction. Using questionnaire data from the Athens, Greece, bus and trolley bus systems, this article demonstrates the potential use of structural equation modeling (SEM) for measuring customer satisfaction, and relays useful results regarding perceived service quality. The questionnaire results yield essential information in determining current and near-term requirements and customer expectations, helping set priorities for service improvements, identifying system weaknesses, targeting user groups and identifying their specific needs, and setting performance benchmarks that can be used to compare the system to its competitors and track its performance over time.

\section{Introduction}

As with most public and private firms that use traditional business practices, transit systems suffer from increasingly less efficient management (TCRP 1995). In many instances, management has not kept pace with changing societal demands and demographic patterns, shifting employee and customer 
expectations, increasing competition and fiscal constraints, and the need to adopt and use advanced technologies. This inability to satisfy changing market conditions has resulted in shrinking ridership figures, declining market share, increased operating costs, and reduced customer service.

In the past decade, amid talks for dramatic decreases in operating subsidies, transit management has been under pressure to control operating costs and recapture market share. In response, fares have frequently been increased, privatization (and service subcontracting) has been examined, and part-time workers have been hired (Obeng and Ugboro 199.9). While the results of these measures may vary, transit is still facing difficult times. Many transit systems are experimenting with quality management strategies, with frequently promising results (Obeng and Ugboro 1999). ' This quality-focused management helps an organization move from traditional outdated management to a more progressive way of running the company (transit system). Part of this process helps the organization learn how to improve and evolve continuously by focusing on people first: passengers, employees, and the community in general (TCRP 1995).

As in U.S. and international transit systems, the Athens Urban Transportation Organization decided to move toward a quality management environment. As part of this process, transit riders (customers) become the explicit service target, and the organization strives to offer a quality of service that meets, and, at a later stage exceeds, customer expectations. The organization believes that its success clearly depends on retaining current riders and attracting new ones. Further, a transit system that is well organized and offers high-quality service can be a very effective part of any traffic management strategy. Of course, a well-integrated traffic strategy needs to include issues such as parking strategies, high-occupancy vehicle (HOV) lanes, park-'n-ride policies, congestion pricing, etc. But, a qualitatively solid transit system should be the cornerstone of any such strategy. This article focuses on the narrower issue of transit quality viewed through the traffic management scope.

How should overall performance as well as more specific aspects of performance be surveyed and measured? This information, once collected and analyzed, can help determine current and near-term requirements and customer 
expectations, set priorities for service improvements, identify system weaknesses, target user groups and identify their specific needs, and set performance benchmarks that can be used to compare a system to its competitors and track its performance over time. Many different techniques have been used in the past to assess customer satisfaction, or perceived service quality. The most widely used techniques are simple bivariate correlation, regression analysis, factor analysis, and multidimensional scaling. An in-depth review of these techniques and their application to transit customer satisfaction can be found in TCRP (1998) and Weinstein (2000).

This article develops a performance and service-quality scheme based on SEM. The scheme allows for more complex and realistic performance assessment than do the previously mentioned methods. The article briefly describes the Athens urban transport system and discusses the data collection process. It also reviews the methodological approach used and presents the estimation results. In addition, the article assesses perceived quality for different user groups.

\section{Characteristics of the Greater Athens Urban Transport System}

The urban region of Athens, the capital of Greece, has an area of 1,470 $\mathrm{km}^{2}$ and a population of approximately 4.1 million people. During the last decade, the population of the greater Athens area has increased by about 10 percent; car ownership has also increased considerably, approaching 250 automobiles per 1,000 inhabitants. This has led to an increase in travel time by 26 percent in the last 12 years, which, along with the insufficient urban road network in the central areas, has led to a deterioration of traffic conditions in the capital. Further, the modal split has changed in favor of automobile travel, from an automobile-to-transit ratio of 40:45 to 54:32 (Table 1). For the Athens metropolitan area, there is a daily demand for 5,650,000 journeys (linked trips), with a $1,080,000$ two-hour peak demand. There are $6,300,000$ singlemode daily trips, a 26 percent increase in the last 12 years.

Athens is served by a mass transit system of 1,840 motor buses, 1,550 of which are in operation daily; 356 trolley buses, 290 of which are in operation daily; and 3 metro lines with 268 cars. The bus system is made up of 41 trunk lines, 116 central lines, 9 intermunicipal lines, 98 local-feeder lines, 8 express 


\begin{tabular}{|lcccc|}
\hline \multicolumn{5}{|c|}{ Table 1 } \\
Modal Split in the Athens Metropolitan Area \\
\hline Year & Public Transport & Automobile & Taxi & Walk \\
\hline 1983 & $40 \%$ & $45 \%$ & $6.0 \%$ & $9 \%$ \\
1996 & $31.7 \%$ & $54.5 \%$ & $6.0 \%$ & $7.8 \%$ \\
\hline
\end{tabular}

lines, and 6 school lines, with a total annual ridership of 403 million passengers. This ridership is complemented by 90 million annual riders from the trolley buses, and 92 million passengers from Metro's Line 1 (total bus and trolley system boardings appear in Figure 1). Transit providers serve a system that has faced a 3.5 percent annual increase in traffic during the last 10 years and that has 22 percent of its signalized intersection junctions in the center of this highly-congested city (levels of service E-F). Obviously, the provision for mixed-traffic transit services in such a congested network is very difficult.

\section{Data Collection}

The data commonly used to assess service quality and performance come from questionnaires. Excellent guides on how to develop transit-related questionnaires as well as examples of successful ones can be found in TCRP (1998,

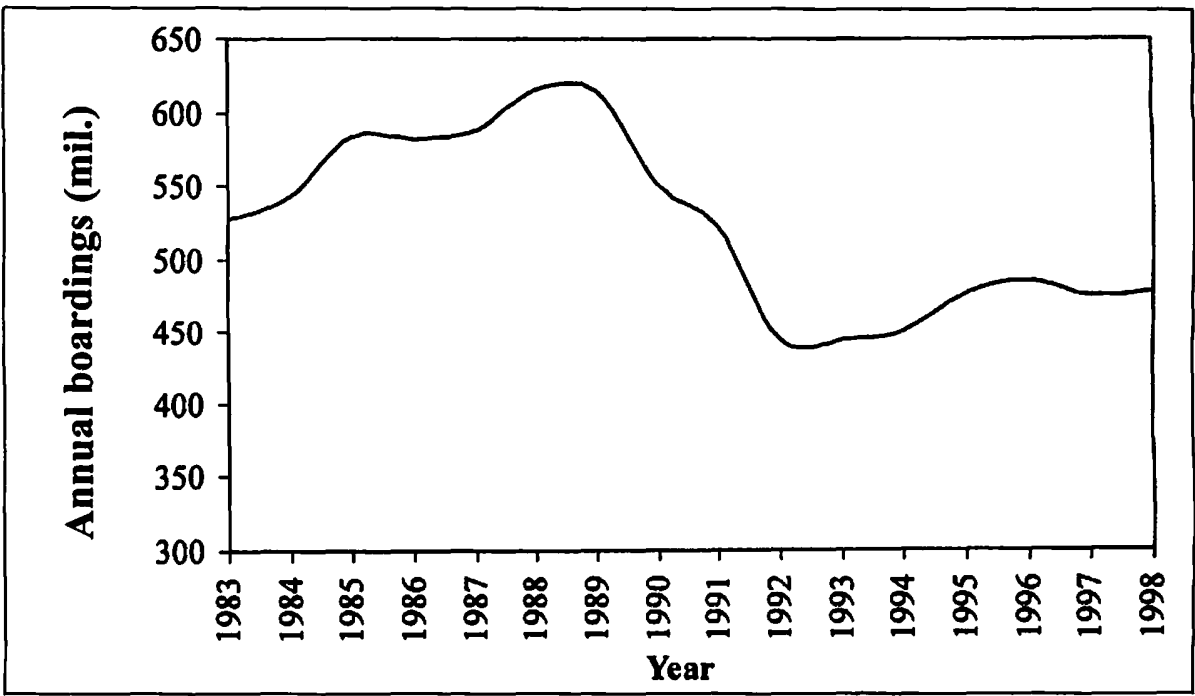

Figure 1. Annual ridership (boardings) for the Athens bus and trolley bus systems 
1999). The survey described in this article included 35 attributes (e.g., employee performance, security, customer service, comfort, bus environment, and trip performance), as well as socioeconomic characteristics for the respondents. The surveys were developed and completed using onboard, face-to-face interviews. ${ }^{2}$ To select the most representative sample of bus and trolley riders, a multistage stratified sampling process was followed.

The strata of the survey were the two main modes considered (buses and trolley buses) and the six different types of lines within the bus network (trunk, central, intermunicipal, local-feeder, express, special). From each stratum, a random sample of lines was selected, the size of which was proportional to the ridership of the stratum, with the probability of selecting each line proportional to its ridership (proportional to size sampling). Finally, weighted random sampling (using age and sex as the weights) was used to select the interviewed individuals. ${ }^{3}$

A total of 3,169 complete questionnaires were collected ( $83 \%$ from the buses and $17 \%$ from the trolleys). This number is quite high, especially when compared with other customer satisfaction surveys of systems with ridership figures similar to those of Athens. TCRP (1999) reports results of various studies using sample sizes between 300 and 500 respondents. ${ }^{4}$ The sample collected suggests that 71 percent of the riders use transit on a daily basis and 24 percent use the system one to three times a week. The sample of this study, and more generally the public using the system, is made up of frequent users as 95 percent of the individuals surveyed use transit at least weekly.

\section{The Methodological Approach}

This section examines the methodology used in this study and presents the estimation results.

\section{Structural Equation Modeling}

SEM, also known as latent-variable modeling, is a thorough technique for testing hypotheses for the relationship between observed and unobserved (latent) variables. The first account of the statistical theory underlying SEM appeared in the early 1970s (Joreskog 1973; Wiley 1973). The increasing complexity of the research questions examined and the appearance of user-friendlier SEM software packages increased the interest and use of the method as a standard approach to testing research hypotheses. 
The structural equation general models are defined by two components: the measurement model and the structural model. The measurement model is that component of the general model where latent variables are prescribed; it describes how well various exogenous variables measure latent variables. Latent variables are unobserved variables implied by the covariance structure among two or more observed indicators (variables). The structural model is that component of the general model where the relationship between latent variables and observed variables that are not indicators of latent variables are prescribed. Multiple regression, for example, is a structural model without latent variables, while classical factor analysis is a typical measurement model.

Following Joreskog and Sorbom (1993), the structural model can be written, in matrix form, as:

$$
\eta=\beta \eta+\Gamma \xi+\zeta
$$

where:

$\eta$ is an ( $m \times 1)$ vector of $m$ latent dependent variables.

$\xi$ is an $(n \times 1)$ vector of $n$ latent independent variables.

$\beta$ and $\Gamma$ denote the relationships among the latent variables. $\beta$ is an $(m$ $\mathrm{x} m$ ) matrix of structure coefficients that relate latent dependent variables to one another. $\Gamma$ is an $(m \times n)$ matrix of structure coefficients that relate the latent independent variables to the latent dependent variables.

$\zeta$ is the error term that contains the equation prediction errors or disturbance terms.

Similarly, the measurement model for the latent independent variables can be written as:

$$
\mathrm{X}=\Lambda_{\mathrm{x}} \xi+\delta
$$

where:

$\mathrm{X}$ is a $(q \times 1)$ vector of observed variables for the measures of the latent variables $\xi(n \times 1)$. 
( $q \times n)$ matrix $\Lambda_{\mathrm{x}}$ denotes the relationships between the observed variables and the latent variables (commonly termed factor loadings).

$(q \times 1)$ vector $\delta$ denotes the measurement errors for the Xs.

SEM, much like correlation, multiple regression, and analysis of variance (ANOVA), is a linear statistical method. Interestingly, standard linear models, such as linear regression and ANOVA, can be treated as special cases of the general structural equation model. SEM suffers from some of the same problems as the other linear techniques: models are valid only if certain underlying assumptions are met, and none of the methods offer statistical tests of causality. But, unlike the other methods, SEM has the capacity to estimate and test relations between latent variables. The ability to deal successfully with latent variables makes SEM useful and popular with performance and customer satisfaction studies. SEM has some similarities to Multidimensional Scaling (MDS), another very popular transit market research technique. However, while the primary goal of SEM analysis is to uncover the underlying relationships between observed variables and reduce them to a smaller number of latent factors, MDS is used to produce quadrant maps and perform SWOT (Strengths-Weaknesses-Opportunities-Threats) analyses.

\section{Estimation Results}

The initial step in the estimation process was to perform an exploratory factor analysis procedure, uncover some of the most basic relationships between the variables, and determine the approximate number of factors (latent variables) to retain as a first step (initial measurement model estimation). ${ }^{5}$ Once the relationships became clearer, the structural model was also estimated. The Wald and Lagrange multiplier tests were used for the modifications and testing. These two tests are used to evaluate the $X^{2}$ change as a result of respecifying one or more of the parameters. The maximum likelihood estimation was used to overcome the violations of the normality assumption necessitated by the method. The final model, after a series of modifications and testing, appears in Figure 2.

The path diagram shown in Figure 2 is a pictorial representation of the estimated structural equation model. Rectangles are used to indicate observed variables; ellipses, latent variables; straight arrows, association in one direction (from predictor to outcome); and curved arrows, nondirectional association 


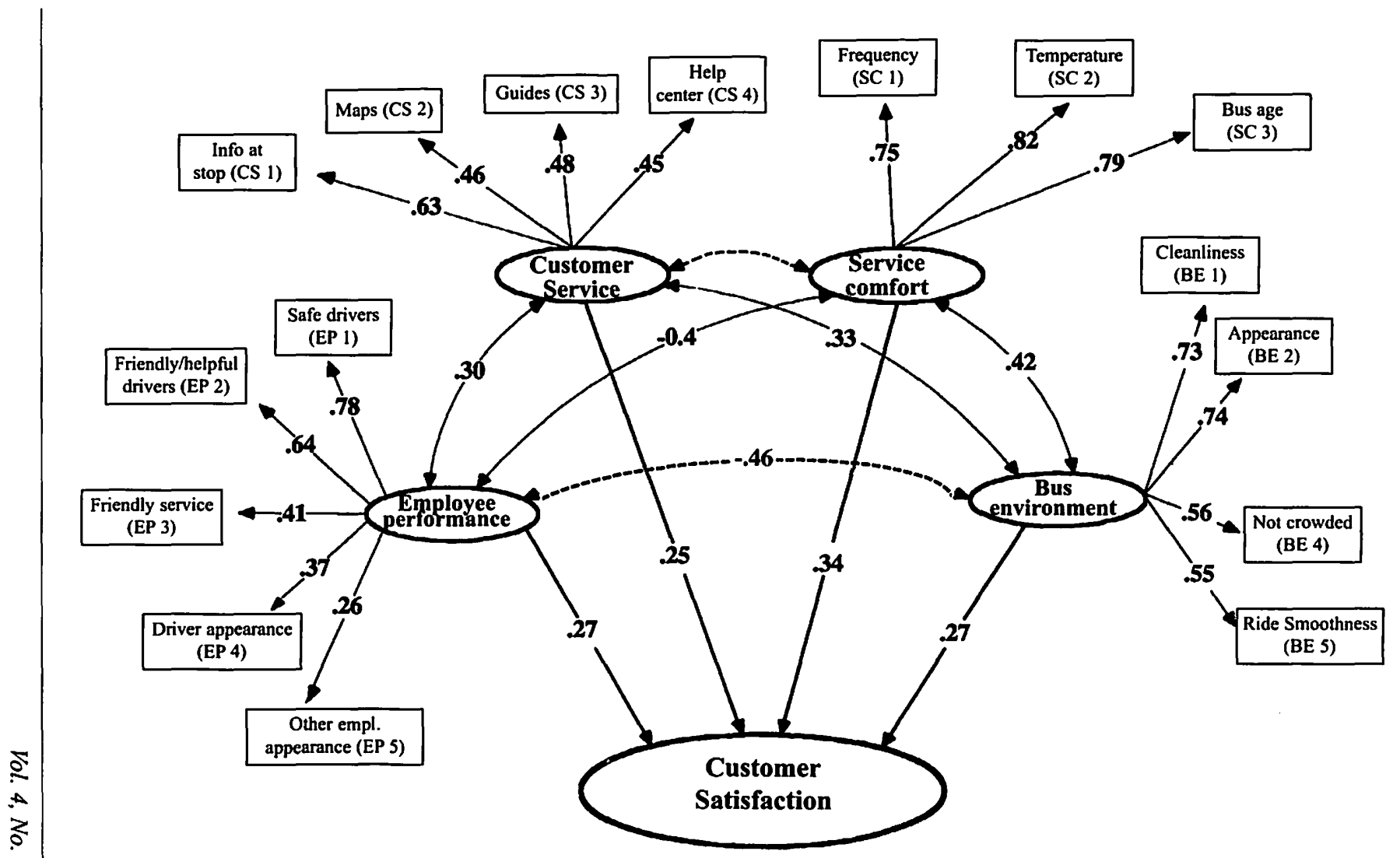

Figure 2. Final model specification 
(correlation). Numbers appearing on the arrows show the standardized parameter estimates that indicate the strength of association or correlation. Standardized parameter estimates are transformations of unstandardized estimates that remove scaling information and, therefore, allow for parameter comparisons in a model. Standardized parameter estimates index the number of standard deviations change in the dependent variable when all remaining independent variables are at zero.

The final model shows that there are four latent independent variables (first level of customer satisfaction assessment): employee performance, customer service, service comfort, and bus environment (the "names" for the latent independent variables were selected based on the observed variables that affect them). Interestingly, many of these latent variables and the indicators that affect them are similar to work performed by other transit systems (TCRP 1998, 1999; Weinstein 2000; Stuart et al. 2000). These latent variables (factors) correspond to four essential dimensions of a transit system's performance and four aspects of perceived service quality. The factors are:

- Employee performance measures the perceived service quality (from a customer's perspective) as it pertains to employees. Safe driving and driver helpfulness are the most important determinants of this factor, with general friendly service, driver appearance, and other employee appearance scoring much lower.

- Customer service is mainly characterized by the quality of information riders receive at the stops. Quality of available maps, help received from travel guides, and the phone center score lower.

- Service comfort is almost equally affected by service frequency, bus temperature (including air-conditioning availability), and age of the bus.

- Bus environment is affected by bus cleanliness, general appearance, and ride smoothness, with ease of paying fare, not crowded buses, and quality of stops and shelters scoring lower.

All the factors are correlated. In particular, employee performance and bus environment, service comfort and bus environment, and employee perfor- 
mance and customer service show statistically significant correlations of .46 , .42 , and .30 respectively. (While these correlation coefficients may seem low for usual bivariate correlation, they are quite high for SEM purposes.) Interestingly, the variables "Ease paying fare (BE3)" and "Ride smoothness (BE5)," both loading on the latent variable "Bus environment," could be included in the "Service comfort" latent variable. Initially, while an explicit effort was made to load variables BE3 and BE5 on the "Service comfort" latent variable, the two variables not only had very low coefficients, but also made the fit of the other three variables worse. As such, the decision was made to maintain the latent structure as it currently appears in Figure 2. Even if variables BE3 and BE5 were completely excluded from the model, the results would not be significantly affected because of their rather low correlation. Further, the positive correlation between "Service comfort" and "Bus environment" allows for these variables to be, indirectly at least, related to both latent variables.

A second latent-variable level (dependent latent variable) was then introduced. The four factors were introduced in a new model (structural model) as latent independent variables, with (overall) customer satisfaction forming the dependent latent variable. This dependent variable is intended to capture the overall system customer satisfaction levels. As a measure, this is very important since it yields a single customer satisfaction index that can be traced over time and compared to those of other systems. The results show that service comfort is clearly the most important determinant of customer satisfaction, with employee performance, customer service, and bus environment being approximately of equal importance. Finally, the model, using a variety of goodness-of-fit measures, shows a good fit to the data. (Root Mean Square Error, Akaike's Information Criterion, Browne-Cudeck Criterion, and TuckerLewis Index were used for goodness-of-fit purposes.) That is, the structural equation model presented in Figure 2 is a well-fitting model of a transit system's customer satisfaction levels.

\section{Assessing Perceived Quality}

In general, the goal of SEM analysis is to estimate a relatively simple structure in which each variable loads highly (high correlations are considered those over .5) on only one latent variable with small, and statistically not sig- 
nificant, loadings on all other latent variables. (In this article, since the observed variables loaded high on only one latent variable at a time, they were not "loaded" on the other latent variables.) As was discussed, the variables that load highly on one latent variable will help to interpret the "meaning" of that variable. The estimated parameters from the latent variables are then used to assign scores to each observation.

These scores are frequently called "factor scores" and, unlike the standardized parameter estimates that are used to assess the impact of various observed variables on the independent latent variables, they use the standardized parameter estimates as an input to obtain a single index. That is, factor scores can be used to obtain a score on all, independent and dependent, latent variables using the raw scores that customers gave for each of the observed variables. From the original answers and using the factor scores, analysts can infer, in index form, the various aspects of customer satisfaction.

A number of different methods have been proposed to estimate factor scores. One simple procedure adds, with equal weights, the values on the observed variables that are most highly correlated with the factor-a robust and rather extensively used approach. However, the most widely used method recognizes that the desire is to predict the latent variable, the factor, from a set of observed variables. Multiple regression is an accepted way of making predictions of a given variable from a set of explanatory variables. For this analysis, the regression method (Bollen 1989) to estimate factor scores is used. Table 2 presents the factor score weights for customer satisfaction yielded by the model presented in Figure 2.

The existence of such scores allows for a more formal and in-depth examination of the characteristics of customer satisfaction. ${ }^{6}$ Figure 3 presents the mean factor scores for various age groups. The scores for all latent variables do not show much variation for the different age groups. As such, it can be inferred that age is not a significant determinant of overall customer satisfaction. Figure 4 presents mean scores for the three income levels. Interestingly, higher-income riders tend to be less satisfied with the transit system. This could potentially happen because these customers compare the transit system to their private auto. Figure 5 shows mean scores for frequent and infrequent users. Frequent users, a focus group for this investigation, tend to give higher scores to the transit system. 
Table 2

Factor Score Weights for Customer Satisfaction Measurement

Latent

$\begin{array}{ll}\text { Variable } & \text { Observed Variable" }\end{array}$

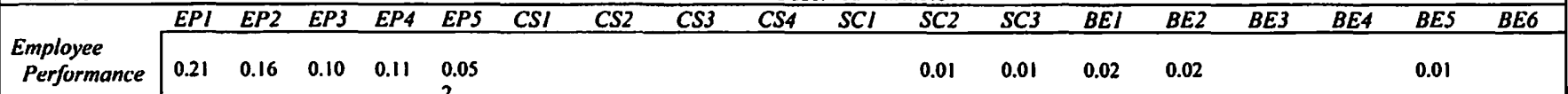

Employee

0.01

Bus

Environment

0.03

0.01

$-0.01$

$-0.04$

$-0.03 \quad 0.22$

Customer

Service

$\begin{array}{ll}0.06 & 0.01\end{array}$

0.03

0.25

0.11

0.12

0.09

$\begin{array}{cccc}-0.01 & -0.01 & 0.04 & 0.04\end{array}$

0.27

$0.08 \quad 0.07$

Service
Comfort

Overall

Customer

Satisfaction

"See Figure 2 for explanation of variables. Empty cells signify factor scores $<0.005$. 


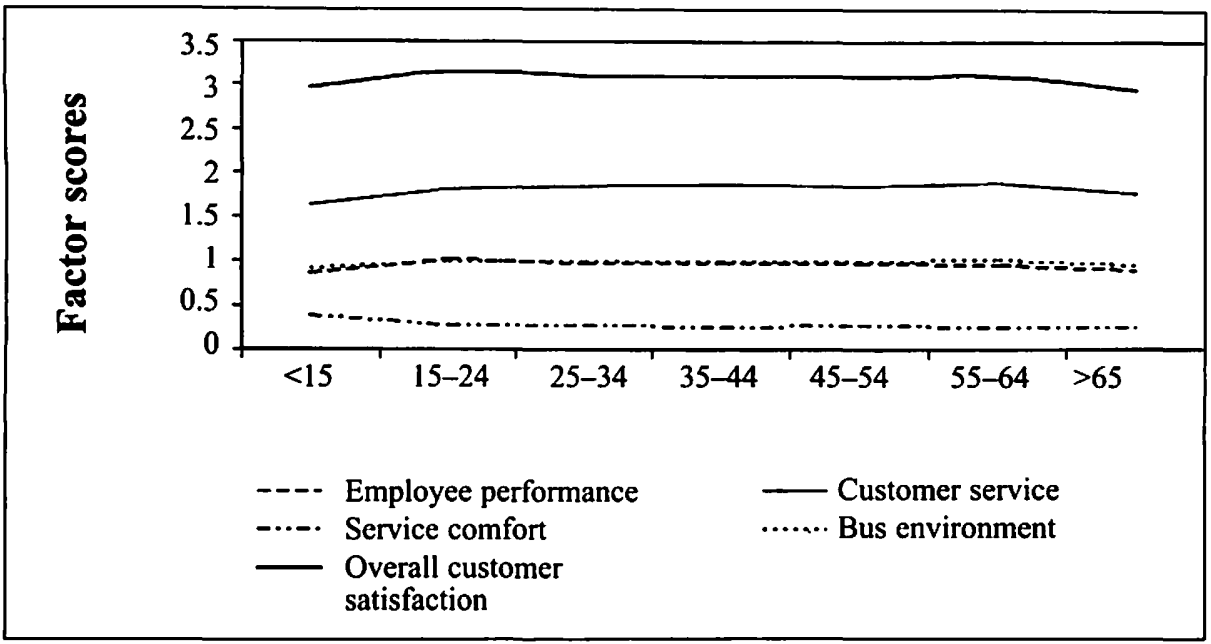

Figure 3. Factor scores for various age groups

Results of high importance to the transit systems appear in Figure 6, where mean scores are presented for the variety of line types operated by the transit system. ${ }^{7}$ A within-system trend is clearly visible. Trunk lines receive, by far, the lowest scores, and express lines receive the highest. Interestingly, trunk lines have the highest service frequency. Nevertheless, buses serving these lines are frequently packed, with all the problems that follow packed buses, and customers award them low scores. Similarly, it also seems that central lines

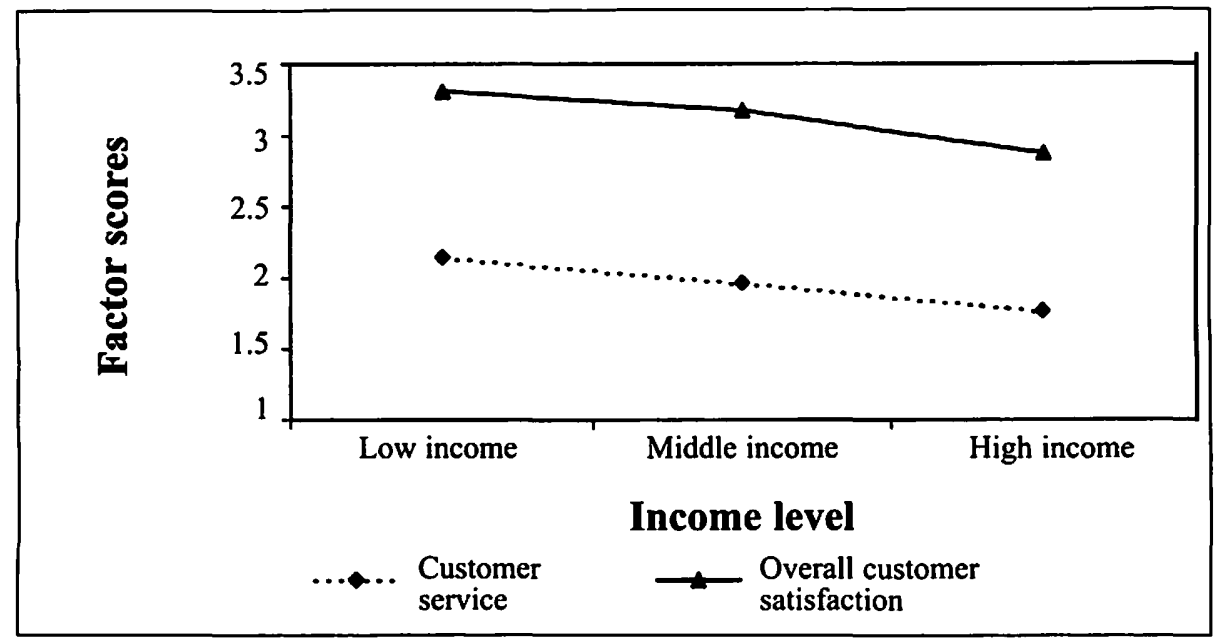

Figure 4. Customer satisfaction scores for various income levels 


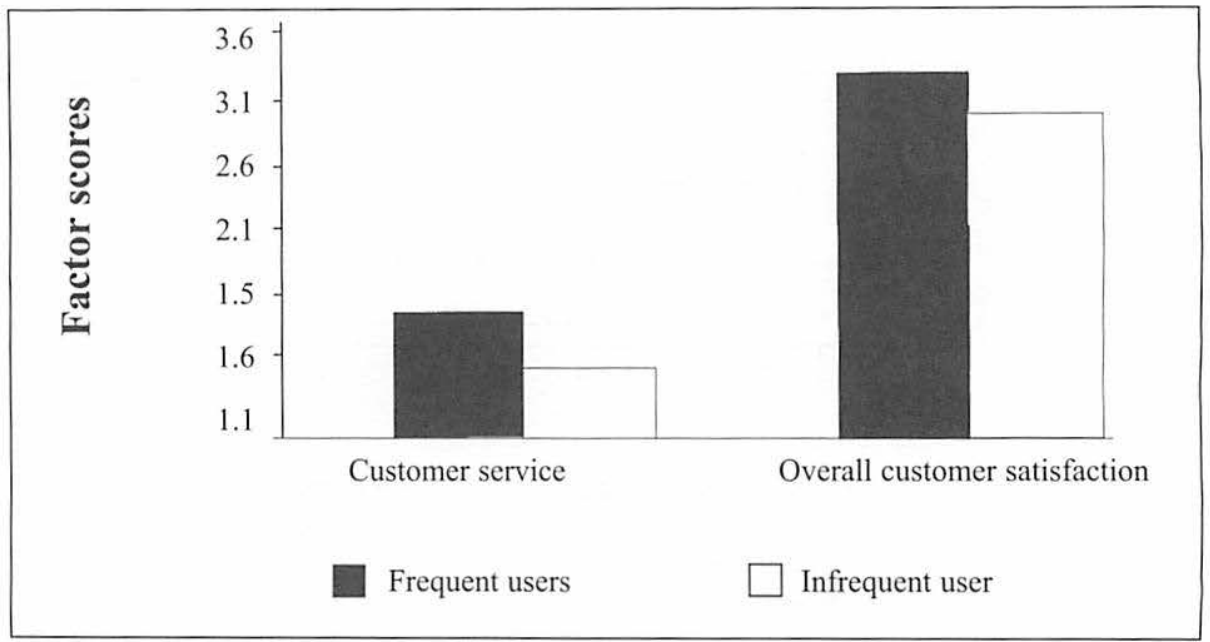

Figure 5. Customer satisfaction scores for frequence of use

suffer from the same problems as trunk lines. Express lines, which receive the highest scores, are served by the newest, air-conditioned buses have lower travel times, and are less packed than other lines. From these results it becomes clear that, to increase customer satisfaction, the Athens Urban Transport Organization needs to increase the quality of service in trunk, central, and intermunicipal lines.

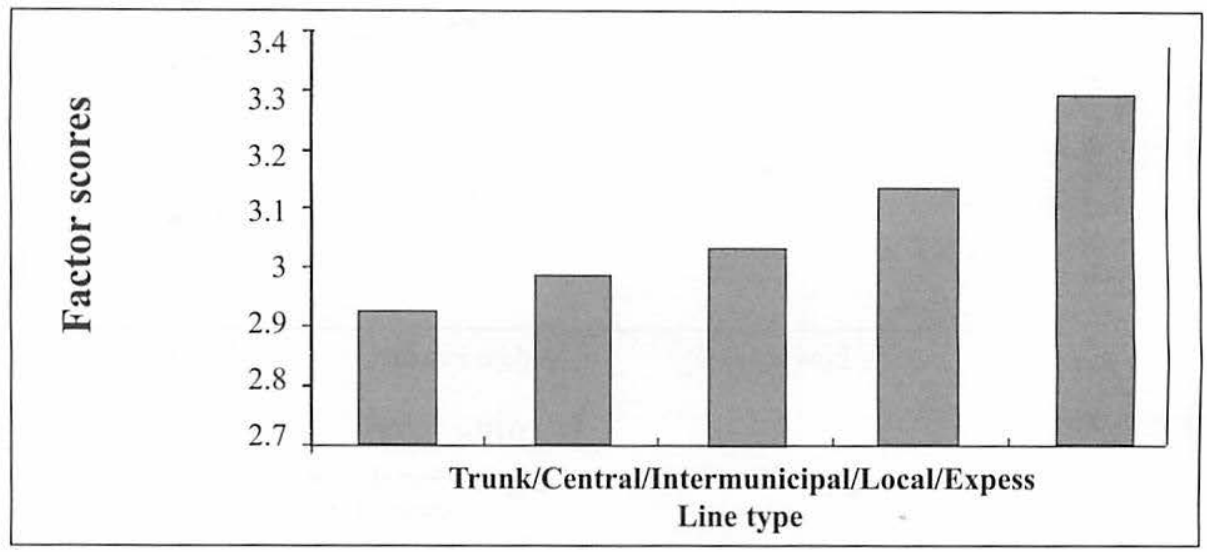

Figure 6. Customer satisfaction scores for various line types 


\section{Conclusions}

Faced with declining ridership numbers, shrinking market share, decreasing operating subsidies, and increasing operating costs, many transit systems are experimenting with quality management strategies. Quality-focused management helps an organization move from traditional, outdated management to a more progressive, effective, and efficient way of running the transit system. Part of this process helps the organization learn how to improve and evolve continuously by putting the customer (passengers) first. Another part of this strategy considers transit as an indispensable part of every integrated transport management strategy. As such, it is necessary for a transit system to offer an attractive, high-service-quality alternative to other modes of transport.

An important component of any quality-focused management is measurement of customer satisfaction. This information is essential in determining current and near-term requirements and customer expectations, helping set priorities for service improvements, identifying system weaknesses, targeting user groups and identifying their specific needs, and setting performance benchmarks that can be used to compare a system to its competitors and track its performance over time. The purpose of this article was to present a customer satisfaction scheme based on SEM. This scheme allows for more realistic and useful performance assessment than do the previously utilized methods. This assessment explicitly evaluates both overall customer satisfaction and its various separate dimensions.

Using survey data from an onboard, face-to-face interview questionnaire from Athens, Greece, this article demonstrates both the potential use of the proposed methodology and the factor scores obtained for various user subgroups. These scores indicate that the transit system examined needs to upgrade service provided in certain lines (trunk, central, intermunicipal), while it attempts to offer service levels that will satisfy higher-income users, hopefully diverting them from their automobiles. Finally, this same survey should be repeated annually, to allow the transit system to track its performance over time.

\section{Endnotes}

1. Interestingly, in the quality world, Total Quality Management is being replaced by Six Sigma. The Six Sigma strategy, originally instituted by 
Motorola during the 1980s, is a statistical term that means "six standard deviations from a statistical performing average." While many of the tools are the same, Six Sigma has a very clearly defined toolbox and would be very useful for transit agencies (Armstrong and Kotler 2000).

2. Surveys were collected for buses, trolley buses, and Metro's Line 1. The results from the surveys of the first two modes are presented here. For space considerations the exact survey instrument is not presented; it is available from the authors upon request.

3. A computer program was also used to test different combinations of sample sizes per stratum to identify the most effective sampling process, at the 95 percent level of significance.

4. Similar to many other customer satisfaction surveys, a four-point scale was used for the answers to the questions of this survey. That is, the responders could pick answers that ranged from "very satisfied" to "very unsatisfied."

5. SAS's PROC FACTOR was used for this initial analysis. PROC FACTOR's power and flexibility in exploratory factor analysis made it a very useful tool for this step of the analysis.

6. Once factor score weights (Table 2) have been estimated, it is very simple to estimate factor scores. The factor scores used in this article, for example, have been estimated using a spreadsheet program.

7. While the results presented here cover one year of data, many interesting insights can be gained by examining the evolution of a system's quality over time. This is the goal of the American Customer Satisfaction Index, which tracks customer satisfaction in more than two dozen U.S. manufacturing and service industries. Based on some of the findings of this index, overall customer satisfaction has been declining slightly in recent years, and it is unclear whether this has resulted from a decrease in product and service quality or from an increase in customer expectation. It will be interesting, at a later stage, to examine the evolution of a transit system's (and the industry's) quality, over time. 


\section{References}

Armstrong, G., and P. Kotler. 2000. Marketing: An introduction. New Jersey: Prentice-Hall.

Bollen, K. A. 1989. Structural equations with latent variables. New York: Wiley and Sons.

Joreskog, K. G. 1973. A general method for estimating a linear structural equation system. In A. S. Goldberger and O. D. Duncan (eds.), Structural equation models in the social sciences, 85-112. New York: Academic.

Joreskog, K. G., and D. Sorbom. 1993. LISREL 8: Structural equation modeling with the SIMPLIS command language. Hillsdale, NJ: Erlbaum.

Obeng, K., and J. Ugboro. 1999. Application of TQM in public transit firms. Transportation Quarterly 50(3): 79-84.

Stuart, K. R., M. Mednick, and J. Bobkman. 2000. A structural equation model of customer satisfaction for the New York City subway system. Paper presented at the Transportation Research Board Annual Meeting, Washington, DC.

TCRP. 1995. The quality journey: A TQM roadmap for public transportation. Washington, DC: Transportation Research Board.

TCRP. 1998. A handbook: Integrating market research into transit management. Washington, DC: Transportation Research Board.

TCRP. 1999. A handbook for measuring customer satisfaction and service quality. Washington, DC: Transportation Research Board.

Weinstein, A. 2000. Customer satisfaction among transit riders: How do customers rank the relative importance of various service attributes? Paper presented at the Transportation Research Board Annual Meeting, Washington, DC.

Wiley, D. E. 1973. The identification problem for structural equation models with unmeasured variables. In A. S. Goldberger and O. D. Duncan (eds.), Structural equation models in the social sciences, 69-83, New York: Academic. 


\section{About the Authors}

MaTtHew G. KaRLAFTis (mgk@central.ntua.gr) received his Ph.D. in civil engineering from the School of Civil Engineering at Purdue University in Indiana. His research interests include transportation statistics, traffic engineering, management and safety, public transportation, and the deployment of Intelligent Transportation Systems (ITS) technologies. His current position is lecturer in the Department of Transportation Planning and Engineering of the National Technical University of Athens.

JoHN GoLIAS (igolias@central.ntua.gr)is a civil engineer with more than 20 years of expertise in Greek and international projects and research in the field of highway and traffic engineering, road safety, and transportation planning. He is the author of a number of published papers in these areas. He is an associate professor in the Department of Transportation Planning and Engineering of the National Technical University of Athens.

EFstratios Papadimitriou (stratos@ath.forthnet.gr) received his Ph.D. in civil engineering from the Polytechnic Institute of New York. His research interests include transportation management, freight logistics, and public transportation. He is an assistant professor in the Department of Maritime Studies at the University of Piraeus, and managing director of the Athens Urban Transportation Organization. 


\title{
The Modernization of Routes
} and New Railway Lines: Different Viewpoints and Instruments
for Commercial Objective

\author{
Andrés López-Pita and Francesc Robusté
}

Center for Transportation Innovation, Technical University of Catalonia

\section{$\overline{\text { Abstract }}$}

This article presents the concept of "objective travel time" as a key variable in railway line modernization decision making. The concept tries to achieve a threefold goal: optimization of economic resources, significant presence of the railway in the market share of the corridor, and a positive operational balance. The concept has been successfully applied in the new Rail Investment Program in Spain.

\section{Introduction}

The desire to improve the quality of intercity railway passenger services by reducing journey times has always existed. In the 1950s, this desire became an indispensable necessity in Europe for two reasons: (1) the rapid development of new road infrastructures (e.g., dual carriageways and motorways) and (2) the increasingly widespread use of the airplane for middle- and long-distance journeys within Europe. This increase in the use of air transport services was due to the introduction of the reactor, which provided greater speed, safety, and comfort.

In an initial phase (1960-1975), some European countries, especially France and the United Kingdom, carried out important modernizations on their 
principal lines to achieve higher running speeds and, as a result, shorter journey times.

After having exhausted the possibilities of modernizing the routes constructed in the 19th century, each country took a different approach:

- France opted for the construction of new railway infrastructures, suitable for running speeds of $300 \mathrm{~km} / \mathrm{h}$.

- The United Kingdom chose to put its faith in the technology of the vehicles whose bodies tilt when negotiating curves.

The technical, commercial, and economic success achieved by the French railways with the operation of the new high-speed line between Paris and Lyon immediately gave rise to the construction of new high-speed lines in France: TGV-Atlantic and TGV North. Soon after in 1991, the French government approved the Guidelines for New Railway Lines, which basically involved constructing a new, 4,700, km-long high-speed line.

Meanwhile, British Rail was unable to perfect its tilting-body train, called APT, and eventually abandoned this approach in 1986. Interestingly, two years later, in 1988, the Italian railway company put a tilting-body train (the ETR 450 ) into commercial service. In 1980, Spain's Talgo Pendular train had entered into commercial service.

In short, the major European railway companies adopted two different approaches: on the one hand, the construction of new lines that allow trains to run at high speeds and, on the other, the use of trains with tilting bodies.

The construction of new railway infrastructures requires significant financial resources, which are increasingly substantial due to the need to take greater precautions for protecting the environment. For example, the cost per $\mathrm{km}$ of the first high-speed line in France (between Paris and Lyon) was a third of the cost per $\mathrm{km}$ of the new line between Valence and Marseilles, which entered into commercial service in June 2001.

In Europe, this situation has recently given rise to an extensive debate about the relative merits of investing in the use of rolling stock with tilting bod- 
ies as opposed to the construction of new lines, given the lower financial cost that this represents.

In this context, this article offers an in-depth analysis of this problem and, at the same time, explains the methodology proposed to decide which investment is most advisable for any given service. This methodology was used by the Spanish government during 1999.

\section{The Need for New Railway Infrastructures in Europe: An Objective Fact?}

The first efforts to improve the quality of intercity railway passenger services in Europe focused on the maximum exploitation of the possibilities offered by the existing routes. However, we should not forget that the Japanese national railway company's decision at the end of the 1950 s to construct a new line for the development of high speed between Tokyo and Osaka marked the beginning of a duality that still exists today: constructing new infrastructures or modernizing those already in existence.

It is useful to recall what Louis Armand, the former president of the International Union of Railways (UIC), stated in 1967:

The future of railway passenger transport cannot be imagined without the development of high speed. The main approaches to be taken in this field can be divided into two categories: the modernization of what already exists, should we wish to surpass a certain level of speed (approximately $160 \mathrm{~km} / \mathrm{h}$ ), or the construction of new lines, as the Japanese have already done with the new Tokaido. The problem is, therefore, deciding whether we want to invest in order to perfect or in order to create.

The process undergone in certain European countries from the 1960s to the present day can teach us a number of lessons that relativize theoretical dogmas and provide interesting approaches for guiding the investment decision required of each railway line.

In this context, the construction of the first high-speed infrastructure in France was, in our opinion, essentially based on three facts: 
1) The worrying evolution of the French railway company's share of the market on the Paris-Lyon route, as shown in Tablel. Despite the fact that the railway offered a journey time of four hours (commercial speed of $128 \mathrm{~km} / \mathrm{h}$ ), as opposed to three hours by airplane and five hours by private vehicle (from the center of Paris to the center of Lyon), the railway lost 17 percent of the share of the market in four years (1963 to 1967), a loss which, in accordance with the forecasts, was to have increased by a further 23 percent only nine years later.

2) Problems relating to a lack of capacity that the Paris-Lyon line suffered in the early 1970 s, with over 260 journeys on certain days.

3) Verification from 1972 onwards of the continuing fall in the number of first-class passengers using intercity services from Paris (Figure 1). At that time, Paris was linked to 143 French towns and cities at more than $100 \mathrm{~km} / \mathrm{h}$ in terms of commercial speed, with 67 towns and cities at 120 $\mathrm{km} / \mathrm{h}$, and with 6 cities at more than $140 \mathrm{~km} / \mathrm{h}$.

Table 1

Modal Distribution of Passenger Traffic on the Paris-Lyon Route (1963-1976)

\begin{tabular}{|c|c|c|c|}
\hline Mode of Transport & 1963 & 1967 & $\begin{array}{c}\text { Forecast for } \\
1976\end{array}$ \\
\hline Railway & $65 \%$ & $48 \%$ & $25 \%$ \\
Airplane & $7 \%$ & $20 \%$ & $39 \%$ \\
Road & $28 \%$ & $32 \%$ & $36 \%$ \\
\hline
\end{tabular}

Source: Walrave (1970).

With respect to the approach taken by the United Kingdom to improve the quality of its railway passenger transportation services, the decision was, in our opinion, basically due to these facts:

1) The satisfactory position of British Rail in terms of market share on the routes situated within a radius of approximately $400 \mathrm{~km}$ from London (Table 2). 


\begin{tabular}{|l|c|c|c|}
\hline \multicolumn{4}{|c|}{$\begin{array}{c}\text { Table } 2 \\
\text { Modal Distribution of Passenger Traffic on Certain Routes } \\
(1980)\end{array}$} \\
\hline \multirow{3}{*}{ From London to } & Road & Airplane & Railway \\
\hline Manchester (300 km) & 42 & 27 & 31 \\
Newcastle (430 km) & 20 & 35 & 45 \\
Leeds (288 km) & 48 & 9 & 43 \\
\hline
\end{tabular}

Source: Button (1993).

2) The introduction of commercial services with tilting-body vehicles which, due to the nature of certain sections of the routes, could reach speeds of $250 \mathrm{~km} / \mathrm{h}$ would significantly reduce the journey times (Table 3). Consequently, it was estimated that between London and the three cities mentioned in Table 3, the railway would have a market share of 80 percent, as opposed to the 20 percent corresponding to the airplane.

3) The construction of a new high-speed line heading north out of London would only significantly benefit the most distant population centers: Glasgow and Edinburgh $(650 \mathrm{~km})$. With the tilting-body vehicles it would be feasible to link both cities in four hours, giving the railway an estimated market share of between 50 and 60 percent with respect to the airplane.

Subsequently, we must ask whether the respective approaches of each country were right.

\begin{tabular}{|c|c|c|}
\hline \multicolumn{3}{|c|}{$\begin{array}{c}\text { Table } 3 \\
\text { Foreseeable Effect of Tilting Trains on Journey Times on Certain } \\
\text { Routes } \\
\end{array}$} \\
\hline \multirow[b]{2}{*}{ From London to } & \multicolumn{2}{|c|}{ Journey Time } \\
\hline & $\ln 1980$ & With Tilting Trains \\
\hline $\begin{array}{l}\text { Manchester } \\
\text { Newcastle } \\
\text { Leeds }\end{array}$ & $\begin{array}{l}2 \mathrm{~h} 25 \\
3 \mathrm{~h} \\
2 \mathrm{~h} 07\end{array}$ & $\begin{array}{l}2 \mathrm{~h} \\
2 \mathrm{~h} 20 \\
1 \mathrm{~h} 45\end{array}$ \\
\hline
\end{tabular}

Source: Authors. 


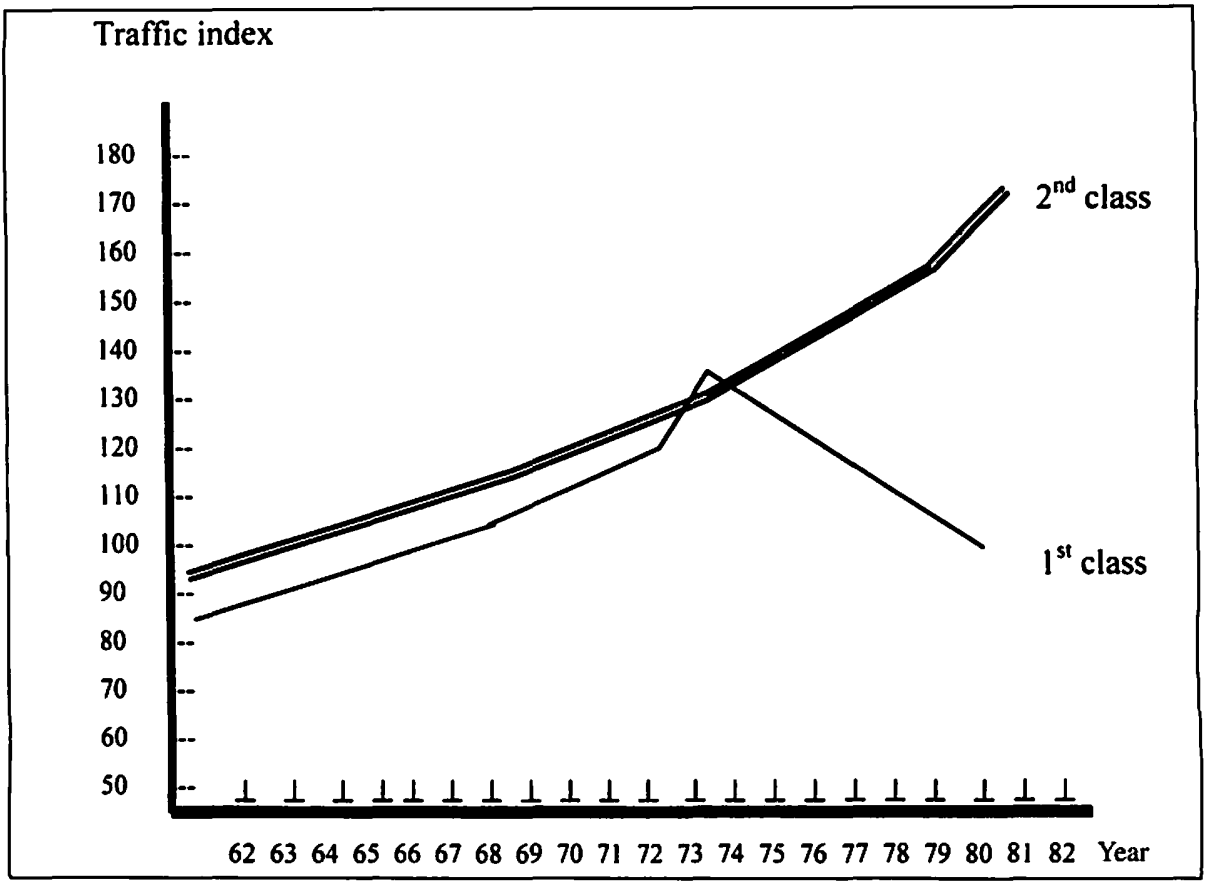

Source: Mireaux (1985).

Figure 1. The evolution of long-distance passenger traffic in SNCF 1962-1982

As for the French, the existing experience with the evolution of railway passenger traffic on intercity routes not served by high-speed lines confirms that the right decision was made (Table 4).

In fact, on routes offering high-speed services, traffic increased by 45 percent between 1990 and 1995, whereas on the routes without this type of service, traffic fell by 18 percent. These trends are still evident today.

In regards to the English decision, it was impossible to perfect the tiltingbody vehicle, leading to the project being abandoned in 1986 (Figure 2).

The commercial use of vehicles with tilting bodies, as proposed by British Rail, required a 20- to 30-year research period. This technology was not actually available when the construction of the high-speed line between Paris and Lyon began (Figure 2).

At the moment, tilting-body technology has reached a satisfactory level of development. This type of rolling stock will enter into service on the 
Table 4

Evolution of Long-Distance Passenger Traffic on French Railways (1990-1995)

\begin{tabular}{|c|c|c|}
\hline \multirow{2}{*}{ Year } & \multicolumn{2}{|c|}{ Rate of Evolution of Traffic on } \\
\cline { 2 - 3 } & Lines with TGV Services & $\begin{array}{c}\text { Lines without High- } \\
\text { Speed Services }\end{array}$ \\
\hline 1990 & 100 & 100 \\
\hline
\end{tabular}

Source: Authors.

London-Glasgow and London-Edinburgh lines in 2003/2004, once the respective layouts have been suitably modernized.

Whatever the case, we do not believe that false comparisons should be made between new infrastructures and tilting-body vehicles. Both possibilities are useful instruments at the railway's disposal for providing the most suitable commercial, technical, and financial response to the needs of the demand on any given route.

Table 5 shows how an approach based on modernization of lines, pendulation, tilting, or construction of new infrastructures has enabled the railway to secure very significant market shares. This reality confirms the value of each of these actions.

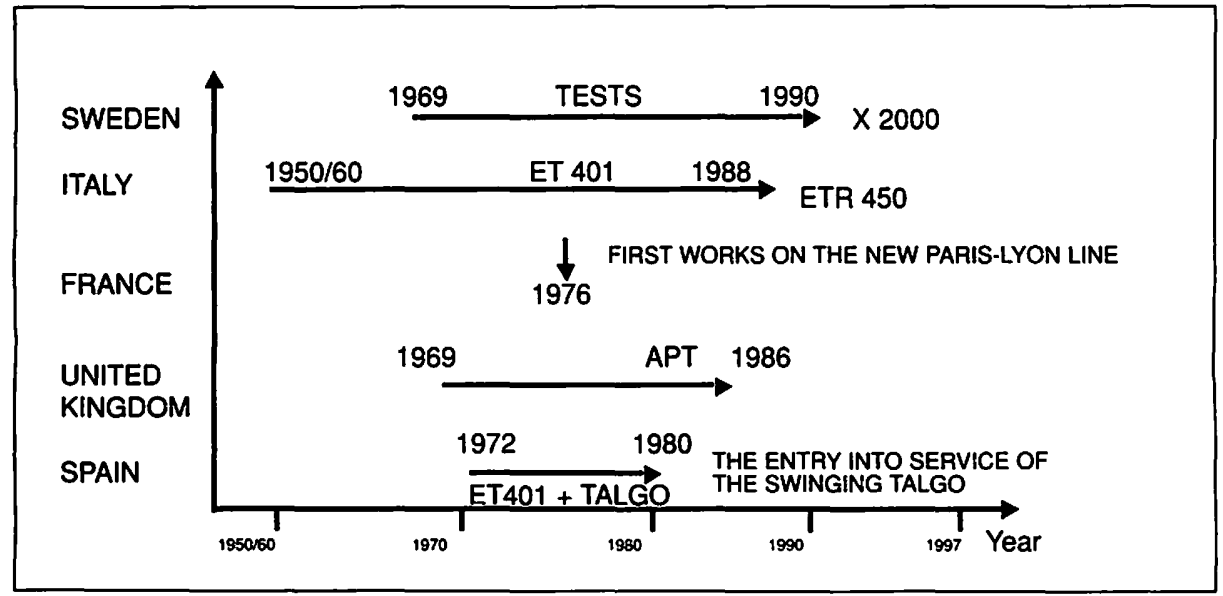

Source: López-Pita (1999).

Figure 2. Historical development of tilting-body systems 


\begin{tabular}{|c|c|c|c|c|c|}
\hline \multirow[b]{4}{*}{ Country } & \multicolumn{5}{|c|}{$\begin{array}{c}\text { Table } 5 \\
\text { The Technology Used and Railway Market Share }\end{array}$} \\
\hline & \multirow[b]{3}{*}{ Service } & \multirow[b]{3}{*}{ Line } & \multirow{3}{*}{$\begin{array}{l}\text { Journey } \\
\text { Time }\end{array}$} & \multicolumn{2}{|c|}{ Market Share } \\
\hline & & & & Rail & Rail \\
\hline & & & & All Modes & Air \\
\hline Germany & $\begin{array}{l}\text { Hamburg-Frankfurt } \\
\text { Frankfurt-Munich }\end{array}$ & New + Modemized & $3 h 40$ & $39 \%$ & $44 \%$ \\
\hline & & New + Modernized & $3 \mathrm{~h} 30$ & $37 \%$ & $53 \%$ \\
\hline Sweden & Stockholm-Gothenbourg & $\begin{array}{l}\text { New }+ \text { Modemized }+ \\
\text { Rocking }\end{array}$ & $2 \mathrm{~h} 59$ & $\cdots$ & $55 \%$ \\
\hline Spain & $\begin{array}{l}\text { Madrid-Seville } \\
\text { Madrid-Malaga }\end{array}$ & $\begin{array}{c}\text { New } \\
\text { New + Swinging }\end{array}$ & $\begin{array}{c}2 \mathrm{~h} 15 \\
4 \mathrm{~h}\end{array}$ & $48 \%$ & $\begin{array}{l}82 \% \\
30 \%\end{array}$ \\
\hline France & $\begin{array}{l}\text { Paris-Lyon } \\
\text { Paris-C. Ferrand } \\
\text { Paris-Strasbourg } \\
\text { Paris-Montpellier }\end{array}$ & $\begin{array}{c}\text { New } \\
\text { Modernized } \\
\text { Modemized } \\
\text { New + Modemized }\end{array}$ & $\begin{array}{c}2 \mathrm{~h} \\
3 \mathrm{~h} 19 \\
4 \mathrm{~h} \\
4 \mathrm{~h} 15\end{array}$ & $\begin{array}{c}40 \% \\
35 \% \\
\cdots \\
-\cdots\end{array}$ & $\begin{array}{l}90 \% \\
80 \% \\
44 \% \\
49 \%\end{array}$ \\
\hline
\end{tabular}

Source: López-Pita (1999).

\section{A New Methodology for Making Decisions}

Practical experience shows that journey time plays an essential role in the customer's choice of transport mode. The methodology proposed below is based on the idea of defining journey time ("objective").

Specifically, this methodology involves determining the quality of the service (with respect to journey time), which, by optimizing financial resources, represents a significant presence of the railway in the transport system of any given corridor, and determines a positive operating balance for the operator of the line. That is, it is not a matter of traveling as fast as is technically possible, but as fast as commercially and financially necessary. Two examples are presented here to illustrate this point.

Consider, by way of example, the possible influence of the reduction of the current journey time by rail (two hours) between Paris and Lyon. What 
would be the foreseeable effect of an investment aimed at achieving a journey time of, say, $1 \mathrm{~h} 45 \mathrm{~m}$ ?

The application of demand modeling techniques and the evaluation of income and operating costs associated with a certain kind of traffic allow us to obtain a response for that specific route. From the point of view of securing extra demand, all of which would come from air traffic, the railway's current 90 percent share of the market would rise to 95 percent. With regard to this existing relationship with air traffic, the vast majority of new customers are captured from air traffic due to connections and reasons of proximity to their place of residence or work.

From the point of view of operating costs, the market share would increase significantly. This would be due to the need to raise the maximum speed from $260 / 270 \mathrm{~km} / \mathrm{h}$ to $300 \mathrm{~km} / \mathrm{h}$, with the consequent increase in energy consumption that this would entail.

The overall economic balance is negative. It cannot be said that an investment decision, which, with respect to the route in question aimed to reduce the existing journey time by rail, would be commercially and financially justified (and without taking into account the possible supplementary investments in the railway line and in the rolling stock). We call this phenomenon "the price of excess speed."

The second example corresponds to the opposite situation: insufficient commercial performances. Consider the case of the Madrid-Barcelona route in Spain. At one stage the possibility of constructing two variants along the length of this route was considered a way of reducing the journey time by rail. The investment required for constructing these variants exceeded $\$ 1$ billion and the journey time would fall from $6 \mathrm{~h} 30 \mathrm{~m}$ to approximately $5 \mathrm{~h} 30 \mathrm{~m}$.

Once again, the application of demand modeling techniques allows us to quantify this effect. The expected result for the capture of new demand was relatively insignificant.

This conclusion should be analyzed in light of the fact that there are 62 flights a day in each direction between Madrid and Barcelona, with fares similar to those of the railway at certain times of the day.

The two preceding illustrative examples lead to the following reflections: 
1) On occasion, reducing the journey time by rail below a certain level may imply an unsuitable and unnecessary investment (first example).

2) On occasion, investing to reduce the journey time by rail, but keeping this time above a certain level, may imply an investment that is of little interest to the railway (second example).

Based on the above reflections, it is advisable for each railway route under consideration to establish the journey time ("objective"). This will depend on, among other variables, the transport market conditions corresponding to the route in question.

Figure 3 shows that for railway to achieve market shares, with respect to other transport modes, of around 48 percent, it is not necessary to achieve the same journey time over the same distance, or a similar commercial speed. For a lower market share level $(\sim 40 \%)$, a French example and a German example illustrate the same point.

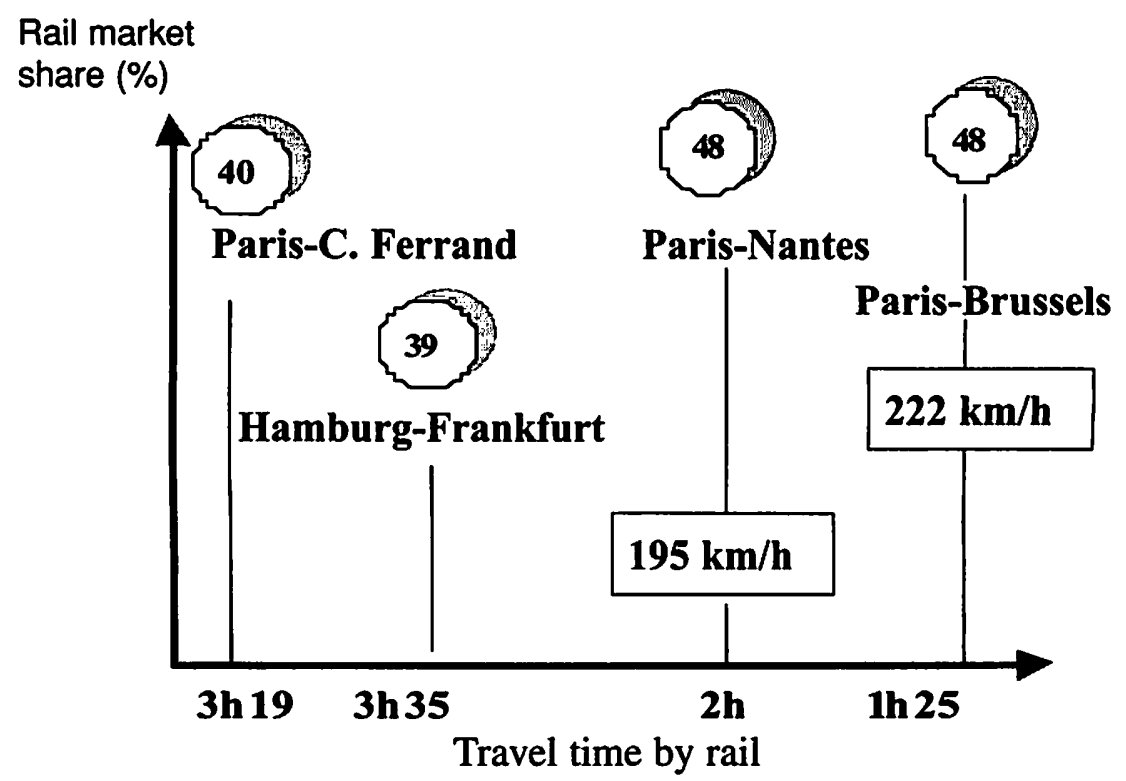

Source: López-Pita (2000).

Figure 3. "Objective travel time" in some European relationships 
Each route considered here is a singular case and requires specific analysis.

In summary, the goal is to establish an investment policy that will make it possible to increase rail transport, and at the same time generate a growth in economic activity on the corridor concerned.

\section{Application to the Spanish Case}

The Spanish railway carries out its activity within the framework of a transport system in which the two principal modes, air transport and road transport, have reached levels of quality and development that are unlikely to undergo major modifications. In this context, it is important to address the role of the Spanish railway in the 21st century within the sphere of intercity passenger services.

For this purpose, a series of studies was carried out in relation to the main corridors, basically radial routes linking Madrid with the rest of Spain's provincial capitals. The objective was to specify the practical significance of the "attractive railway offer" concept. This concept encompassed three aspects:

1) The need to optimize the financial resources allocated to railway investments, especially at a time when European governments are attempting to achieve a zero public deficit.

2) The suitability of achieving a significant presence of the railway, in terms of market share, to reduce the excessive demand that burdens other modes of transport.

3) The need to achieve a positive economic balance in the operation of the lines.

From a practical point of view, the methodological process consisted of analyzing, for each route considered, the effect of reducing the existing journey time by rail. In general, two or three inferior times were considered and their effect was quantified in terms of:

- investment required,

- traffic the railway could capture,

- the railway's share of the market, and

- economic balance for the operator, including the possible need to acquire new rolling stock. 
The use of certain complementary indicators, such as the investment relating to the increase in traffic or the additional investment for achieving a certain additional increase in traffic, made it possible to immediately choose the most advisable investment alternative and, therefore, the objective journey time associated with it. Figure 4 shows the results obtained. The construction projects necessary for implementing the scheduled investments are currently in the process of being drawn up.

\section{Conclusions}

This article has highlighted the fact that investment in the railway aimed at improving the quality of intercity passenger services cannot be based on apriorisms about the type of action: construction of new lines or utilization of tilting-body vehicles.

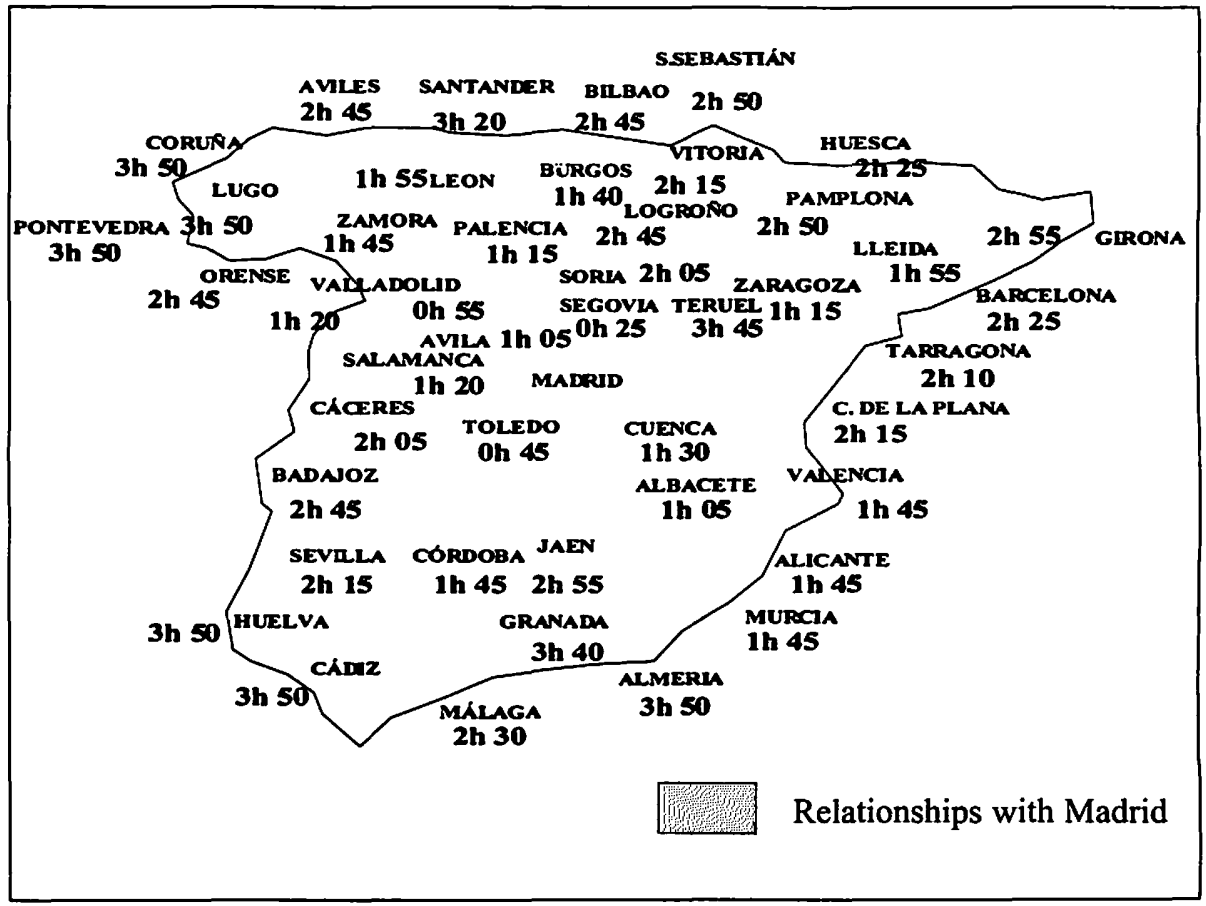

Source: Ministerio de Fomento (2000).

Figure 4. Investment program in railway infrastructures 2000-2007 objective travel lines 
With regard to each country and each route considered, it is necessary to carry out an analysis that determines the most suitable course of action from the commercial and financial points of view.

The Spanish railway has adopted a methodology based on finding the "objective time" of each route (i.e., the service quality that optimizes financial resources and performances).

The evaluation of the "objective time" is the end result of a process that considers a series of journey times by rail that are inferior to the existing time, and selecting them by comparison with those offered by road or air transport.

This methodology has been applied to the Spanish railway and has made it possible to avoid approaches based on radical, generally willful hypotheses, or approaches based on hypotheses that have an insufficient effect on the improvement of the rail service.

\section{References}

Button, K. 1993. High speed rail transport. Its role in the U.K. The third International

Conference on Economics of Innovation. The case of the high speed rail, Piacenza, Italy.

López-Pita, A. 1999. Tilting trains and line construction. Ministerio de Fomento.

López-Pita, A. 2000. El tiempo óptimo de viaje y las decisiones de actuación en un corredor ferroviario. IV Congreso de Ingenieria del Transporte, Valencia, Spain, 4: 2103-21011.

Mireaux, J. 1985. Le projet de nouvelle lere clase. Revue Générale des Chemins de Fe, October: $35-42$.

Walrave, M. 1970. L'analyse de la demande. Revue Générale des Chemins de Fer March: 70-80.

\section{About the Authors}

ANDRÉs LóPEZ-PITA (andres.lopez-pita@upc.es) is a lecturer in railway engineering and director of the Center for Transportation Innovation at the Technical University of Catalonia. He has several years of research experience in transportation planning. He has been a member of the board of directors of Spanish railways. 
FranCESC RobusTÉ (f.robuste@upc.es) received his Ph.D. in engineering at the Technical University of Catalonia at Barcelona, and a master of science in operations research and master of engineering in transportation at the University of California at Berkeley. He is an associate professor of transportation and academic secretary of the Civil Engineering School at Barcelona. Dr. Robusté is the author of 146 publications and a member of the editorial board of Transportation Research (1992-2000). 


\title{
A Rural Transit Vehicle Management System and Condition Predictor Model
}

\author{
Michael D. Anderson and Adam B. Sandlin \\ The University of Alabama in Huntsville
}

$\overline{\text { Abstract }}$

In an ongoing effort to improve mobility and quality of life for Alabama's citizens, a computer database system has been developed to improve the State's ability to manage and assess the condition of its rural transit fleet. The development of this management program consisted of a physical inspection of all state-owned vehicles. Upon completion of the physical inventory, the research team developed a vehicle inventory database to track Alabama's public transit vehicles and a data model to predict the condition of individual vehicles. The prediction model is presented as a tool to allow the State Department of Transportation to assign an individual vehicle condition rating for each vehicle, without the cost of a physical inventory. This vehicle rating is intended to support the equitable acquisition and disposal of vehicles reflecting the varied roadway conditions and socioeconomic conditions found statewide.

\section{Introduction}

Personal mobility is a vital component of an individual's welfare and quality of life. However, in many rural areas of Alabama, a large portion of the residents lack the resources or ability to provide for their own mobility and are dependent on the State's rural transit program. Alabama's rural public transit system (49 U.S.C. Section 5311) consists of 27 individual operators located 
throughout the State, with each operator responsible for a geographical area in the state ranging in size from one to nine counties (University Transportation Center for Alabama 2000). The vehicles comprising this fleet are generally 15passenger standard vans or cutaway chassis vehicles seating between 17 and 21 passengers. The rural transportation program in Alabama provides residents with needed transportation services for shopping, medical, social/recreational, and other trip purposes.

To maintain the rural public transit fleet in the best operating condition, a fleet management system has been developed to improve the State's ability to assess the condition of its rural transit fleet and better justify vehicle acquisition strategies. The program consists of a physical inspection of all state-owned vehicles to verify vehicle identification numbers and collect current mileage, age, and overall condition of the vehicle based on physical appearance, perceived passenger comfort level, and maintenance needs. The data collected will be used to develop a vehicle inventory database to track Alabama's public transit vehicles, and design a data model to predict the condition of individual vehicles based on vehicle age, mileage, roadway conditions, and general countywide or regionwide statistics. The prediction model will be presented as a method to assess vehicle condition, without the cost of a physical inventory, to support the equitable acquisition and disposal of vehicles reflecting the varied roadway conditions found statewide.

This article explores how the statewide vehicle inventory database was developed, and the design of the vehicle condition predictor model. It presents the results of the physical inventory, the database development to manage the existing and expanded fleet, and the predictor model developed to assess a condition rating for rural public transit vehicles to be used for vehicle acquisition and disposal decisions in future years. The article concludes with some analysis of the variables used in the predictor models such as the influence of regional income levels and the impact of nonpaved roadways on vehicle condition.

\section{Data Collection Effort}

The data collection effort involved an on-site inventory of all rural public transit vehicles in Alabama. An inventory form was developed to assist in the data 
collection process. The form was used by the examiners as they walked around the vehicles from the front driver's side to the rear (Figure 1). Items collected on the form include vehicle identification number, mileage, seating capacity, and vehicle type. In addition to these basic data elements, each inspector was required to assign a condition rating to the vehicle based on its physical appearance, perceived passenger comfort level, and maintenance needs. Possible condition ratings were excellent, good, fair, poor, and bad, with each being assigned a number from four to zero, respectively. The condition ratings assigned to the vehicles were intended to define the urgency of each vehicle with respect to replacement. For example, a vehicle given a "bad" rating should be replaced immediately as it is no longer considered safe and comfortable for passenger transit. A vehicle with a "poor" rating is one that might need to be replaced, however, it is not an urgent matter. See Anderson (2000) for a complete review of col-

\begin{tabular}{|c|c|c|c|}
\hline $\begin{array}{l}\text { Regislered Owner } \\
\text { Mame }\end{array}$ & Baldwin County & & \\
\hline Vin Number & 1FDKE30G2NHB65013 & Verificalion 1999 & ai \\
\hline $\begin{array}{l}\text { Chassis } \\
\text { Manufacturer }\end{array}$ & Ford & Design Capacity & 17 \\
\hline Mileage & 219360 & Vehicle Type & CV \\
\hline $\begin{array}{l}\text { Body } \\
\text { Manufacturer }\end{array}$ & Supreme & Model Year & 1993 \\
\hline $\begin{array}{l}\text { Body Serial } \\
\text { Number }\end{array}$ & NO 8454 BS 25 & Federal Program & 5311 \\
\hline Tag Number & $19120 \mathrm{CO}$ & Dellvery Date & $10 / 2 / 92$ \\
\hline Lift_Equipped & 9 & & \\
\hline Lift Manufacturer & Braun & $\begin{array}{l}\text { Year } \\
\text { Yearement }\end{array}$ & \\
\hline Stations & 2 & Total Cost & $\$ 40,614.00$ \\
\hline Comments: & UAH condition raling $=$ poor & & \\
\hline
\end{tabular}

Figure 1. Inventory collection form 
lected data. To ensure consistency in the condition rating between different data collectors, all people associated with the vehicle inventory calibrated their condition rating using a single agency, with the Alabama Department of Transportation present. This calibration exercise, which included discussion of features and conditions, was used to ensure that all data collectors were assigning consistent ratings. The data collection effort required approximately 600 hours of work and was performed for a period of three months.

\section{Database Development}

The database was designed to allow for new vehicle acquisition, annual updates, and vehicle disposals. Using Microsoft's Access Database program (Microsoft Corporation), a table was developed containing all required fields to support these three stages in a vehicle's life. Then, separate data entry and report forms were developed to review, alter, or enter specific vehicle information. (See Figures 2 and 3 for examples of the forms for vehicle acquisition and disposal.)

\section{Vehicle Predictor Model}

In addition to the vehicle database, a vehicle condition rating predictor model was developed to identify vehicles in need of replacement in future years without the costly physical inventory. Initially, it was assumed that the vehicle condition rating would be a function in the form

Vehicle Condition Rating $=f($ age, mileage $)$.

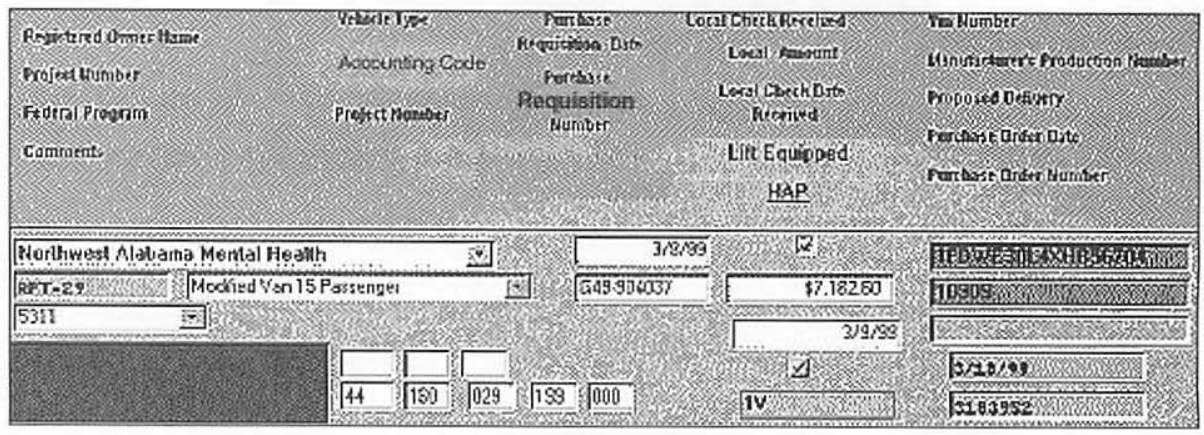

Figure 2. Vehicle acquisition form 


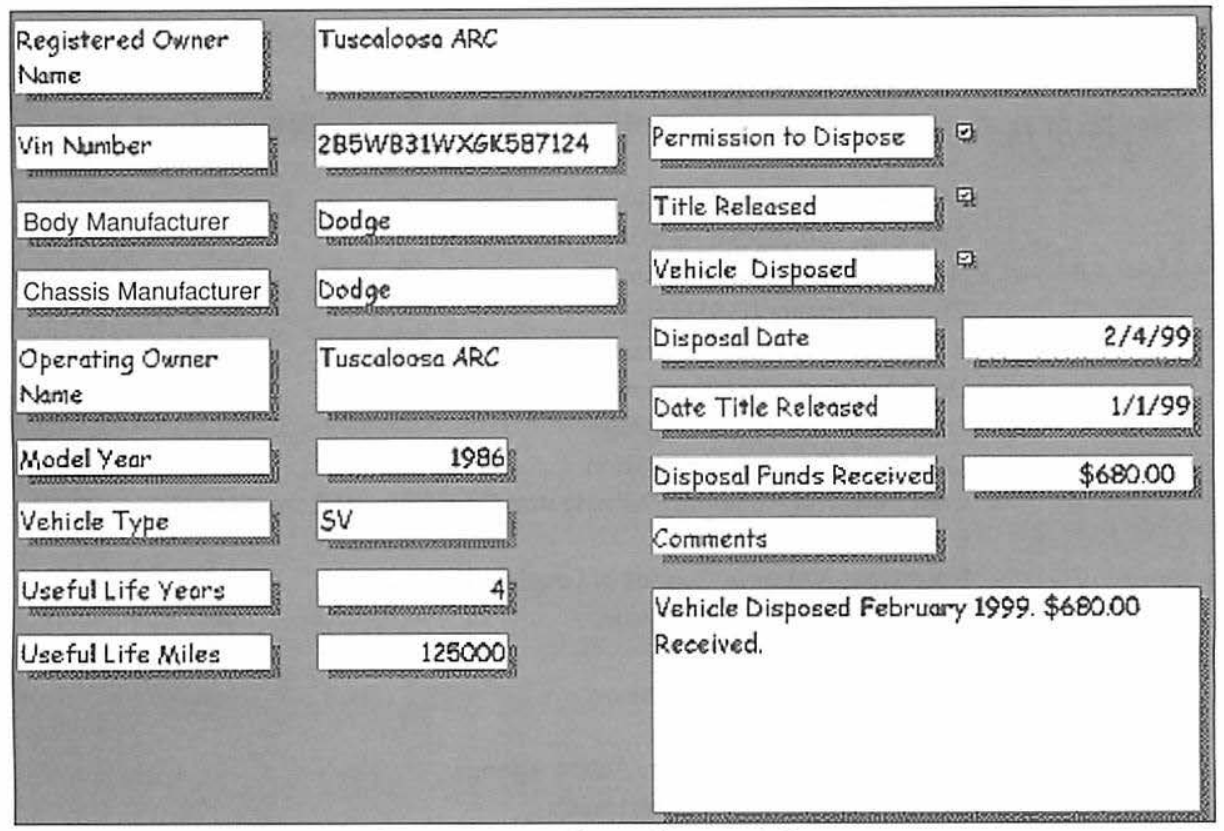

Figure 3. Vehicle disposal form

However, when the database records were entered into a regression analysis using these two variables, the prediction equation for the vehicles was:

Vehicle Condition Rating $=3.975-0.243$ (age) -0.00000445 (mileage)

The best adjusted correlation coefficient (adjusted $R$ squared) for the data was only .52. The model was predicting just over half of the variables necessary to determine the condition rating. However, using this equation and a sample rural transit vehicle driven 20,000 miles per year, the decrease in vehicle condition rating would drop to approximately zero after 12 years of operation.

Applying Equation (2) to determine vehicle acquisitions, Table 1 shows a comparison of the anticipated number of vehicles each agency would receive (70 total vehicles as would be purchased in a typical year) using the physical inventory results and Equation (2). The number of vehicles each agency would receive using the physical inventory was developed by ordering the vehicles with respect to age and mileage, then selecting the 70 oldest vehicles with highest mileage used to break ties between vehicle age. Using Equation (2), the 70 vehicles with 


\begin{tabular}{|c|c|}
\hline \multicolumn{2}{|c|}{$\begin{array}{c}\text { Table } 1 \\
\text { Vehicle Acquisitions Using Equation (2) }\end{array}$} \\
\hline \multicolumn{2}{|c|}{ Physical Inventory } \\
\hline 25 & West Alabama Health Services \\
\hline 7 & Alabama Tombigbee Regional Commission \\
\hline 6 & Baldwin County Commission \\
\hline 5 & Cullman County (CARTS) \\
\hline 4 & Blount County Public Transportation \\
\hline 4 & DeKalb County Commission \\
\hline 3 & Lawrence County Commission \\
\hline 2 & Covington County Commission \\
\hline 2 & East Alabama Regional Planning and Development Commission \\
\hline 2 & Exceptional Children \\
\hline 2 & Northwest Alabama Council of Local Governments \\
\hline 1 & Cleburne County Commission \\
\hline 1 & Decatur, City of \\
\hline 1 & Escambia County Commission \\
\hline 1 & H.E.L.P. Inc. \\
\hline 1 & Macon Russell Community Action Agency \\
\hline 1 & Northwest Alabama Mental Health \\
\hline 1 & Shelby County Commission \\
\hline 1 & Southeast Alabama Regional Planning \& Development Commission \\
\hline 70 & Total vehicles \\
\hline \multicolumn{2}{|c|}{ Equation (2) } \\
\hline 34 & West Alabama Health Services \\
\hline 6 & Alabama Tombigbee Regional Commission \\
\hline 5 & Northwest Alabama Council of Local Governments \\
\hline 4 & Blount County Public Transportation \\
\hline 3 & Baldwin County Commission \\
\hline 3 & Exceptional Children \\
\hline 2 & H.E.L.P. Inc. \\
\hline 2 & Lawrence County Commission \\
\hline 2 & Northwest Alabama Mental Health \\
\hline 2 & Southeast Alabama Regional Planning \& Development Commission \\
\hline 1 & Covington County Commission \\
\hline 1 & Cullman County (CARTS) \\
\hline 1 & DeKalb County Commission \\
\hline 1 & Escambia County Commission \\
\hline 1 & Jackson County Commission \\
\hline 1 & Macon Russell Community Action Agency \\
\hline 1 & Morgan County Commission \\
\hline 70 & Total vehicles \\
\hline
\end{tabular}


the lowest vehicle condition rating were selected. Examining Table 1 shows that the simple vehicle condition rating predictor model seems to identify the same general list of agencies that are in need of replacement vehicles as the physical inventory. However, the number of vehicles that each agency would be entitled to purchase under this model showed some wide variation.

For the 70 vehicles that would be acquired following the calculated rating in Table 1, all had a calculated vehicle condition rating less than 1.34. If the State wanted to remove all vehicles in less than "fair" condition, it would need to replace 216 vehicles (out of 483 vehicles, or $45 \%$ ), as the average calculated vehicle rating was 2.06. (For comparison, the physical inventory average rating was 2.02.) Reviewing the results of the simple model formulation, the model to predict vehicle condition rating presented in Equation (2) provides a reasonable method to predict vehicle condition as the average condition rating and acquisitions per agency were similar. However, with the high degree of uncertainty in the model and the differences in vehicle acquisitions, it might be difficult to convince representatives from all agencies that this model produced the most equitable distribution.

To improve the prediction equation, it was recalled that while conducting the physical inventory some relatively new vehicles were determined to be in "poor" or "bad" condition due to external factors, such as engine troubles or faulty air conditioners. It was hypothesized that these vehicles were having a negative influence on the predictor model, essentially introducing uncertainty in the model as these vehicles did not follow the typical vehicle pattern and would therefore be considered problem vehicles that would be replaced independently from the population of typical vehicles. Therefore, the physical inventory records were reviewed and 24 vehicles that received low condition ratings based on maintenance or other mechanical problems were removed from the sample. After this operation was performed, a new predictor model based on mileage and age was developed (although miles per year was used instead of total mileage):

Vehicle Condition Rating $=4.07-0.258$ (age) -0.000026 (mile/yr) 
The best adjusted correlation coefficient (adjusted $R$ squared) for the data improved to .62. Although this new equation improved the adjusted $R$-squared value, application of this equation predicted the highest calculated vehicle rating for the 70-vehicle replacement scenario being 1.27 ; the average calculated rating continued to be 2.06, while the physical inventory increased to equal 2.06 .

To further improve the vehicle predictor model, other factors beyond age and mileage that might possibly affect the rural public transit fleet condition were introduced into the equation. Additional factors included varying roadway conditions encountered while traveling in the State (essentially the percentage of unpaved roadway in the county or region multiplied by vehicle miles of travel) and socioeconomic measures for the county or region. Table 2 shows all the variables that were added to the vehicle predictor model.

When entering these values into MINITAB (a commercial statistics software), it was determined that seven of the variables were insignificant in the prediction of condition (MINITAB, Inc.). This left a nine-variable prediction equation for determining vehicle condition rating, presented as

Vehicle Condition Rating $=2.01-0.255$ (Age) -0.000070 (mile/yr on unpaved roadways) -0.155 (lift equipped) -0.000002 (population) +20.4 (\% 1-person households) -1.51 (\% who work inside the county $)+96.8$ (\% transit commuters $)-7.60$ (\% poverty) -0.0253 (household density).

The best adjusted correlation coefficient (adjusted $R$ squared) for the data improved to .67. Again, the calculated average vehicle condition rating for the fleet was 2.06, which equaled the physical inventory average for the fleet. In addition, this model was tested for linearity (through a plot of the residual values) and distribution of variables (through a plot of residual values versus variables in the model), as prescribed in a common statistical text (Montgomery and Peck 1992). Table 3 shows vehicle distribution using the physical inventory and Equation (4). 


\begin{tabular}{|l|}
\hline \multicolumn{1}{c|}{ Table 2} \\
Variables Added to Improve Predictor Equation \\
\hline Age of the vehicle \\
Miles per year driven on paved roadways \\
Miles per year driven on unpaved roadways \\
Land accessible via unpaved roadways \\
Does the vehicle have a wheelchair lift? \\
Population of county or region \\
Percent of population making less than $\$ 15,000$ \\
Percent of population older than 65 \\
Percent of population younger than 18 \\
Percent of one-person households \\
Percent minority \\
Percent working inside the county \\
Percent working outside the county \\
Percent commuters on public transit \\
Percent in poverty \\
Households per square kilometer \\
\hline
\end{tabular}

\section{Agency-Wide Vehicle Model}

After the data collection process was completed, it was decided to determine if there were any socioeconomic factors affecting the average vehicle condition rating for an entire agency. To perform this test, condition rating, age, and mileage were averaged to determine the agency statistics. The socioeconomic data used to determine the individual condition rating were added to the agency averages to determine the expected vehicle condition for each agency. Again, using MINITAB, the best equation for average condition rating is

Avg. Vehicle Rating $=0.58-0.239$ (avg. age) -0.000033 (avg. mile/yr paved) - 0.000055 (avg. mile/year unpaved) - 3.73 (\% income $<\$ 15,000)-0.000003$ (population) $+1.79(\%$ pop older than 65$)-$ $1.02(\%$ pop under 18$)+21.0(\%$ 1-person households $)-2.48(\%$ minority) +1.21 (\% work outside county) +150 (\% commuters public transit) 


\begin{tabular}{|lcc|}
\hline \multicolumn{1}{|c|}{ Table 3} \\
Vehicle Acquisitions & \\
\hline & & \\
\hline West Alabama Health Services & Equation (4) & $\begin{array}{c}\text { Physical } \\
\text { inventory }\end{array}$ \\
Alabama Tombigbee Regional Commission & 32 & 31 \\
Northwest Alabama Council of Local Governments & 7 & 7 \\
Baldwin County Commission & 6 & 5 \\
Cullman County (CARTS) & 3 & 4 \\
Blount County Public Transportation & 3 & 4 \\
Covington County Commission & 3 & 3 \\
Exceptional Children & 3 & 3 \\
DeKalb County Commission & 2 & 3 \\
Escambia County Commission & 2 & 2 \\
Lawrence County Commission & 2 & 2 \\
Jackson County Commission & 2 & 2 \\
Northwest Alabama Mental Health & 2 & 1 \\
Morgan County Commission & 1 & 1 \\
H.E.L.P.Inc. & 1 & 1 \\
\hline Total vehicles & 1 & 1 \\
\hline
\end{tabular}

The best adjusted correlation coefficient (adjusted $R$ squared) for the data was .67 .

\section{Results}

For Equation (4), the vehicle acquisition pattern statewide very closely follows the physical inventory conducted (Figure 4).

An examination of individual variables that contribute to the condition rating shows, as would be expected, the older the vehicle the lower the condition rating. One interesting aspect of the equation is that amount of travel on paved roads had no significant impact on vehicle condition; however, the amount of travel on unpaved roadways had a significant impact with the decrease in vehicle condition rating. In fact, the likelihood that a vehicle would experience unpaved roadway travel had a large influence on the vehicle condition rating, and no agencies with less than 24 percent unpaved roadways (with the exception of the Jackson County Commission's one vehicle) would be entitled to acquire any vehicles.

A vehicle-specific factor that tended to lower the condition rating was whether the vehicle had a wheelchair lift. The authors believe that these vehicles 


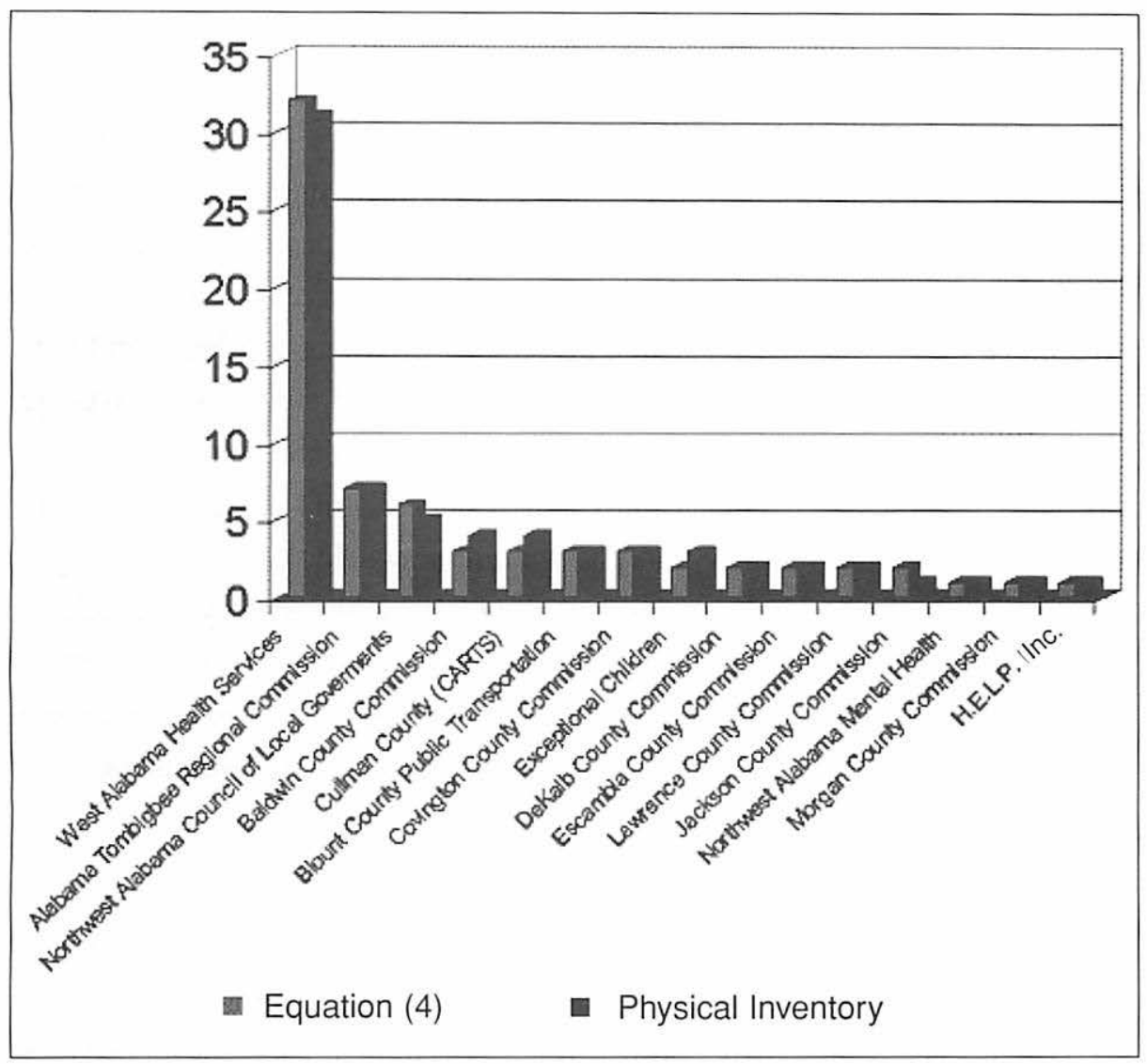

Figure 4. Vehicle acquisitions using Equation (4) and physical inventory

received a lower score based on the wear and tear and extra maintenance requirements for wheelchair-lift vehicles. Statewide there are 119 wheelchair-lift vehicles, and the 70-vehicle acquisition scenario identified 14 of these vehicles.

Countywide or regionwide socioeconomic factors including population, percentage of the population living in poverty, and percentage of individuals working inside the county all generally reduce the vehicle condition rating; whereas having a large percentage of one-person households tended to increase the vehicle condition rating. Interestingly, agencies reporting a high amount of commuters who use public transit actually had improved vehicle condition ratings. The authors believe agencies with an increased percentage of riders are required to keep vehicles in better condition to retain the high usage. 
In examining the average vehicle condition ratings for an agency and vehicle and socioeconomic factors, the data showed that increases in age, mileage on paved roads, and mileage on unpaved roads all decreased vehicle ratings. When comparing paved to unpaved roadways, the average travel on unpaved roadway mileage accounted for more than 62 percent of the vehicle condition rating reduction experienced for total travel. Increases in population, percentage of low-income residents, percentage of young residents, and percentage of minorities in a county or region all reduced the agency's average vehicle condition rating. The authors believe these socioeconomic factors, especially low-income residents and young residents, limit an agency's ability to generate matching funds required to acquire new vehicles even if an equitable distribution of vehicle acquisition would allow the agency to purchase more vehicles. Socioeconomic factors that allow an agency to increase average vehicle condition ratings are percentage of one-person households, percentage of residents who work outside the county, and percentage of commuters.

\section{Conclusions}

The State of Alabama's commitment to improve the mobility and quality of life for its citizens was the driving force behind the physical inventory. Developing an inventory system and vehicle condition prediction model to identify vehicles that should be replaced will help ensure that an agency's need for new rural public transit vehicles is identified. This improved ability to identify vehicles in need of replacement through the agency's submission of annual mileage and vehicle age reports (which are currently required) will enable the Department of Transportation to establish a vehicle acquisition schedule without the costly physical inventory. Overall, application of the vehicle condition predictor model will allow the state to allocate new vehicle purchases in an equitable pattern to ensure all residents are traveling in the best possible vehicles.

\section{Acknowledgments}

The authors would like to thank the Alabama Department of Transportation Multimodal Transportation Bureau for funding this study, and all 5,311 agencies in Alabama for cooperating with the individuals conducting the vehicle inventory. 


\section{References}

Anderson, M. D. May 2000. Vehicle inventory of Alabama's 5,311 rural transit fleet. Developed for the Alabama Department of Transportation Bureau of Multimodal Transportation, Montgomery, AL.

Microsoft Corporation. Microsoft Access 97. Redmond, WA.

MINITAB Inc. MINITAB statistical software, Release 13.20. State College, PA.

Montgomery, D. C. and Peck, E. A. 1992. Introduction to linear analysis 2 nd ed. New York: Wiley Publishing.

University Transportation Center for Alabama (UTCA). August 2000. Alabama public transportation needs assessment. Tuscaloosa, AL: University of Alabama.

\section{About the Authors}

MiChaEl D. ANDERSON (mikea@cee.uah.edu), an assistant professor of civil engineering at the University of Alabama in Huntsville, is working on rural public transportation and transportation forecasting. Dr. Anderson teaches courses in traffic engineering, urban planning, and Geographic Information Systems. He received his Ph.D. from Iowa State University in 1998.

ADAM B. SANDLIN (adamsan@hiwaay.net) is a graduate student studying civil engineering at the University of Alabama in Huntsville. Mr. Sandlin is a graduate of the university with a degree in engineering from the Department of Civil and Environmental Engineering. 


\section{Decision Structuring and Robustness Analysis in Selecting Urban Transit Alternatives}

Isam A. Kaysi and Mohamed-Asem U. Abdul-Malak American University of Beirut

\section{Abstract}

Public policy-makers in many cities worldwide have recognized the need to seek urban passenger transport solutions in the domain of urban transit systems. However, with the availability of many transit technologies and systems, decision-makers need support in identifying the advantages and disadvantages of each system, and in evaluating their suitability for the specific urban context being considered.

In this article, the Analytical Hierarchy Process (AHP) is proposed as a decision-support methodology for evaluation of urban transit systems. A hierarchy is proposed for the evaluation of system choice, and an illustrative example is presented. The hierarchy reflects overall objectives of transit systems, which include achieving betterment in the urban transport picture and mitigating possible implementation impediments. On the betterment side, the transit system objectives considered in the hierarchy include appropriate level of service and performance, congestion reduction potential, support of economic development, and flexibility. On the other hand, transit system impediment factors comprise system cost, environmental impacts, and implementation and operation barriers. The article demonstrates the value of the proposed approach in decision structuring for selecting among urban transit alternatives and in providing the facility of analyzing the robustness of the decision with respect to various judgments that are made in the selection process. 


\section{Introduction}

Many cities around the world have realized that they cannot satisfy mobility and accessibility needs of their inhabitants by relying solely on transport facilities serving private automobile travel. Recent findings (Newman and Kenworthy 1999) have indicated that automobile-dependent cities are proving to be very costly in economic and environmental terms, and that there is a need to move toward a modal split which is less automobile-oriented. As such, public policy-makers worldwide have recognized the need to seek urban passenger transport solutions in the domain of urban transit systems. However, with the availability of many transit technologies and systems, decision-makers need support in identifying the advantages and disadvantages of each system, and in evaluating their suitability for the specific urban context being considered.

In this article, the AHP is proposed as a decision-support methodology for evaluation of urban transit systems. The proposed approach is quite helpful in decision structuring for selecting among urban transit alternatives due to its flexibility in incorporating a decision hierarchy and associated judgments. Moreover, it facilitates robustness analysis of the transit technology selection decision with respect to various judgments that are made in the selection process.

This article presents a brief description of urban transit systems and their characteristics. It discusses a number of methods that have been utilized in the evaluation of urban transit alternatives, and provides an overview of the AHP. In addition, the hierarchy being proposed for the evaluation of urban transit systems is presented, followed by an illustrative example.

\section{Transit Alternatives and Characteristics}

The most common urban transit technologies typically include motor buses, light rail, and heavy rail (Canadian Urban Transit Association 1993). The most widespread technology of urban transit is the motor bus, which comes in several sizes (small rigid, standard rigid, and articulated), and its common use of shared right-of-way represents a clear cost advantage over transit technologies that require special supporting infrastructures. Urban buses may also operate on exclusive busways, and can provide local and express services.

Light rail represents another urban transit technology and provides a 
means of separating transit vehicles from other traffic. Light rail transit (LRT) embodies some benefits of rail transit in that it provides greater capacity and operates at relatively high speeds. At the same time, it may be implemented at a relatively low cost if the system shares readily available rights-of-way with other street traffic.

Heavy rail systems operate with full protection of the right-of-way, thus enabling high-speed operation and providing high line capacities with reasonable fleet size. In dense urban areas and city centers, right-of-way protection is typically provided by an underground alignment, with elevated and at-grade guideways also being common. Extensive supporting infrastructure is required for heavy rail to take advantage of the speed and capacity capabilities inherent in the technology. Such infrastructure includes high-level loading and offboard fare collection, thus resulting in relatively complex station structures.

\section{Evaluation Methods for Urban Transit Alternative}

This section examines several methods used to evaluate urban transit alternatives.

\section{Conventional Evaluation Methods}

In traditional, single-criterion evaluation methods, all benefits and costs are reduced to monetary terms. The present worth, annual cost, benefit to cost, and rate of return methods all fall into this category, since maximization of net benefits is the single objective of concern. However, transportation planning (including evaluation of urban transit alternatives) typically deals with many objectives that reflect the interest of the community (e.g., cost, capacity, level of service, and environmental impacts).

As such, the Multicriteria Evaluation Method may be used to address such cases. In this method, the planner defines a number of measures of effectiveness for system objectives, and then assigns values to each alternative based on collected data. With use of weighting factors for objectives, a composite score is determined for each alternative, with the alternative with the highest score being the preferred one (Khisty 1990; Janarthanan and Schneider 1986).

Two other techniques address the multicriteria and multiple-goal nature of urban transportation problems (Dickey 1983). In the Goals-Achievement 
Technique, each potential project alternative is assessed in terms of its impacts with respect to the proposed objectives. Quantitative measures are employed in this process, although some may be subjective and even probabilistic.

On the other hand, in the application of the Cost-Effectiveness Analysis, the attributes of the alternative are separated into two classes-costs and indicators of effectiveness, or the degree to which an alternative achieves the set objectives. The Cost-Effectiveness framework is useful in that it illustrates trade-offs between alternatives and identifies dominated systems.

\section{Other Evaluation Methods and Applications}

An evaluation of alternative transit system configurations that could best provide service in travel corridors within the Greater Milwaukee area is reported in Meyer and Miller (1983). Transit system plans were developed and then evaluated for each alternative future scenario based on measures of transit ridership, cost, and cost-effectiveness. A total of 21 plans were tested and evaluated, and the elements of the plans not meeting tests for cost-effectiveness were eliminated from further consideration, and the resulting "truncated" plans were then reevaluated.

An evaluation of high-speed rail alternatives along two main corridors in Greece combined three existing evaluation methods, namely financial analysis, cost-benefit analysis, and multicriteria analysis (Tsamboulas et al. 1992). Financial analysis was carried out at the first stage of the evaluation process to determine the commercial viability of the system to be executed, while cost-benefit analysis was carried out to quantify and evaluate the various impacts of the project from the national economic point of view. Moreover, since benefit-to-cost could only evaluate a single criterion, multicriteria analysis was used to overcome this difficulty and to account for nonquantifiable impacts. Evaluation criteria included transport, environmental, regional development, and safety considerations.

A different approach was adopted for providing technical support to decision-makers charged with evaluating transit technologies to be possibly implemented in British cities. The adopted approach attempted to capture the knowledge base of experts in cities in continental Europe regarding factors influenc- 
ing choice of public transport technology, and developed this experience into an expert system, a form of artificial intelligence (Mackett 1994). The knowledge base was designed to incorporate information regarding characteristics of transit technologies, systems used in different cities, and cost considerations.

Finally, multiattribute utility theory, a normative model of decision making, was used to evaluate different system designs and technologies associated with the emerging field of Advanced Public Transportation Systems (Reed et al. 1994). It is argued that multiattribute utility theory provides decision support in environments involving multiple, possibly conflicting, objectives by decomposing tasks, such as transit system design, into smaller issues and by requiring a priori elaboration of design objectives. In one presented example, the hierarchy for transit system design had system implementability, satisfaction, and affordability as overall objectives.

\section{AHP Evaluation: Background and Structur}

The AHP is a methodology for solving complex problems that involve many criteria using the knowledge, expertise, and judgment of the decisionmaker. By applying this technique to the transit system evaluation problem, transit planners are provided with a hierarchy in which all relevant factors are organized in a logical and systematic way from the goal to the factors and subfactors and down to the transit system alternatives. Moreover, it facilitates robustness analysis of the transit technology selection decision with respect to various judgments that are made in the selection process.

Expert Choice, an AHP-based decision analysis software, was used to conduct automated analyses of the designed hierarchy; the basic principles of AHP are covered in the literature (Saaty 1980; Skibniewski and Chao 1992). In the AHP evaluation procedure, planners of transit systems are asked to judge the elements of the hierarchy as to their relative importance. The judgments are made using pairwise comparisons on a one-to-nine numerical scale or its verbal equivalent. The pairwise comparisons are then synthesized to rank the alternatives from which the choice is to be made.

The strengths of AHP include its sound mathematical basis, its ability to integrate subjective judgments into the overall evaluation in a structured and 
consistent manner, and the possibility of incorporating both qualitative as well as quantitative decision criteria. While the AHP provides a unique decisionstructuring tool that ranks the alternatives being considered, it does not eliminate the need for conducting further analysis that may be warranted to, for example, assess the financial, economic, or environmental viability of the preferred alternative.

\section{The Evaluation Hierarchy}

This section examines the hierarchy proposed for the evaluation of urban transit systems.

\section{System Objectives}

In general, a transit system should achieve betterment in the urban transport picture and needs to mitigate possible implementation impediments. On the betterment side, transit systems are perceived to offer a wide variety of benefits; methods to measure such benefits have been suggested in the literature (see, for example, Horowitz and Beimborn 1995). A synthesis of the literature has resulted in adopting the following transit system objectives in the decisionstructuring and robustness analysis: appropriate level of service and performance, congestion reduction potential, support of economic development, and flexibility (Khisty 1990; Mackett and Edwards 1996).

On the other hand, mitigation of impediments requires that transit system objectives include cost control and cost effectiveness, environmental sensitivity, and implementability (Reed et al. 1994; Mackett and Edwards 1996). An elaboration of the AHP evaluation hierarchy is presented below in terms of system characteristics bearing on both betterment and impediment factors (Figure 1).

\section{Betterment Factors}

As indicated in the proposed evaluation hierarchy (Figure 1), transit system betterment factors include system level of service and performance, congestion relief potential, support of economic development, and system flexibility. The following discussion provides illustrations of specific factors by referring to urban transit systems relying on bus, light rail, and heavy rail technologies. 


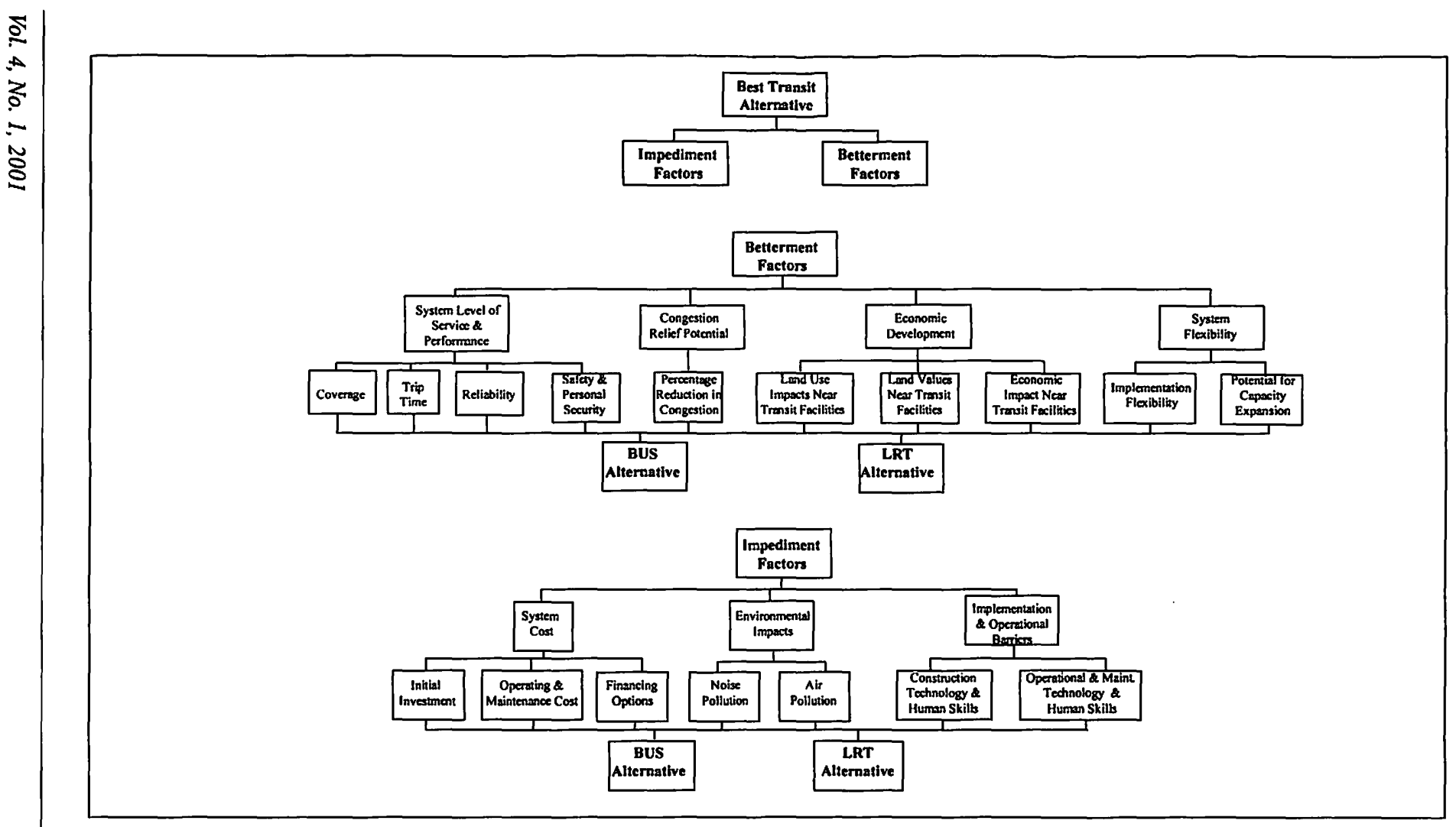


System Level of Service and Performance. Transit system level of service and performance may be related to coverage, trip time, system reliability, as well as safety and personal security concerns. Coverage reflects the area covered by the proposed network and typically includes activities lying within onequarter mile on either side of a transit line (see, for example, Khisty 1990). Trip time represents a significant determinant of transit level of service and is defined as the sum of the in-vehicle and out-of-vehicle time spent to make a certain trip. Total trip time consists of the walk or access time, wait time, station dwell time (loading and unloading), line-haul time (function of the vehicle speed), and egress time. As such, travel times for various urban transport modes depend on operational characteristics that relate to each of the components as evidenced by many studies. One study compared ride time and nonride time for the transitway (bus operating on reserved lane) and light rail, considering a typical route with feeder service at one end and with a connecting (distribution) service at the other end (Nisar and Khan 1992). The study concluded that, due to its more frequent service, the out-of-vehicle time and total trip time for the transitway were less than those for the LRT system. The impact of contra-flow and with-flow (reserved) lanes on travel times of buses and high-occupancy vehicles (HOVs) has also been the subject of research (Flachsbart 1989). Such operational measures have been found to have a significant impact on transit system level of service and its betterment capabilities.

In addition, system reliability has a bearing on the betterment rating of transit systems. One aspect of system reliability reflects the extent of variability in travel time from day to day. In general, transit modes that operate on an exclusive right-of-way provide more reliable service. Another important factor in this context relates to the power source for the transit system. If the system operates on fuel that is mainly imported, or on electric power, and shortages occur in either energy source, then system reliability may be compromised. Finally, safety and personal security on a transit system, being two factors influencing system level of service, are related to accident rates. There is evidence to indicate that the heavy rail transit (HRT) system is associated with a better safety record, followed by the LRT system, then the bus system (Khisty 
1990). Moreover, other evidence indicates that dedicated rights-of-way of HOV facilities are safer than non-HOV facilities as far as accident rates are concerned (ITE Technical Committee 6A-37 1988). In addition, studies have concluded that while the transitway and the LRT options are very good in securing personal safety, the LRT system, with the separated guideway and more controlled at-grade crossings, could be considered slightly safer (Nisar and Khan 1992).

Congestion Relief Potential. The betterment prospect of a transit system may also be related to its potential to reduce congestion in the corridor or travel context of concern, by capturing the maximum number of commuters in the peak hour. The expected ridership on a transit mode reflects the percentage of the peak flow that will be attracted and is a function of coverage, trip time, and headway of the transit system as well as the characteristics of competing modes (e.g., private auto and the jitney). Table 1 provides prototypical values of frequencies, headways, and capacities for a number of transit technologies

\begin{tabular}{|c|c|c|c|c|c|}
\hline \multicolumn{6}{|c|}{$\begin{array}{c}\text { Table } 1 \\
\text { Prototypical Transit System Frequencies and Capacities }\end{array}$} \\
\hline Mode & $\begin{array}{c}\text { Units } \\
\text { per Hour }\end{array}$ & $\begin{array}{l}\text { Vehicles } \\
\text { per Unit }\end{array}$ & $\begin{array}{l}\text { Headway } \\
\text { (seconds) }\end{array}$ & $\begin{array}{l}\text { Max. Passengers } \\
\text { per Vehicle }\end{array}$ & $\begin{array}{c}\text { Capacity } \\
\text { (passengers } \\
\text { per hour) }\end{array}$ \\
\hline \multicolumn{6}{|l|}{ Mixed traffic } \\
\hline Buses & 90 & 1 & 40 & 80 & 7200 \\
\hline Streetcars & 60 & 1 & 60 & 100 & 6000 \\
\hline \multicolumn{6}{|l|}{ Exclusive lanes } \\
\hline Buses & 120 & 1 & 30 & 80 & 9600 \\
\hline Streetcars & 75 & 2 & 48 & 100 & 15000 \\
\hline \multicolumn{6}{|l|}{ Busways } \\
\hline On-line stations & 180 & 1 & 20 & 80 & 14400 \\
\hline \multicolumn{6}{|l|}{ LRT } \\
\hline Rigid Cars & 30 & 6 & 120 & 100 & 18000 \\
\hline HRT & 30 & 9 & 120 & 160 & 43200 \\
\hline
\end{tabular}

Source: Adapted from Canadian Transit Handbook. 1993

Vol. 4, No. 1, 2001 
in different operational environments. (System headway is the time between two successive units in a transit system, and is directly related to frequency of service, waiting time, target system capacity, and required fleet size.)

Economic Development Impacts. In general, land-use impacts near transit facilities are manifested in commercial or residential developments that are attracted to locations close to transit stations. In Toronto, for instance, it was estimated that almost half of high-rise residential development was concentrated in four districts that all have good access to the city's subway (ITE Technical Committee 6A-37 1992). However, this process of development is not automatic since developers would only build new projects near a transit station under favorable circumstances including consumer demand and economic strength. Another factor in this context lies in the increase in land values near transit facilities due to the improved access to transit service and facilities. However, the process of increase in land values depends on the quality of service offered by the transit system (ITE Technical Committee 6A-37 1992) and, in some cases, transit stations may have negative impacts on residential land values due to parking and congestion problems near transit stations.

Moreover, economic impacts near transit facilities represent another potential betterment dimension of transit facilities. In general, urban rail transit promotes efficient metropolitan travel and provides an appropriate environment for economic development, possibly in the form of increased area employment opportunities, quicker travel to retail centers, and location of large office complexes near stations. Such development typically results in a broader community tax base including income, sales, business, and real estate taxes (ITE Technical Committee 6A-37 1992).

System Flexibility. The two main factors characterizing transit system flexibility relate to implementation flexibility and the potential for capacity expansion. The possibility of the transit technology option being implemented in phases bears positively on the system flexibility rating and provides system planners with the ability to customize system design to cater to travel needs on a staged basis. This may be the case, for instance, with dedicated rights-of-way that may be first used for busways and later for light rail. Moreover, a desir- 
able quality of a transit system relates to the potential for capacity expansion that leaves room for incrementally introducing system capacity and/or expanding the system at a future date. For instance, light rail projects may benefit from incremental development and enhancement of service which takes the form of double-tracking single track lines, adding new vehicles, expanding the power system, line extension, and grade separation at important intersections (Larwin 1989).

\section{Impediment Factors}

As indicated in the proposed evaluation hierarchy (Figure 1), transit system impediment factors include system cost, environmental impacts, and implementation and operation barriers. The discussion presented below provides illustrations of specific factors by referring to urban transit systems relying on bus, light rail, and heavy rail technologies.

System Cost and Financing. The initial investment or capital cost of a transit system includes the total price of the fleet of vehicles to be purchased, in addition to the money required to implement the infrastructure needed. The required fleet size is determined based on target system capacity. As such, cost per transit vehicle and cost per kilometer of infrastructure needed constitute the major determinants of capital cost. Service life of a transit asset, defined as the number of years after which it would be no more economical to keep operating the asset, is an important factor that has to be considered in estimating capital renewal costs of different transit technologies. Another component of system costs consists of operating and maintenance costs required to operate and maintain transit equipment, in addition to maintenance of the right-of-way. Unit operating costs per hour of service and per kilometer of service are typically used to estimate time- and distance-based variables or operating costs in transit systems.

Research and available literature (Canadian Urban Transit Association 1993; Dickey 1983; Nisar and Khan 1992; Parody et al. 1990) provide reference values for various system cost aspects including:

- prototypical costs per vehicle and per infrastructure unit;

- operating and maintenance costs for diesel bus and LRT; 
- operating and maintenance expenses and total passenger-miles for bus and subway systems in North America;

- annual operating and maintenance costs for four different rapid transit systems in one English city;

- and economic life for the motor bus, diesel bus, light rail vehicle, heavy rail vehicle, and various other transit assets.

The financing burden of transit systems constitutes another impediment factor. Financing options for transit systems include charges on benefiting properties, joint ventures with the private sector, and marketing and merchandising approaches (Johnson and Hoel 1987; ITE Technical Committee 6Y-33 1988). The extent to which transit system financing constitutes an impediment is related to the differential possibilities offered by various transit system technologies with respect to financing techniques falling within each of the above categories of options.

Environmental Impacts. In many urban areas, transportation is a major source of noise. Hence, excessive noise can lower the quality of life for many, and can seriously interfere with sleep causing stress and, indirectly, stressrelated diseases. As such, noise pollution is introduced in the evaluation hierarchy as an impediment factor with differential values for competing modes. Moreover, since air pollutants emitted from engines of transit vehicles may have significant adverse effects on air quality both on a regional and local scale, air pollution is considered as another environmentally oriented impediment factor. Again, available literature (for example, Khisty 1990; Dickey 1983; Flachsbart 1989; Wayson and Bowlby 1989) provides reference values for engine noise from diesel operation, noise from LRT and HRT (dominated by noise from wheel/rail interaction), commuter exposure to motor vehicle exhaust, and relative capability of the bus, LRT, and HRT to reduce air pollution impacts.

Implementation and Operational Barriers. The basis on which the transit alternatives will be ranked with respect to construction technology and human skills involves the length of time for construction implementation, 
whether the construction technology is imported or locally available, and if imported, whether the technology is too sophisticated for implementation by local workers. For instance, with a bus-oriented transit system, expertise is usually available locally for construction of highways and bus terminals and facilities. On the other hand, the construction sector in many countries may not be prepared to handle projects involving LRT or HRT, especially if tunnels and other underground structures are required. Similar questions have to be posed with respect to operation and maintenance technology and human skills. Are technologies locally available? Are vehicles and routes to be maintained frequently? How much does it cost to import the technology and the human skills? Can the local population be readily trained to operate and maintain the new technology?

\section{Integration with the Political Environment}

The hierarchy presented in Figure 1 provides a solid basis for integrating the AHP-based transit alternatives evaluation approach with the political environment. While the input has to be primarily technical at the system (lowest) level, the hierarchy calls for public input in addition to technical judgments at the subcriteria (second lowest) level. In this regard, public participation meetings can help provide input with respect to relative weights of subcriteria which have a direct bearing on the end-user, such as those below the "System Level of Service and Performance" criterion. Moreover, the task of weighing the decision criteria under the "Betterment" and "Impediment" factors should reflect political priorities prevailing in the selection of viable transit alternatives. Finally, the decision structuring inherent in the proposed AHP-based approach ensures transparency in the decision-making process, a desirable objective in similar undertakings.

\section{Illustrative Example}

To illustrate how the proposed evaluation is performed, a prototypical application involving the selection of an appropriate transit technology for a commuter corridor in the City of Beirut, Lebanon, is considered. The Ministry of Transportation in Lebanon has commissioned a feasibility study to evaluate the possibility of utilizing an old coastal rail right-of-way to provide modern 
mass transit services between the towns of Jounieh and Jiyeh, passing through the City of Beirut. The proposed system is expected to become an integral element in a multimodal alternative to the auto-only transportation environment that currently dominates Greater Beirut. To enhance its chances of success, the mass transit system will provide park-and-ride facilities and will integrate with feeder systems of public and private bus services (IBI Group 2000).

The problem of selecting between the bus (operating mostly as bus rapid transit) and LRT technologies for this corridor is considered. For this purpose, the decision-support software Expert Choice is used. Information on the properties of the bus and LRT systems is assimilated from the literature referred to in the previous sections and used, with adjustments to reflect local conditions when appropriate, in the evaluation process (Table 2).

The first step in the process is to build a well-defined evaluation hierarchy that formulates the decision problem and defines its different levels

\begin{tabular}{|ccc|}
\hline \multicolumn{2}{|c|}{$\begin{array}{c}\text { Table } 2 \\
\text { Input Data Used for Setting Out Priorities }\end{array}$} & LRT \\
\hline & Bus & 25 \\
\hline Coverage (sq. miles) & 30 & 57.9 \\
\hline $\begin{array}{c}\text { Trip time (min.) } \\
\text { Safety (\%) }\end{array}$ & 50.4 & 20 \\
\hline $\begin{array}{c}\text { Pollution noise level } \\
\text { (DBA) }\end{array}$ & 15 & 87 \\
\hline $\begin{array}{c}\text { Air pollution } \\
\text { reduction (\%) }\end{array}$ & 90 & 30 \\
\hline \begin{tabular}{c} 
Congestion relief (\%) \\
\hline
\end{tabular} & 20 & 27 \\
\hline
\end{tabular}


(Figure 1). Next, the hierarchy model is input into the software database, creating an Expert Choice model (Figure 2). This model organizes the various elements of the problem into a hierarchy or tree. Each element in the tree is called a node. The top level contains the goal, whereas intermediate levels represent factors affecting that goal. The bottom level contains the alternatives of choice.

Once the Expert Choice model is built, the following step consists of evaluating the criteria. Instead of assigning weights or priorities that may be arbitrary and difficult to justify, Expert Choice helps the decision-maker apply data, knowledge, and experience to derive priorities. Evaluation, or weighing of the different criteria, is accomplished by performing pairwise comparisons. Pairwise comparison may be expressed in terms of importance, preference, or likelihood. For example, the decision-maker compares the relative importance of the criteria with respect to the goal and compares the relative preference of the alternatives with respect to each objective.

To facilitate the weighting process, Expert Choice runs a questionnaire that asks the decision-maker to make a judgment on the elements under the same parent node. Figures 3 through 5 show the questionnaires provided by the software and the decision-maker's weighting of elements under the goal (Figure 3), impediment (Figure 4), and system cost nodes (Figure 5). In Figure 3, for instance, the judgment entered (value of 1.0) indicates an equal importance for "betterment" and "impediment" with respect to the overall "goal." Moreover, Figure 6 illustrates the relative preference indicated by the decision-maker in ranking the two alternatives under the initial investment node, with a value of 9.0 indicating a very high preference for bus. This arrangement makes it possible for decision-makers to focus on each and every part of the complex problem, and to derive "local" priorities (relative priorities of factors with respect to the next higher-level factor). Expert Choice also tests the consistency of comparisons and helps the user improve it by providing an inconsistency measure.

Arrays of criteria weights and of alternatives weights are generated for each level of the hierarchy as a result of the pairwise comparison. A final priority ranking at the lowest level is then determined by backward multiplication (performed by the software) of the transformation matrices of all levels. The software then synthesizes or combines the "local" priorities to obtain "global" 


\section{TRANSIT SYSTEMS EVALUATION FOR THE CITY OF BEIRUT}

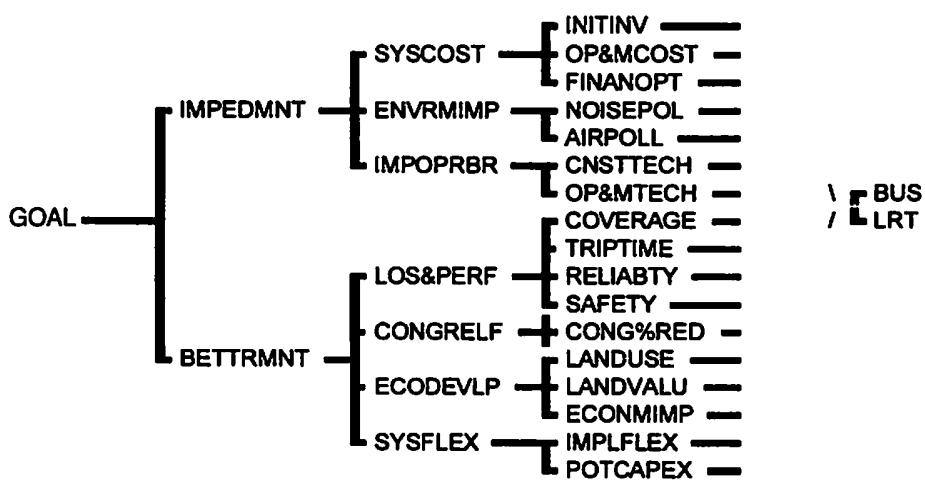

\begin{tabular}{|c|c|}
\hline Abbreviation & Definition \\
\hline \multicolumn{2}{|l|}{ GOAL } \\
\hline$\overline{A I R P O L L}$ & AIR POLLUTION \\
\hline BETTRMNT & BETTERNENT FACTORS \\
\hline BUS & BUS ALTERNATVE \\
\hline CNSTTECH & CONSTRUCTION TECHNOOOGY AND HUMAN SKILLS \\
\hline CONG\%RED & PERCENTAGEE REDUCTIONIN CONGESTION \\
\hline CONGRELF & CONGESTION RELEF POTENTIAL \\
\hline COVERAGE & COVERAGE \\
\hline ECODEVLP & ECONOMIC DEVELOPMENT \\
\hline ECONMIMP & ECONOMIC IMPACTS NEAR TRANSTI FACILITIES \\
\hline ENVRMIMP & ENVIRONMENTAL IMPACTS \\
\hline FINANOPT & FINANCNG OPTIONS \\
\hline IMPEDMNT & IMPEDIMENT FACTORS \\
\hline IMPLFLEX & IMPLEMENTATION FLEXIBILITYY \\
\hline IMPOPRBR & IMPLEMENTATION AND OPERATIONAL BARRIERS \\
\hline INITINV & INITIAL INVESTEMENT \\
\hline LANDUSE & LAND-USE IMPACTS NEAR TRANSIT FACILITIES \\
\hline LANDVALU & LAND VALUE NEAR TRANST FACILITIES \\
\hline LOS\&PERF & SYSTEM LEVEL OF SERVICE \& PERFORMANCE \\
\hline$\overline{\text { LRT }}$ & LIGHT RAIL TRANST \\
\hline NOISEPOL & NOISE POLLUTION \\
\hline OPAMCOST & OPERATING AND MAINTENANCE COST \\
\hline OP\&MTECH & OPERATION \& MAINTENANCE TECHNOOOGY AND HUMAN SKILLS \\
\hline POTCAPEX & POTENTLAL FOR CAPACTY EXPANSION \\
\hline RELIABTY & RELIABILITY \\
\hline SAFETY & SAFETY \& PERSONAL SECURTY \\
\hline SYSCOST & SYSTEM COST \\
\hline SYSFLEX & SYSTEM FLEXBBIUTY \\
\hline TRIPTRME & TRIPTIME \\
\hline
\end{tabular}

Figure 2. Complete unweighted AHP diagram 


\section{TRANSIT SYSTEMS EVALUATION FOR THE CITY OF BEIRUT}

Compare the relative IMPORTANCE with respect to: GOAL <

Circle the more IMPORTANT element and indicate how many times more IMPORTANT it is in the intensity column (enter 1.0 for equality).

Intensity

\begin{tabular}{|l|l|l|}
\hline 1 & IMPEDMNT & BETTRMNT \\
\hline
\end{tabular}

Questionnaire

\begin{tabular}{|l|l|}
\hline \multicolumn{1}{|c|}{ Abbreviation } & \multicolumn{1}{c|}{ Definition } \\
\hline Goal & TRANSIT SYSTEMS EVALUATION FOR THE CITY OF BEIRUT \\
\hline IMPEDMNT & IMPEDIMENT FACTORS \\
\hline BETTRMNT & BETTERMENT FACTORS \\
\hline
\end{tabular}

IMPEDMNT .500

BETTRMNT .500

Inconsistency Ratio $=0.0$

Evaluation/Data

Figure 3. Evaluation of elements under goal node 
or overall priorities (relative priorities of factors with respect to the goal) for the alternatives at the lowest level of the tree. For example, with respect to being an impediment to the adoption of a certain transit system, the system cost factor, among the impediments, has a local priority of 0.627 , which is higher than those of the other factors (Figure 7). This resulted from the comparisons given in Figure 4 with the system cost factor judged to be 5.0 times more important than the environmental impact, and 3.0 times more important than implementation and operational barriers. In turn, the higher calculated priority indicates a greater contribution by this factor to the final decision.

The AHP results synthesized at the subfactor and alternative levels for the betterment and impediment subhierarchies are presented in Figure 8 . Figure 8 refers to the global priorities that represent the portion of the priorities inherited by the various nodes. From the judgments used in this example, the synthesis of the evaluation with respect to the goal yielded a priority of 0.557 for the bus alternative compared to a priority of 0.443 for the LRT alternative, indicating that the former is slightly more preferred to the latter.

\section{Robustness Analysis}

Extensive analysis was performed to study the robustness of the results with respect to the input judgments used. The global priorities of 0.557 and 0.443 generated at the goal level are based on equal weights given to both the negative (impediment) and the positive (betterment) factors as well as on specific relative priorities judged to hold for factors lying at each branch and level of the hierarchy. The robustness of urban transit technology decision to changes in relative priorities of factors under the impediment subhierarchy is considered next. The influence of a change in the importance of the system cost factor is illustrated in Figure 9. The bus alternative is preferred more than the LRT alternative for higher priorities of the system cost factor, whereas the preference level decreases for lower priorities. However, the slopes of the goal priorities are not steep enough to intersect and, thus, induce a change of preference between the two choices (i.e., the bus alternative will be always preferred to the LRT alternative). Moreover, the decision was found to be somewhat sensitive to relative priority of the environmental impact criterion. While the base 


\section{TRANSIT SYSTEMS EVALUATION FOR THE CITY OF BEIRUT}

Compare the relative IMPORTANCE with respect to: IMPEDMNT < GOAL

Node: 10000

For each row, circle the more IMPORTANT element and indicate how many times more IMPORTANT it is in the intensity column (enter $\mathbf{1 . 0}$ for equality).

Intensity

\begin{tabular}{|l|l|l|}
\hline 1 & SYSCOST & ENVRMIMP \\
\hline 2 & SYSCOST & IMPOPRBR \\
\hline 3 & ENVRMIMP & IMPOPRBR \\
\hline
\end{tabular}

\section{Questionnaire}

\begin{tabular}{|c|c|c|}
\hline & ENVRMIMP & IMPOPRBR \\
\hline SYSCOST & 5.0 & 3.0 \\
\hline ENVRMIMP & & $(4.0)$ \\
\hline
\end{tabular}

Row olemonl is _timos moro than colsmn olement unless enclosed in ( )

\begin{tabular}{|l|l|}
\hline \multicolumn{1}{|c|}{ Abbraviation } & \multicolumn{1}{c|}{ Definition } \\
\hline Goal & TRANSIT SYSTEMS EVALUATION FOR THE CITY OF BEIRUT \\
\hline IMPEDMNT & IMPEDIMENT FACTORS \\
\hline SYSCOST & SYSTEM COST \\
\hline ENVRMIMP & ENVIRONMENTAL IMPACTS \\
\hline IMPOPRBR & IMPLEMENTATION AND OPERATIONAL BARRIERS \\
\hline
\end{tabular}

\section{SYSCOST $\quad .627$}

ENVRMIMP .094

IMPOPRBR .280

Inconsistency Ratio $=0.08$

Evaluation/Data

Figure 4. Evaluation of elements under impediment node 


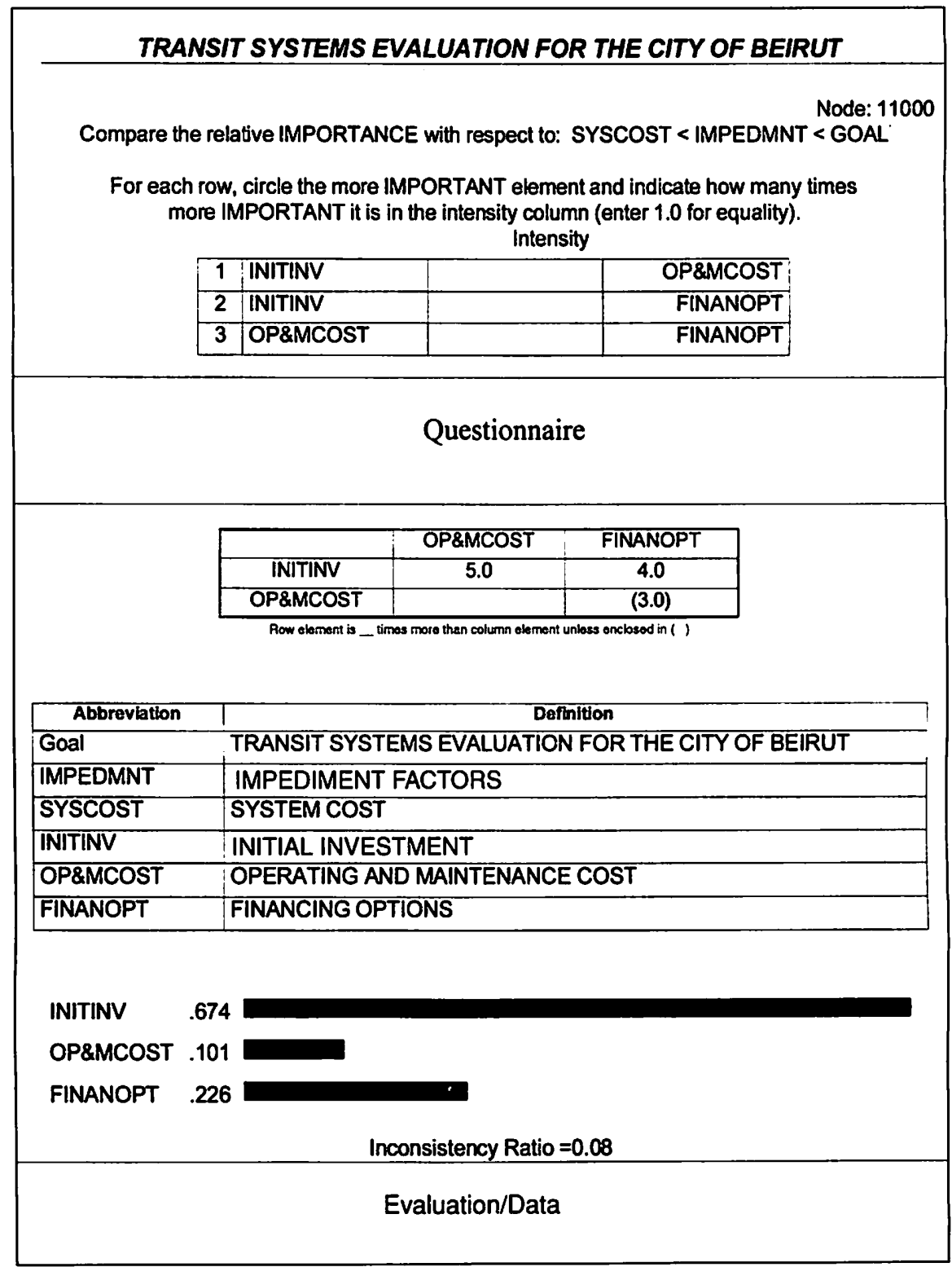

Figure 5. Evaluation of elements under system cost node 


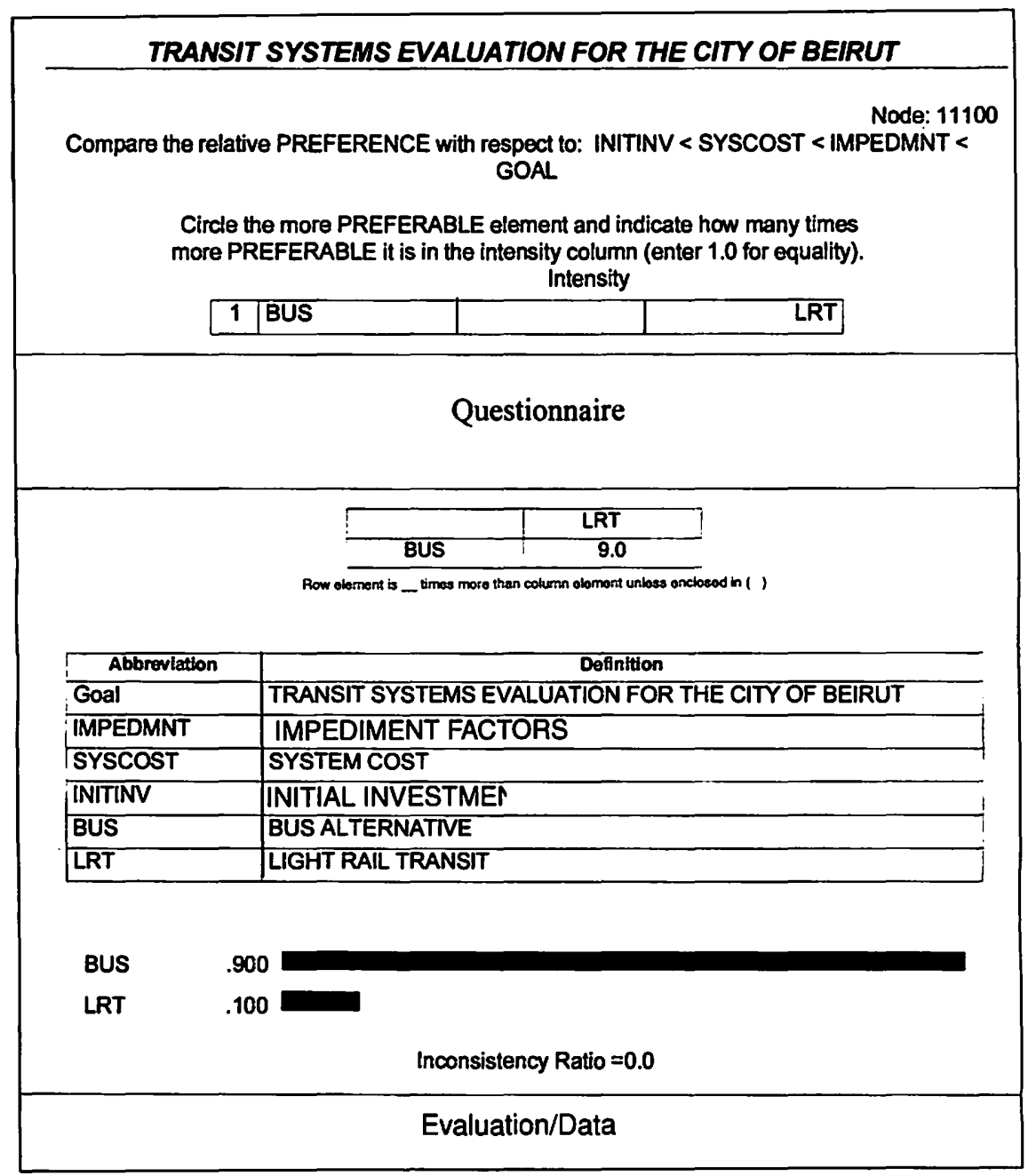

Figure 6. Alternatives preference regarding initial investment 


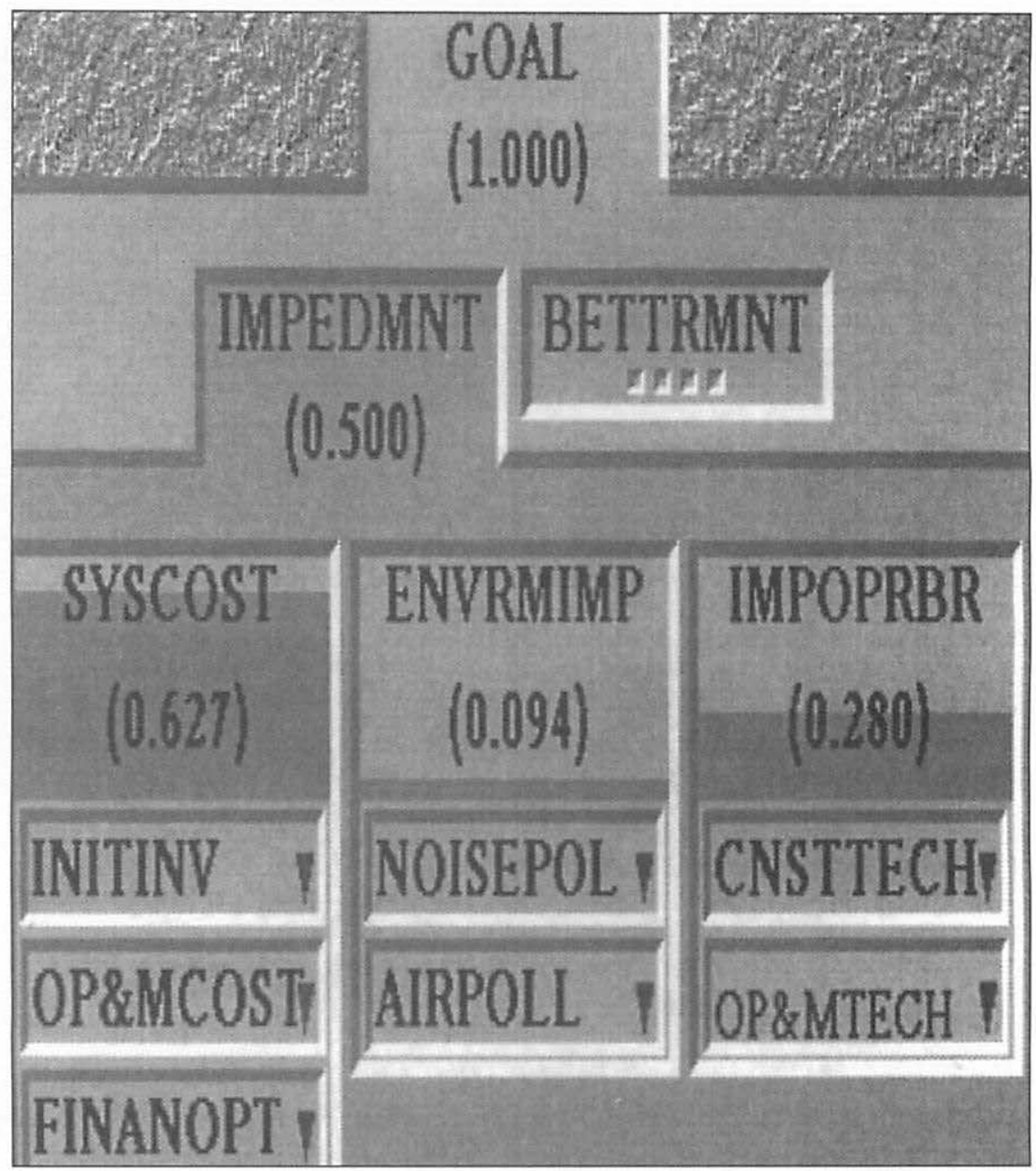

Figure 7. Local priorities under impediment node 


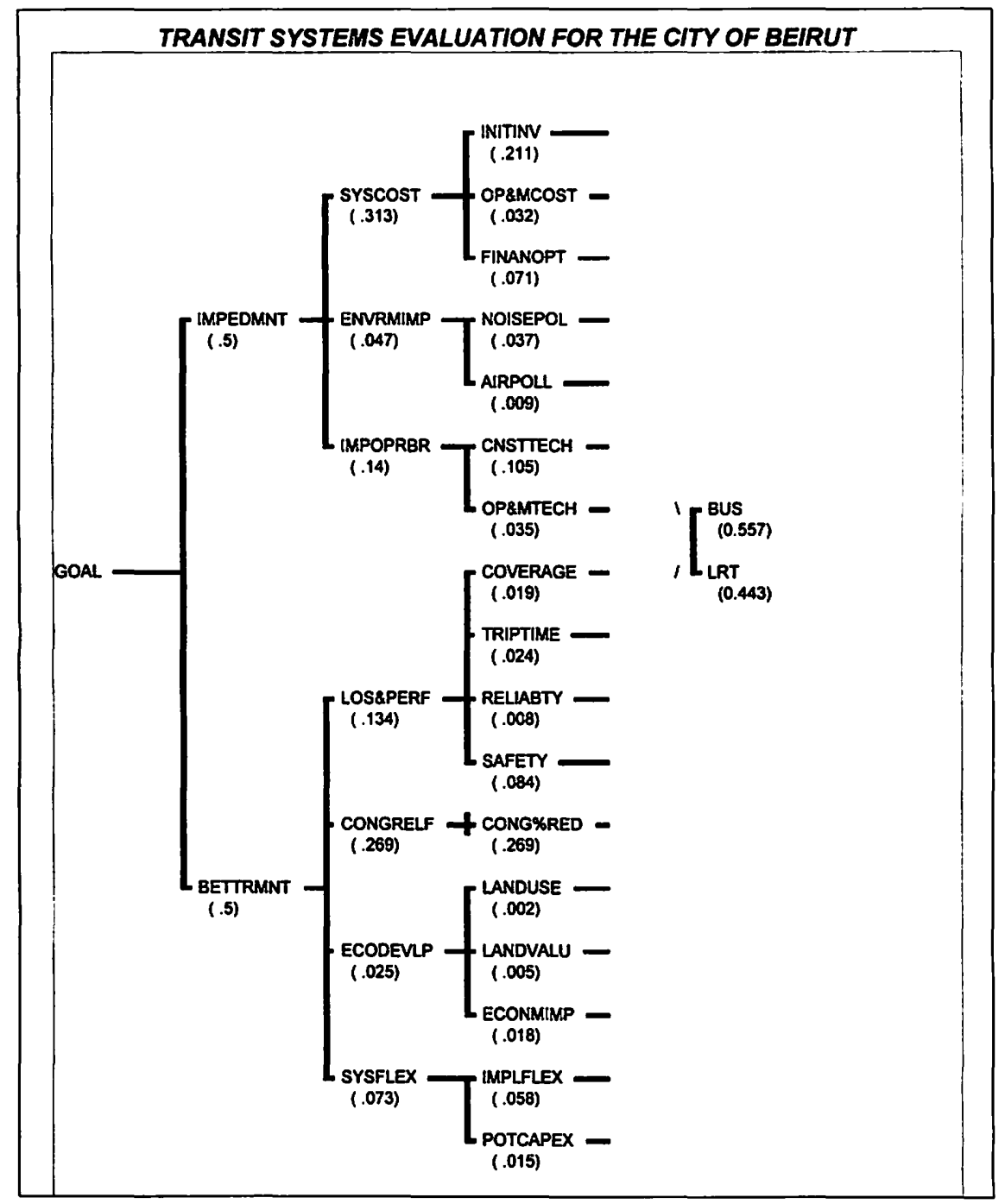

Figure 8. Global priorities for full AHP model 


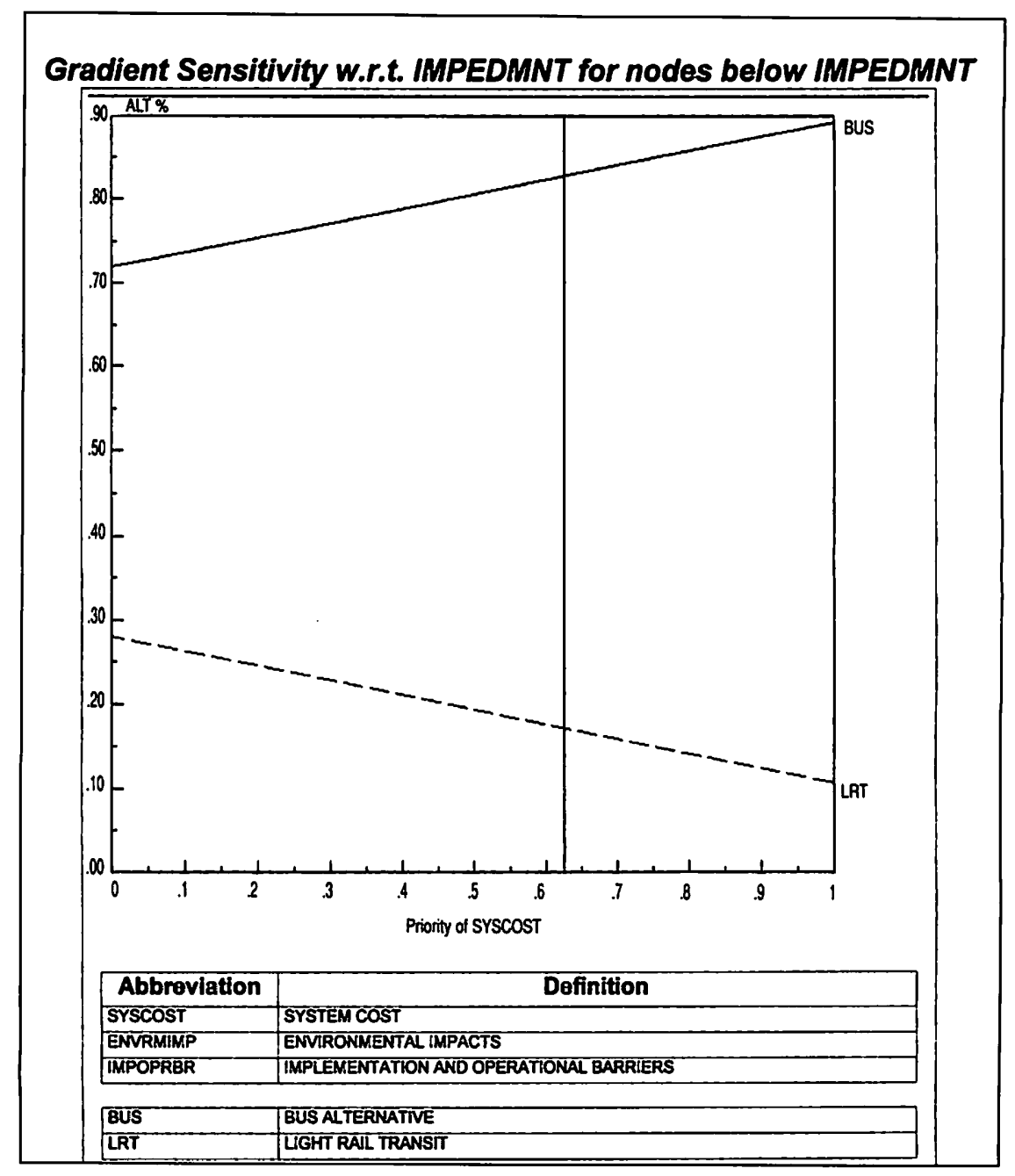

Figure 9. Sensitivity with respect to importance of "system cost" 
priority for the environmental impact criterion among impediment factors is 0.094, the model indicated that there would be a change of preference between the two urban transit alternatives at 0.73 priority value (Figure 10). In other words, if decision-makers judge environmental impacts to have such a high priority compared to system cost as well as implementation and operational barriers, the LRT alternative would then be preferred. Finally, the urban transit technology decision was found to be completely robust with respect to the relative importance of the implementation and operation barrier criterion.

Figure 11 presents the sensitivity of the final decision with respect to priorities at the top level. In the base case of equal priorities for betterment and impediment factors, bus is preferable to LRT. However, Figure 11 indicates that when the priority of impediments decreases to about 0.38 , the two alternatives become equally preferable, and the LRT is, in fact, preferred for impediment priorities lower than this value. This analysis indicates that the decision will hinge on the specific context-whether betterment is determined to be more critical for the urban area under consideration or, on the other hand, impediments represent a heavier constraint on urban transit development. When the priority of the impediments decreases (to 0.38 , for instance), the implication is that decision-makers have judged the need to achieve betterment in the urban transport context to overweigh significantly the challenges expected to be posed by any associated impediments. The approach being proposed, capitalizing on logical structuring of decision elements and factors, is wellsuited to handle similar robustness considerations.

\section{Conclusions}

The evaluation of urban transit alternatives has to take into consideration several objectives that reflect the interest of the community, such as cost, capacity, level of service, and environmental impacts. In this article, a framework for structuring the process of transit system evaluation has been proposed. It incorporates a number of criteria identified to be significant in the transit system planning process. The incorporated criteria are analyzed using the AHP evaluation approach and employing documented relevant characteristics of transit systems and technologies. The proposed approach is character- 


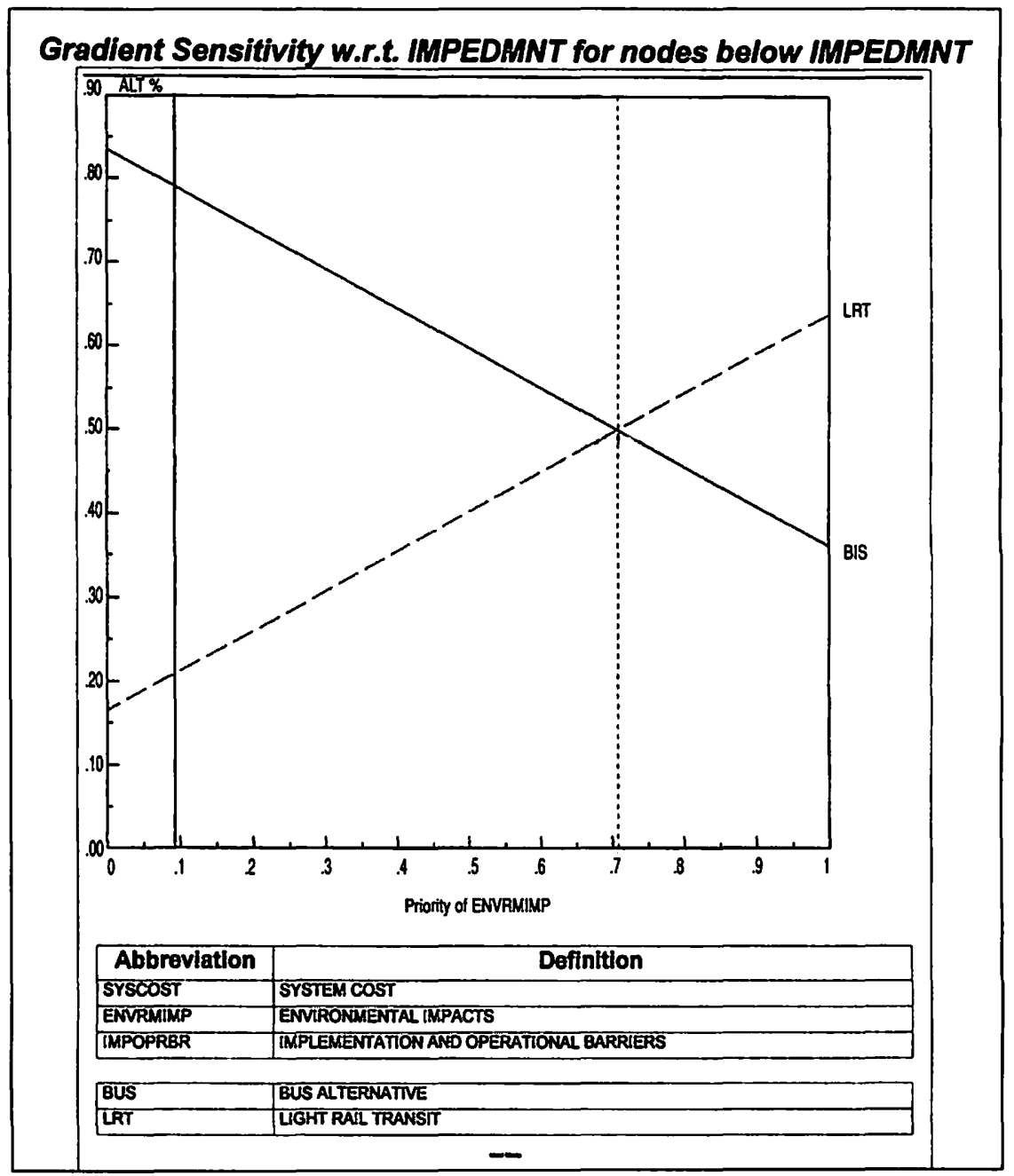

Figure 10. Sensitivity with respect to importance of "environmental impacts" 


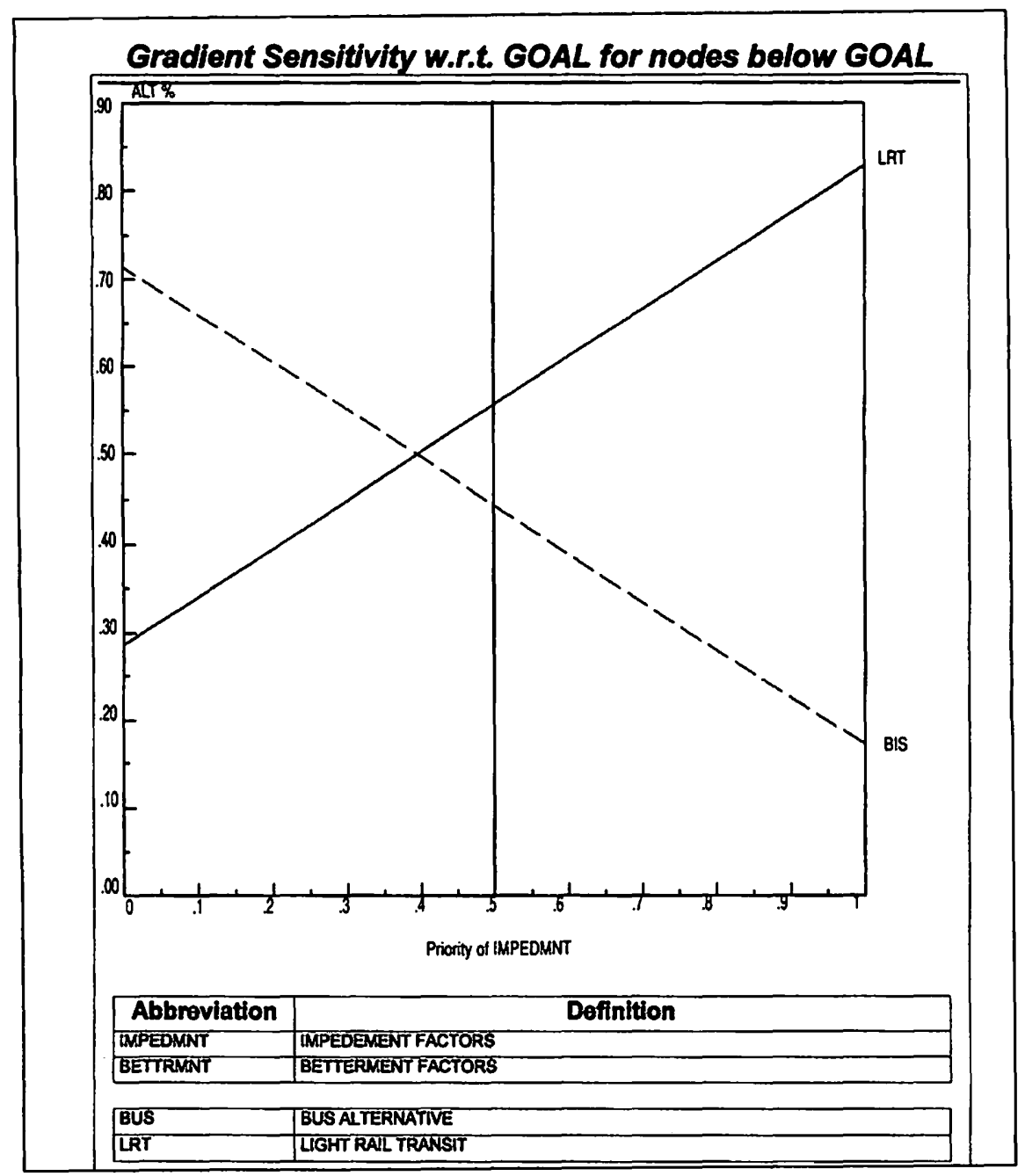

Figure 11. Sensitivity with respect to priority of "impediments" 
ized by its flexibility as far as hierarchy structure and judgments which may reflect the salient features of different urban transport contexts. As demonstrated above, this approach is quite helpful in decision structuring for selecting among urban transit alternatives. Moreover, it provides the facility of analyzing the robustness of the decision with respect to various judgments that are made in the proposed selection process. Finally, the methodology presented in this article aims at addressing the transit evaluation process at the strategic planning level and does not preclude the necessity to carry out life-cycle analysis incorporating costs and benefits relevant to the recommended transit system.

\section{Acknowledgments}

Financial support of this work by the University Research Board of the American University of Beirut is gratefully acknowledged. Thanks are also due to former and current graduate students Mireille Abdallah, Dany Chakour, and Donald Choubassi for their assistance in this research work.

\section{References}

Canadian Urban Transit Association. 1993. The Canadian transit handbook. 3rd ed. Toronto, Canada.

Dickey, J. 1983. Metropolitan transportation planning. New York: Hemisphere Publishing Corp.

Flachsbart, P. G. 1989. Effectiveness of priority lanes in reducing travel time and carbon monoxide exposure. ITE Journal: 4l-45.

Horowitz, A., and E. Beimborn. 1995. Methods and strategies for transit benefit measurement. Transportation Research Record 1496: 9-16.

IBI Group. 2000. Beirut suburban mass transit corridor feasibility study: Ridership and freight analysis. Beirut, Lebanon: Ministry of Transport.

ITE Technical Committee 6A-37. 1988. A summary report: The effectiveness of highoccupancy vehicle facilities. ITE Journal: 17-18.

ITE Technical Committee 6A-37. 1992. A summary of an ITE informational report: Impacts of transit facilities on land use. ITE Journal: 37-39.

ITE Technical Committee 6Y-33 (1988). Private financing of transportation improvements. ITE Journal: 43-51.

Janarthanan, N., and J. Schneider. 1986. Multicriteria evaluation of alternative transit system designs. Transportation Research Record 1064, TRB: 26-34. 
Johnson, G., and L. Hoel. 1987. Review of financing options for highways and transit. Journal of Transportation Engineering 113 (1): 72-83.

Khisty, J. 1990. Transportation engineering-An introduction. Englewood Cliffs, NJ: Prentice Hall.

Larwin, T. 1989. San Diego's light rail system: A success story. ITE Journal: 19-20. Mackett, R. 1994. Determining appropriate public transport system for a city. Transportation Research Record 1451: 44-50.

Mackett, R., and M. Edwards. 1996. Guidelines for planning a new urban public transport system. Proceedings of the Institution of Civil Engineers-Transport 117 (3): 193-201.

Meyer, M., and E. Miller. 1983. Urban transportation planning-A decision-oriented approach. New York: McGraw-Hill.

Newman, P., and J. Kenworthy. 1999. The costs of automobile dependence: A global survey of cities. In Transportation Research Record 1670: 17-26.

Nisar, M., and A. M. Khan. 1992. Transitway: An innovation in public transportation. ITE Journal: $35-39$.

Parody, T. E., M. E. Lovely, and P. S. Hsu. 1990. Net costs of peak and offpeak transit trips taken nationwide by mode. Transportation Research Record 1266: 139-144.

Reed, T., C. White, M. Bolton, and W. Hiller. 1994. Application of multiattribute utility theory to public transit system design. Transportation Research Record 1451: $37-43$.

Saaty, T. 1980. The analytical hierarchy process: Planning, priority setting, resource allocation. London, England: McGraw-Hill.

Skibniewski, M., and L. Chao. 1992. Evaluation of advanced construction technology with AHP method. Journal of Construction Engineering and Management 118 (3): 577-593.

Tsamboulas, D., S. Lioukas, and C. Dionelis. 1992. Evaluating alternative scenarios for high-speed rail investment in Greece. Transportation 19: 245-265.

Wayson, R., and W. Bowlby. 1989. Noise and air pollution of high-speed rail systems. Journal of Transportation Engineering 115 (1): 21-36. 


\section{About the Authors}

IsAM KAYSI (isam@aub.edu.lb) is an associate professor in the department of Civil and Environmental Engineering at the American University of Beirut.

Mohamed-Asem U. Abdul-MaLAK (mamalak@aub.edu.lb) is an associate professor in the Engineering Management Program at the American University of Beirut 